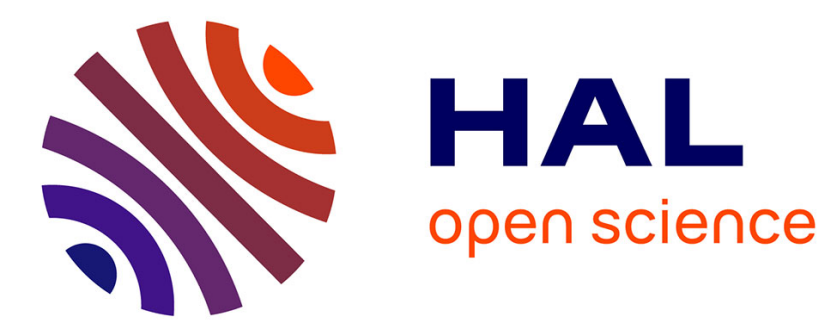

\title{
L'Argonne dans l'Antiquité: étude d'une région productrice de céramique et de verre
}

Michiel Gazenbeek, Sander van Der Leeuw

\section{To cite this version:}

Michiel Gazenbeek, Sander van Der Leeuw. L'Argonne dans l'Antiquité: étude d'une région productrice de céramique et de verre. Gallia - Archéologie de la France antique, 2003, 60, pp.269-317. 10.3406/galia.2003.3056 . hal-01909337

\section{HAL Id: hal-01909337 \\ https://hal.science/hal-01909337}

Submitted on 9 Jan 2020

HAL is a multi-disciplinary open access archive for the deposit and dissemination of scientific research documents, whether they are published or not. The documents may come from teaching and research institutions in France or abroad, or from public or private research centers.
L'archive ouverte pluridisciplinaire HAL, est destinée au dépôt et à la diffusion de documents scientifiques de niveau recherche, publiés ou non, émanant des établissements d'enseignement et de recherche français ou étrangers, des laboratoires publics ou privés.

\section{(1) (1) $\$$}

Distributed under a Creative Commons Attribution - NonCommercial - NoDerivatives 44.0 


\title{
L'ARGONNE DANS L'ANTIQUITÉ
}

\section{Étude d'une région productrice de céramique et de verre}

\author{
Michiel GAZENBEEK* avec la collaboration de Sander VAN DER LEEUW**
}

\begin{abstract}
Mots-clés. Argonne, Antiquité, céramique, verre, ateliers, occupation du sol, paysages.
Résumé. Cet article se propose de replacer les ateliers de céramique et de verre antiques de l'Argonne, toutes productions confondues, dans le contexte de l'occupation du sol de la région à l'époque romaine. Dans cette perspective, l'article identifie les ressources naturelles du pays, étudie les formes du paysage de l'Argonne et fait le point des nouvelles connaissances acquises sur les réseaux de communication ainsi que sur les formes régionales de l'habitat lors des récents travaux de terrain. Un classement des sites de production de céramique est ensuite effectué en fonction de l'évolution de la qualité des produits manufacturés, de la surface des ateliers et de leur durée d'utilisation. L'industrie de la céramique est enfin replacée dans son contexte environnemental naturel et anthropique.
\end{abstract}

Key-words. Argonne, Antiquity, pottery, glass, production centres, settlement patterns, landscapes.

Abstract. The aim of this article is to set the varied Roman pottery and glass production centres of the Argonne area in the regional settlement pattern in association with geographical features. In order to do so, the natural resources of the area and the various landscapes are defined. The transport network and the different types of Roman settlements are listed in connection with the evidence obtained by recent investigations. The pottery-making centres are classified in accordance with the evolution and the quality of their products. and with the size and lifespan of these centres, and then analysed within the natural and human environment.

Schlagwörter. Argonnen, Antike, Keramik, Glas, Produktionszentren, Besiedlung, Landschaften.

Zusammenfassung. Der Beitrag unternimmt den Versuch, die verschiedenen Zentren der gallorömischen Keramik- und Glasproduktion in den Argonnen im Kontext des regionalen Besiedlungsablaufs zu betrachten. Dazu werden zunächst die natürlichen Ressourcen des Landstrichs benannt und die Formen der Naturlandschaft untersucht. Sodann werden die neuesten Erkenntnisse bilanziert zur Frage der Kommunikationsnetze und zu den regionalen Siedlungsformen. Die bekannten Produktionsstätten werden anhand der qualitativen Entwicklung ihrer Produkte und anhand des räumlichen und zeitlichen Ausgreifens der Praduktion bewertet. Schließlich wird die Keramikindustrie der Region in den Kontext ihrer Natur- und Kulturlandschaft gestellt.

Übersetzt vom Stefan WiRTH

L'Argonne, région frontalière entre la Champagne et la Lorraine, est connue pour ses productions de céramiques exportées durant plusieurs siècles dans toute l'Europe du Nord-Ouest. Ses produits jouent un rôle important dans la définition chronologique des sites de consommation. En revanche, la fabrication et la diffusion des différents types de céramiques ainsi que l'organisation spatiale des ateliers restent très mal connues malgré les recherches menées dans la région depuis plus d'un siècle.

L'objectif du programme: "Les ateliers céramiques gallo-romains d'Argonne : bilan, recherche et gestion patrimoniale " (1996-1998) ${ }^{1}$ était de compléter la carte des

* INRAP Grand-Est et Centre d'études Préhistoire, Antiquité, Moyen Âge (Cépam), CNRS, 250 rue Albert-Einstein, Sophia Antipolis, F-06560 Valbonne.

** Université Paris 1, Institut d'art et d'archéologie, 3 rue Michelet, F-75006 Paris.

1. Projet dirigé par S. Van der Leeuw, R. Brandt (fondation RAAP, Pays-Bas) et M. Gazenbeek, en collaboration avec les Services régionaux de l'archéologie de Lorraine et de Champagne-Ardenne. 
ateliers répartis sur une superficie de $200 \mathrm{~km}^{2}$ et de reconstituer l'évolution des techniques de production. Il devait aussi aboutir à des propositions d'orientation de la rcchcrchc ct de gcstion patrimoniale des sites de fabrication. Les travaux réalisés sur le terrain ont consisté principalement en prospections pédestres et géophysiques, liées à l'utilisation d'un système d'information géographique (SIG). Ils ont été suivis d'une analyse des techniques de production de certains ensembles de céramiques trouvées à l'occasion de ces Iravaux. La collecte de données, augmentée d'indications d'ordre environnemental, a abouti à la création de cartes prédictives du potentiel d'implanta-

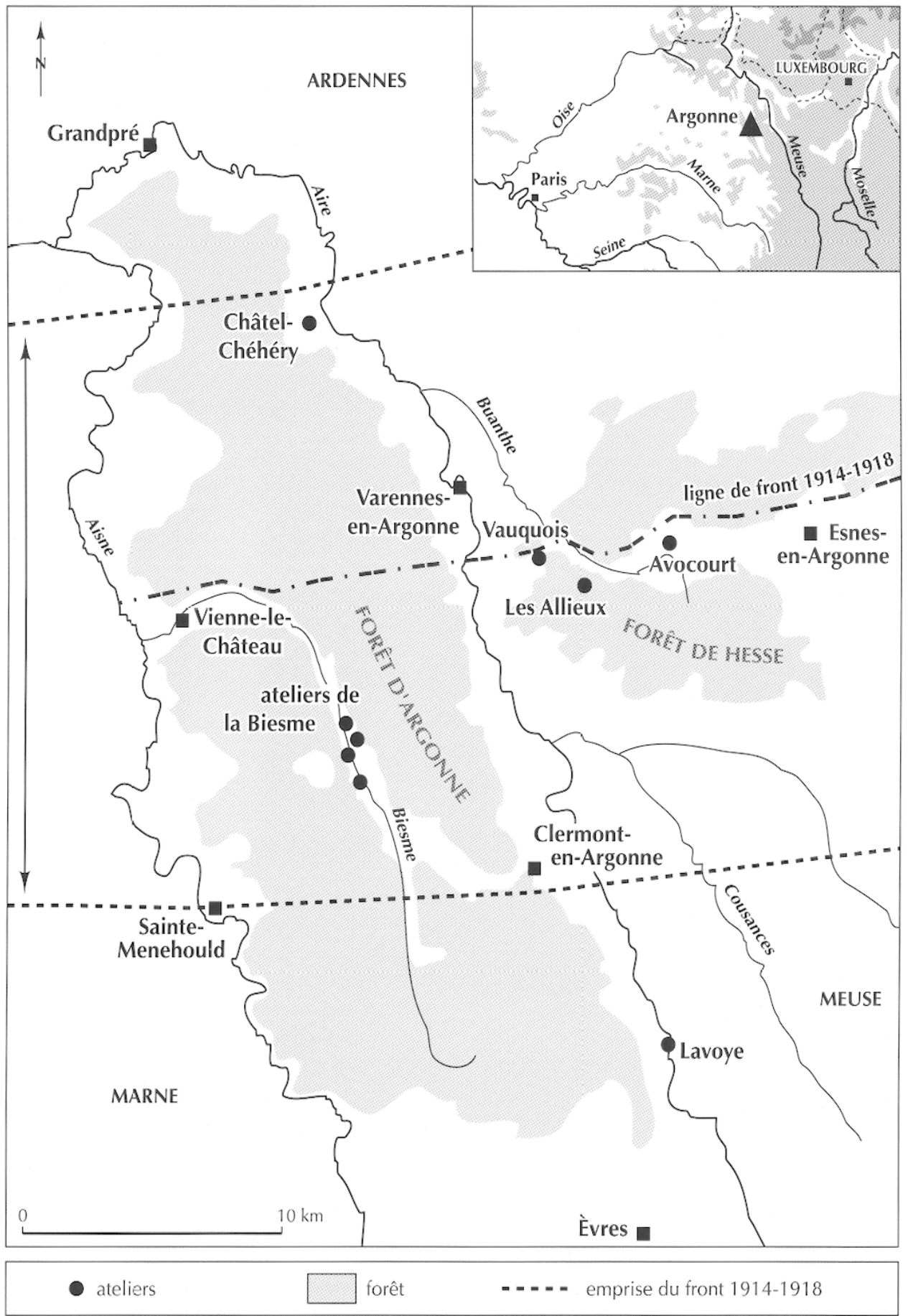

Fig. 1 - Plan de la région étudiée en Argonne (DAO M. Gazenbeek, INRAP). 
tion d'ateliers et de fours de potiers. Enfin, ces mêmes données ont contribué à clarifier les fondements économiques de l'installation des ateliers ainsi que de leur implantation dans un territoire organisé.

Dans cet article, il ne sera question que de ces derniers points. L'étude technologique des productions, l'inventaire des ateliers recensés ainsi que les travaux géophysiques et la modélisation sous un SIG seront abordés ultérieurement dans une publication monographique.

Les travaux que nous avons menés autour des ateliers de fabrication de céramique antique de l'Argonne s'insèrent dans une longue tradition de recherches qui se sont déroulées en trois temps.

Les premières études ont débuté à Lavoye (fig. 1), où le $\mathrm{D}^{\mathrm{r}}$ Meunier fouilla des ateliers à partir de la fin du XIX ${ }^{\mathrm{e}} \mathrm{s}$. (Meunier, 1905, 1908). Ses travaux furent rapidement complétés par ceux de G. Chenet qui explora au début du XX ${ }^{\mathrm{e}}$ s. les ateliers des Allieux, d'Avocourt et de la vallée de la Biesme (Chenet, 1913, 1917). Mais au début du XX $X^{e}$ s., ce sont principalement les archéologues allemands qui définissent la production sigillée de l'Argonne (Fölzer, 1913, p. 37-41, pl. VII, VIII, X, XXVIII, XXXII ; Unverzagt, 1919). Après la guerre de 1914-1918, G. Chenet assiste le $\mathrm{D}^{\mathrm{r}}$ Meunier dans ses travaux à Lavoye, tout en entreprenant de nouvelles fouilles sur le site des Allieux, à Châtel-Chéhéry et dans la forêt de Hesse. Dès les années 1920, les principaux lieux de production sont ainsi rcconnus (Chcnct, 1941). C'est aussi durant cette période que plusieurs ateliers de verre romains sont mis au jour en Argonne (Chenet, 1920a). Malgré le nombre et la taille des sites de production, aucune nouvelle recherche n'aura lieu sur ces verreries.

La deuxième phase correspond à une longue période qui sépare la fin des travaux de G. Chenet et les nouvelles découvertes sur le terrain faites à partir de 1968. Durant ce laps de temps, c'est principalement la collection déposée par G. Chenet au musée des Antiquités nationales à SaintGermain-en-Laye qui retient l'attention des chercheurs. Vers 1960, son classement est effectué par un petit groupe animé par B. Hofmann et P.-H. Mitard. Les éléments composant les catalogues des poinçons et des estampilles sur sigillées moulées de l'Argonne sont alors réunis et publiés par B. Hofmann (1968 et 1972, p. 16-21, pl. V-VIII). Une première synthèse concernant les sigillées moulées est proposée par P.-H. Mitard en 1986, mais le travail le plus important est la publication posthume des notes de G. Chenet consacrée aux sigillées d'Argonne des $\mathrm{II}^{\mathrm{e}}$ et $\mathrm{III}^{\mathrm{e}} \mathrm{s}$. par G. Gaudron (Chenet, Gaudron, 1955).

La troisième phase correspond aux travaux de reboisement et de déclassement des zones rouges après le conflit de 1914-1918 autour d'Avocourt, permettant de relancer des études sur le terrain à partir de la fin des années 1960.
D'interventions ponctuelles (Gallia, XXVI, 2, 1968, p. 380 ; $36,2,1978$, p. $334 ; 38,2,1980$, p. 416), ces recherches prennent, entre 1985 et 1990 , la forme de prospections et de fouilles pluriannuelles sur le site des Allieux, dans la forêt de Hesse et à Avocourt. Elles sont conduites par M. Feller et R. Brulet (Feller, 1989 ; Feller, Brulet, 1995, 1998).

Les prospections effectućes lors des trois années de notre projet (1996-1998) ont permis d'explorer en détail $7 \%$ environ de la région sélectionnée. Plus de 6500 ha ont été prospectés, en quatre campagnes de un mois chacune. Les terrains parcourus ont été choisis avec le souci de couvrir tous les types de paysages présents dans la région, afin d'évaluer leur attirance dans la distribution des sites antiques. Selon les saisons, les prospections privilégiaient les zones de labours (printemps, automne), de forêts ou de prairies (hiver). La répartition des secteurs étudiés s'est donc faite selon leurs caractéristiques géomorphologiques et géologiques, mais également selon l'utilisation actuelle des sols. Les terrains parcourus s'étendent de Grandpré (Ardennes), au nord, à Èvres (Meuse), $40 \mathrm{~km}$ plus au sud. Les données recueillies couvrent toutes les périodes du Paléolithique à l'époque moderne, mais la recherche a ćtć approfondie pour l'Antiquité uniquement. Quelque 140 sites ont été recensés pour cette période, dont certains atteignent plusieurs dizaines d'hectares de superficie.

Les dégâts de la Grande Guerre sont encore fortement visibles dans la partie centrale de l'Argonne. Une large bande est-ouest, allant d'Esnes-en-Argonne à Vienne-leChâteau, en passant par divers champs de batailles comme la butte de Vauquois, est particulièrement riche en vestiges de cette guerre. Les tranchées de combat et les cratères d'obus n'influent pas directement sur la détection en surface des structures archéologiques enfouies : un nombre important de structures antiques a été repéré dans ces zones.

Une grande importance a par ailleurs été accordée à la récolte des informations anciennes, publiées dans la littérature spécialisée. Elles ont été intégrées dans la base de données de la prospection. Malgré leur caractère souvent lacunaire, ces informations permettent d'étoffer notre vision de la répartition de l'habitat antique dans la région, sous condition d'une localisation géographique précise. Certains de ces sites ont été par la suite prospectés.

\section{L'ARGONNE PHYSIQUE}

\section{LES PAYSAGES}

La région de l'Argonne se situe en bordure orientale du Bassin parisien. Elle est limitée par l'émergence de la cuesta barroise à l'est et le front de la cuesta champenoise à l'ouest. Elle dépasse les côtes meusiennes au nord, sans pour autant 


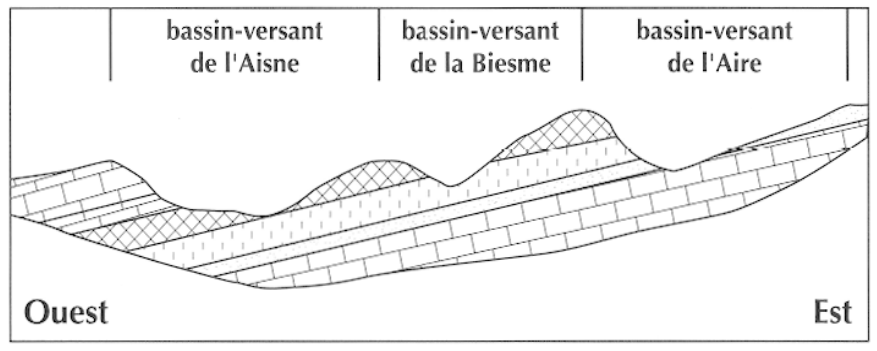

\begin{tabular}{|c|c|c|}
\hline $\begin{array}{l}\text { Crétacé supérieur } \\
\text { craies }\end{array}$ & $\begin{array}{l}\text { Crétacé inférieur } \\
\begin{array}{l}\otimes \text { gaize } \\
\text { argiles du Gault }\end{array}\end{array}$ & $\begin{array}{l}\text { Jurassique } \\
Y Y \text { calcaires portlandiens }\end{array}$ \\
\hline
\end{tabular}

Fig. 2 - Coupe géologique simplifiée de l'Argonne (I)AO M. Gazenbeek, INRAP).

atteindre le cours de la Meuse, et se termine, au sud, par la Champagne humide et le Perthois. La région atteint une superficie de $1500 \mathrm{~km}^{2}$.

\section{LES FORMES DU PAYSAGE NATUREL}

L'Argonne constitue une entité géographique particulière, composée de reliefs calcaires entrecoupés de vallées alluviales. Les couches géologiques affectent une disposition monoclinale, à pendage ouest - sud-ouest. D'ouest en est émergent alors des terrains de plus en plus anciens (fig. 2). Les couches les plus dures, formant les reliefs, alternent avec des sédiments plus tendres et creusés par l'érosion, constituant ainsi les vallées. Les horizons de calcaires et marnes jurassiques affleurent largement dans la moitié orientale de la région. À l'ouest, ces sédiments sont recouverts par les sables verts de l'Albien inférieur qui forment la base des niveaux du Crétacé inférieur, composés d'argiles du Gault ${ }^{2}$ et de gaizes ${ }^{3}$. La zone de contact entre le Jurassique et le Crétacé, orientée nord-sud, correspond aux vallées de l'Aire et de l'Agron et constitue l'axe central de la région (fig. 3).

De ce fait, on peut distinguer trois groupes de paysages différents : le massif argonnais de gaize, l'Argonne orientale des plateaux calcaires jurassiques et le bas pays argonnais au sud qui est caractérisé par une couverture assez homogène d'argiles du Gault.

2. Nom utilisé autrefois comme synonyme d'Albicn, et parfois encore employć pour désigner certaines formations de cet âge. Il s'agit d'une argile grise, parfois bleuâtre et jaunâtre, plastique et quelquefois sableuse vers les niveaux inférieurs.

3. Mot local des Ardennes : grès fin, plus ou moins argileux et calcaire, riche en grains de glauconite. Sa forte teneur en silice cristallisée, entre 68 et $80 \%$, est due à la présence massive de squelettes siliceux d'animaux et de plantes microscopiques.
Le massif argonnais proprement dit est délimité à l'est par les rivières de l'Aire et de l'Agron et par l'Aisne à l'ouest. Comme tous les reliefs de la région, le massif suit une pente générale est-ouest inclinée vers la Champagne. Aux côtes dominant la vallée de l'Aire à l'est, atteignant une altitude moyenne de $300 \mathrm{~m}$, s'oppose un plateau qui descend progressivement vers l'ouest et atteint en moyenne $140 \mathrm{~m}$ au-dessus de l'Aisne qu'il domine de plusieurs dizaines de mètres. Ce plateau est profondément entaillé par l'érosion, ce qui lui donne un aspect très découpé. Ce puissant massif présente une composition lithologique homogène, et seules les vallées les plus profondes (Biesme au centre et Talma au nord de Grandpré) ont permis d'atteindre les argiles du Gault sous-jacentes. À l'ouest du massif de gaize, le lit majeur de l'Aisne forme une coupure nette. Au-delà de la rivière, les formations de gaize plongent rapidement sous les craies de la Champagne. Elles y sont essentiellement visibles sous forme de rebords de terrasses.

L'Argonne orientale, entre l'Aire et la Meuse, se caractérise par des plateaux dont l'altitude moyenne est de $250 \mathrm{~m}$. Ils sont coiffés de buttes témoins, lambeaux du Crétacé, qui culminent à $336 \mathrm{~m}$. Du sud au nord, deux groupes différents de plateaux se succèdent aux revers de la cuesia du Barrois et de la cuesta de la Côte de Meuse. Un premier ensemble, au sud, est constitué par les affleurements massifs du calcaire portlandien. Ceux-ci sont découpés selon des lignes nord-sud par l'Aire et ses affluents, la Cousances et le Vadelaincourt, dont les vallées forment les accidents majeurs du relief. Elles sont de plus en plus encaissées en direction de l'est. Le deuxième groupe est formé par l'extrémité nord de la cuesta du Barrois et les derniers affleurements massifs septentrionaux du Portlandien. Cette région se caractérise par une présence résiduelle, mais importante, de formations du Crétacé. Des plages plus ou moins étendues d'argiles du Gault et de sables verts subsistent sur les dorsaux des plateaux, couronnées par endroits par des buttes témoins de gaize. Les secteurs où ce phénomène est le plus développé et où les séquences du Crétacé sont les plus complètes sont la forèt de Hesse et la région de Romagne-Sommerance. La vallée de l'Aire et ses prolongements au nord, le couloir de l'Agron et les dépressions tourbeuses du Bar forment l'épine dorsale de ces groupes successifs. On remarque immédiatement la dissymétrie du système: au versant oriental bien développé s'oppose, à l'ouest, un court glacis au pied des côtes de gaize. Entre l'Aire et la cuesta de la forêt d'Argonne s'insère une bande étroite de terrain, de 1 à $3 \mathrm{~km}$ de large, où se succèdent rapidement le Portlandien, les sables verts et les argiles du Gault. À l'est de la rivière, les revers des plateaux calcaires montrent une plus grande homogénéité. 


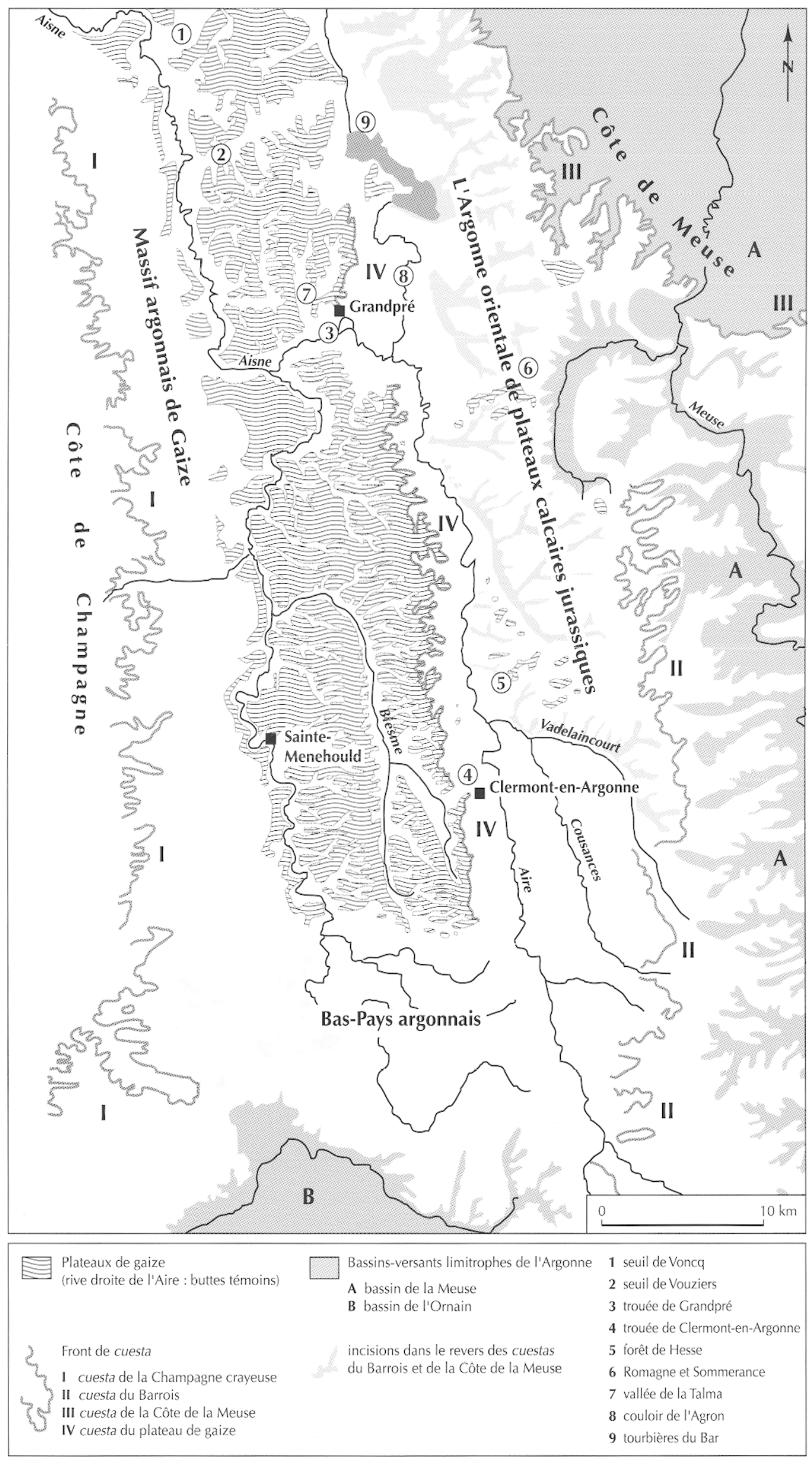

Fig. 3 - Paysages naturels de l'Argonne (DAO M. Gazenbeek, INRAP). 


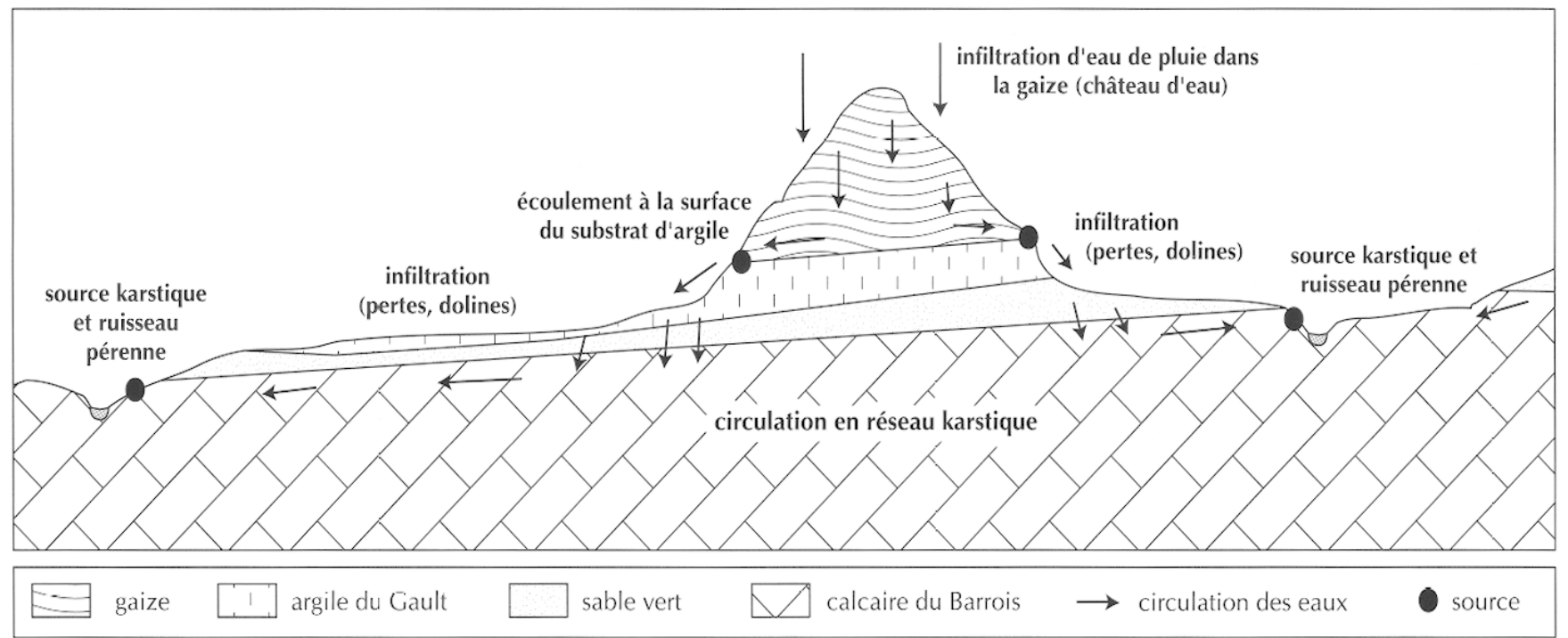

Fig. 4 - Schéma de fonctionnement du double réseau hydrographique en Argonne (DAO M. Gazenbeek, INRAP).

Le bas pays argonnais est beaucoup moins élevé, la cote moyenne se situant autour de $180 \mathrm{~m}$ seulement. Cette zone, à faible relief, forme en fait l'interface entre le massif de gaize au nord de l'Argonne et la vallée de l'Ornain au sud, qui appartient au bassin versant de la Marne et non de l'Oise comme la majeure partie de l'Argonne. Le terrain est composé d'un affleurement massif d'argiles du Gault, qui s'amincit vers l'est, pour laisser la place au calcaire portlandien dans la partie où sont situées les sources de l'Aisne.

Les principales formations pédologiques de la région sont des altérations plus ou moins remaniées de ces substrats, où il convient d'ajouter les horizons développés sur les alluvions anciennes et récentes dans les fonds de vallées. Notons que les sols sur le Crétacé inférieur (gaize, argiles, sables) sont peu profonds, froids et acides. Ils sont de ce fait peu propices aux cultures, ce qui explique qu'une grande partie de la région soit recouverte de forêts.

\section{LE RÉSEAU HYDRUGRAPHIQUE}

L'hydrologie, conditionnée par la construction géologique, est définie par les deux aquifères principaux de la gaize et des calcaires du Portlandien (fig. 4). Ils fonctionnent dans un système à double palier. Les massifs de gaize, qui constituent des " châteaux d'eau ", forment un premier niveau de circulation des eaux. À leur base, des résurgences souvent temporaires apparaissent au contact avec les argiles sous-jacentes. Les eaux de ces sources s'écoulent à la surface des argiles, en général sur des distances fort courtes (de quelques dizaines à plusieurs centaines de mètres), puis disparaissent dans des pertes ou dolines creusées dans les sables verts. Il s'agit d'effondrements au-dessus du réseau karstique du Portlandien. Ce dernier forme le deuxième palier du système hydrographique. Après une circulation dans les karsts du Portlandien, l'eau ressurgit dans de nombreuses sources le long des vallées creusées dans le calcaire. Les ruisseaux que ces sources alimentent sont le plus souvent pérennes.

Les sources dans le Portlandien peuvent être réparties en plusieurs ensembles, selon leur position topographique. L'origine des eaux est également différente. La plupart des sources situées dans une couronne autour des buttes de gaize fonctionnent dans le système de double palier. Une deuxième série de sources se situe à une plus grande distance de ces massifs et à des niveaux plus bas. Leur alimentation sur le Portlandien est davantage conditionnée par les précipitations. Il s'agit d'une série de sources apparaissant dans les rebords des plateaux qui surplombent les vallées majeures de la région.

\section{LES RESSOURCES NATURELLES}

En France, c'est l'Argonne qui possède les affleurements de gaize les plus importants. Cette donnée a fortement marqué la distribution des ressources naturelles de la région: argiles, sables et roches du Crétacé inférieur couvrent plus de la moitié de sa superficie et ont facilité un développement durable de l'artisanat de la terre et du verre grâce à leurs qualités minéralogiques et à la végétation associée à ces formations (fig. 5).

Les affleurements d'argiles du Gault atteignent près de $20 \mathrm{~m}$ d'épaisseur. À l'époque moderne, cette argile était 
massivement employée par un grand nombre de tuileries et par plusieurs ateliers de céramiques communes ainsi que par des faienceries ${ }^{4}$.

Les sables verts sont fins, quartzeux et riches en glauconies, avec une granulométrie assez. régulière. Ils contiennent des proportions notables de fer et de manganèse.

La troisième composante est la gaize. Facile à travailler, la gaize est utilisée comme pierre de construction. Sa composition lui donnant des propriétés réfractaires, elle est également employée pour la construction de parois de fours. Cette pierre fournissait au siècle dernier la silice dont les verreries des cantons de Varennes-en-Argonne et de Clermont-en-Argonne avaient besoin ${ }^{5}$.

L'importance de la superficie occupée par des terrains siliceux et argileux, peu propices à une mise en culture généralisée, explique l'étendue des forêts. Avant l'introduction massive des mélèzes et des épicéas, la forêt d'Argonne appartenait à quatre grands groupes floristiques, qui reflétaient la configuration géologique de la région (Gianordoli, 1979) : la flore silicicole de la gaize (chênaiehêtraie), les forêts des argiles calcaires du Gault et des sables siliccux (aulnaic-frênaie, chênaie-charmeraie), la flore calcicole sur les calcaires portlandiens et kimméridgiens (chênaie-charmeraie) et enfin une flore hygrophile.

Si environ $40 \%$ de l'Argonne sont aujourd'hui couverts de forêts, ce pourcentage a fluctué dans le temps. Au début du XIX ${ }^{\mathrm{e}}$ s., $32 \%$ seulement du territoire était boisé (Hussenet, 1982, p. 369-370). La pression démographique a occasionné des mises en culture de secteurs forestiers impropres à l'agriculture, les " terres infernales ", qui retournaient d'ailleurs rapidement à leur état premier. Au $\mathrm{XIX}^{\mathrm{c}}$ s., le remplacement du charbon de bois par le charbon minéral a également favorisé l'extension de la forêt. Le massif de gaize est peu touché par les reboisements de cette époque ( $7 \%$ supplémentaires seulement, à comparer avec $25 \%$ dans l'Argonne calcaire orientale), ce qui montre la grande stabilité de la couverture forestière sur ce substrat.

Pour l'Antiquité romaine, aucune donnée paléoenvironnementale n'est disponible. Les seuls diagrammes polliniques dans la région concernent les tourbières du Bar, au nord, qui sont trop loin des ateliers céramiques pour être utiles.

4. La faïenceric a été produite dans une dizaine de communes d'Argonne, essentiellement dans la vallée de l'Airc, mais aussi dans la Biesme (Les Islettes) (Hussenet, 1982, p. 397-399). L'un des centres de production de la céramique commune a étć Avocourt (Chenet, 1934). La fabrication de tuiles et de briques concernait plus d'une cinquantaine d'établissements durant tout le XIX ${ }^{e}$ s. (Hussenct, 1982, p. 394-397).

5. Voir Buvignier, 1852, p. 545. Cet auteur note que pour « éviter les frais de trituration, on emploie à cet usage les sables d'alluvions formés de débris de gaize" ".

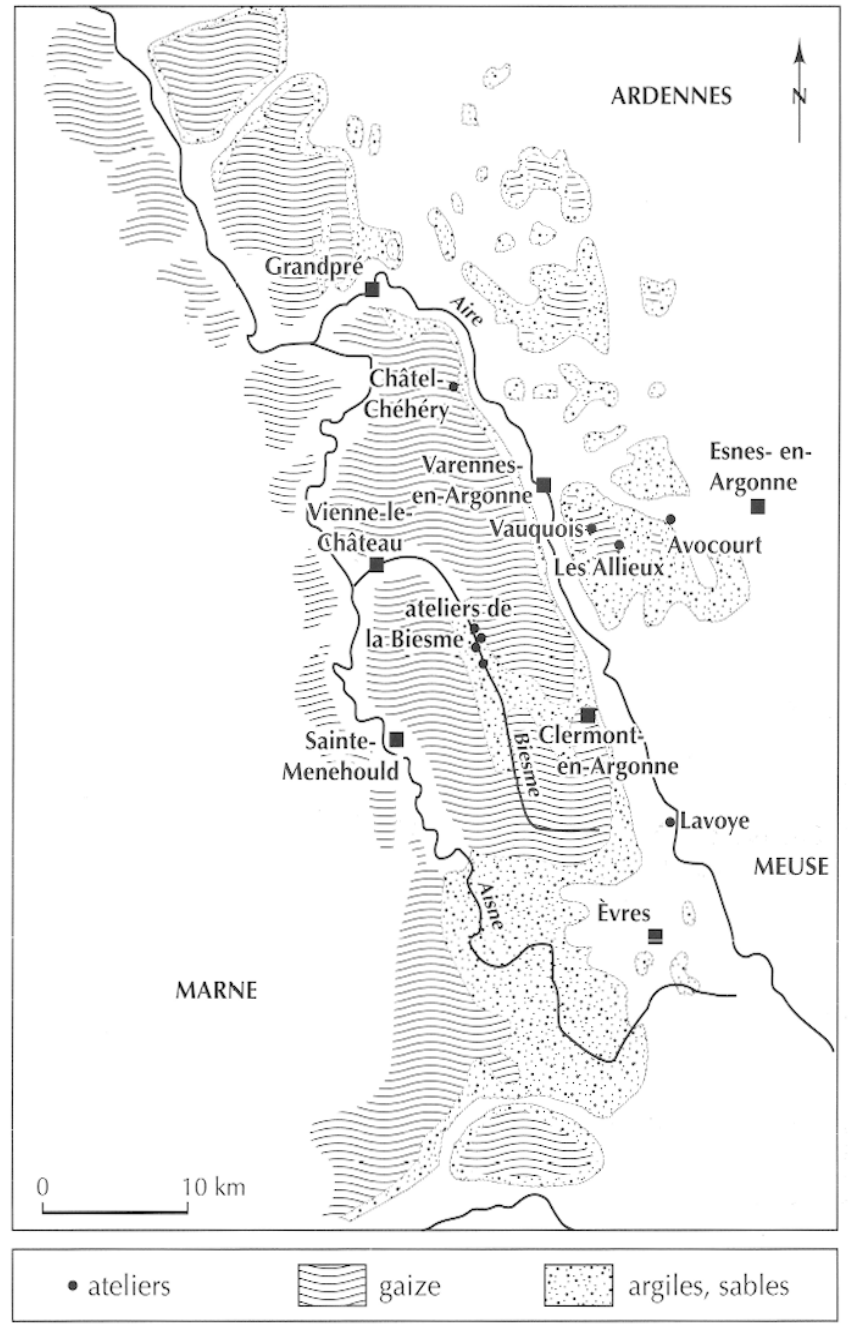

Fig. 5 - Les ressources naturelles (DAO M. Gazenbeek, INRAP).

Quoi qu'il en soit, cette étendue de forêt, conditionnée par la géologie, a été un des éléments-clés dans le développement des industries du feu dans la région au Moyen Âge et à l'époque moderne. Les nombreuses fonderies de fer, les verreries (une cinquantaine sont recensées dans le massif de l'Argonne), les tuileries et, à partir du XVIII ${ }^{e}$ s., les faïenceries se sont approvisionnées simultanément en combustible dans les forêts d'Argonne pendant plusieurs siècles.

\section{L'ARGONNE ET L'OCCUPATION ANTIQUE}

Les études consacrées à l'Argonne durant l'Antiquité ne considèrent généralement que les ateliers de céramiques et leurs productions, au détriment du réseau d'occupation dans lequel ils s'inscrivent. L'occupation du sol durant la 


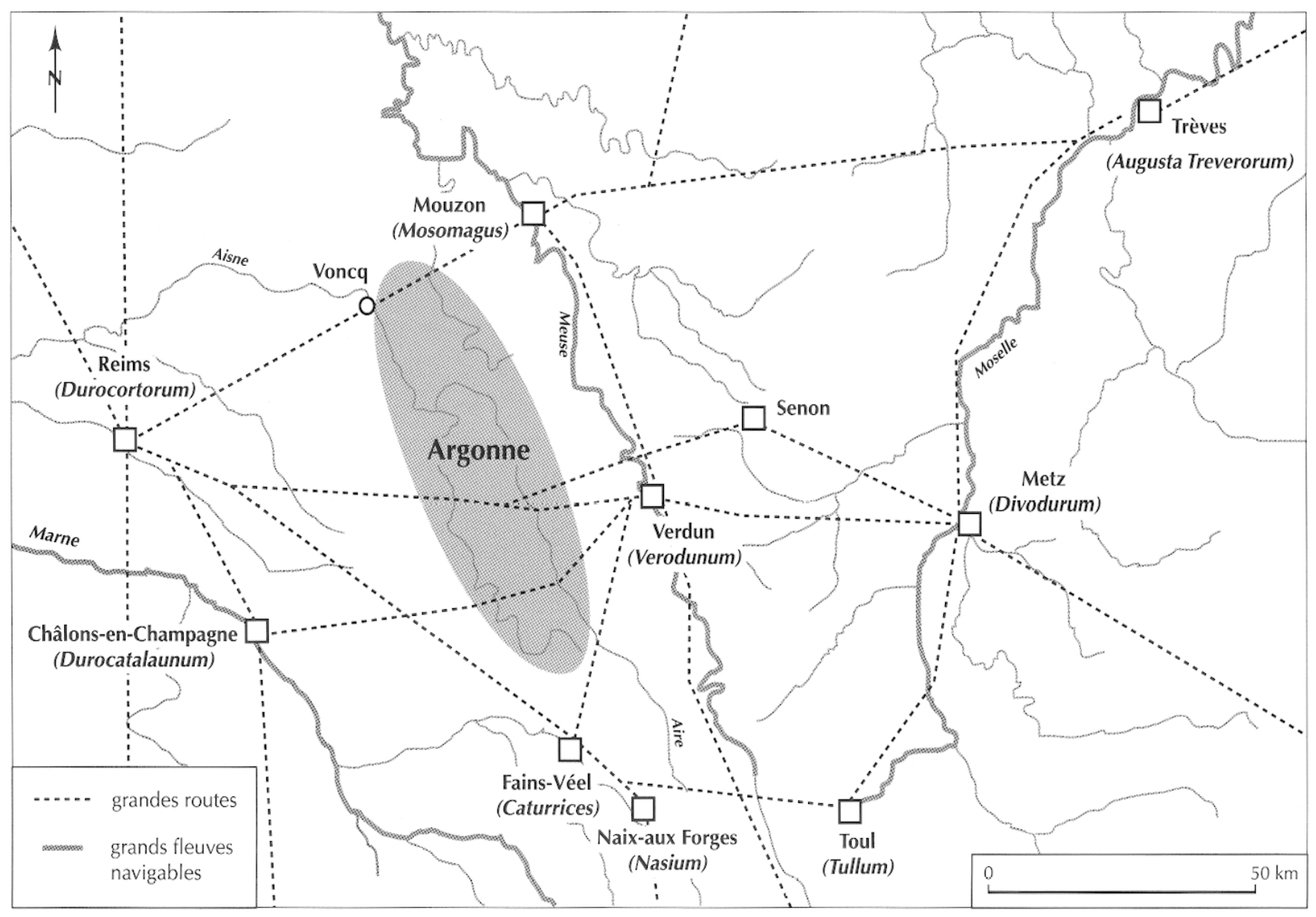

Fig. 6 - Réseau suprarégional de communications en Argonne (DAO M. Gazenbeek, INRAP).

période romaine comprend principalement un réseau de communications et des habitats. Deux types de sources permettent de reconstituer son maillage. Il s'agit des publications des érudits du $\mathrm{XIX}^{\mathrm{e}} \mathrm{s}$. et du début du $\mathrm{XX}^{\mathrm{e}} \mathrm{s}$. et des résultats de nos propres prospections.

\section{LE RÉSEAU DE COMMUNICATIONS}

À l'époque romaine, l'Argonne est desservie par un réseau routier performant, permettant des relations directes avec les chefs-lieux des cités des Remi et des Mediomatrices, qui encadrent la région. Ces routes mettaient aussi l'Argonne à la portée des fleuves navigables (fig. 6).

\section{LE RÉSEAU ROUTIER}

Le réseau de communications antique a sans doute joué un rôle de première importance dans la distribution des ateliers de potiers. Ce réseau, tel que nous le connais- sons aujourd'hui, a été identifié par les érudits du XIX ${ }^{\mathrm{e}} \mathrm{s} .{ }^{6}$. Cinq voies ont été identifiées dans l'Argonne : trois axes estouest, respectivement de Verdun à Châlons-en-Champagne, de Verdun à Reims et de Senon à Reims, ainsi que deux axes sud-nord, de Verdun et de Fains-Véel vers les Ardennes (fig. 7). Seule la route Reims-Verdun est bien connue.

À une échelle plus large, l'Argonnc est encadrée par deux grands axes routiers et est recoupée par un troisième, orienté grosso modo ouest-est. Ils sont tous les trois mentionnés par l'Itinéraire d'Antonin et relient certaines des villes antiques les plus importantes de cette partie de la Gaule. Depuis le noud de Reims à l'ouest, une voie partait en direction de Trèves vers le nord, traversait l'Aisne à Voncq

6. Le premier qui ait fait une étude cohérente du réseau des routes antiques de la région a été Liénard (1881-1885). Il a fait le point sur toutes les informations alors connues pour la partie meusienne de l'Argonnc. Le réseau viaire, tel qu'il l'a défini, a été reproduit ensuite par tous les auteurs. Pour la Marne, l'étude principale a été faite par Savy en 1855 . 


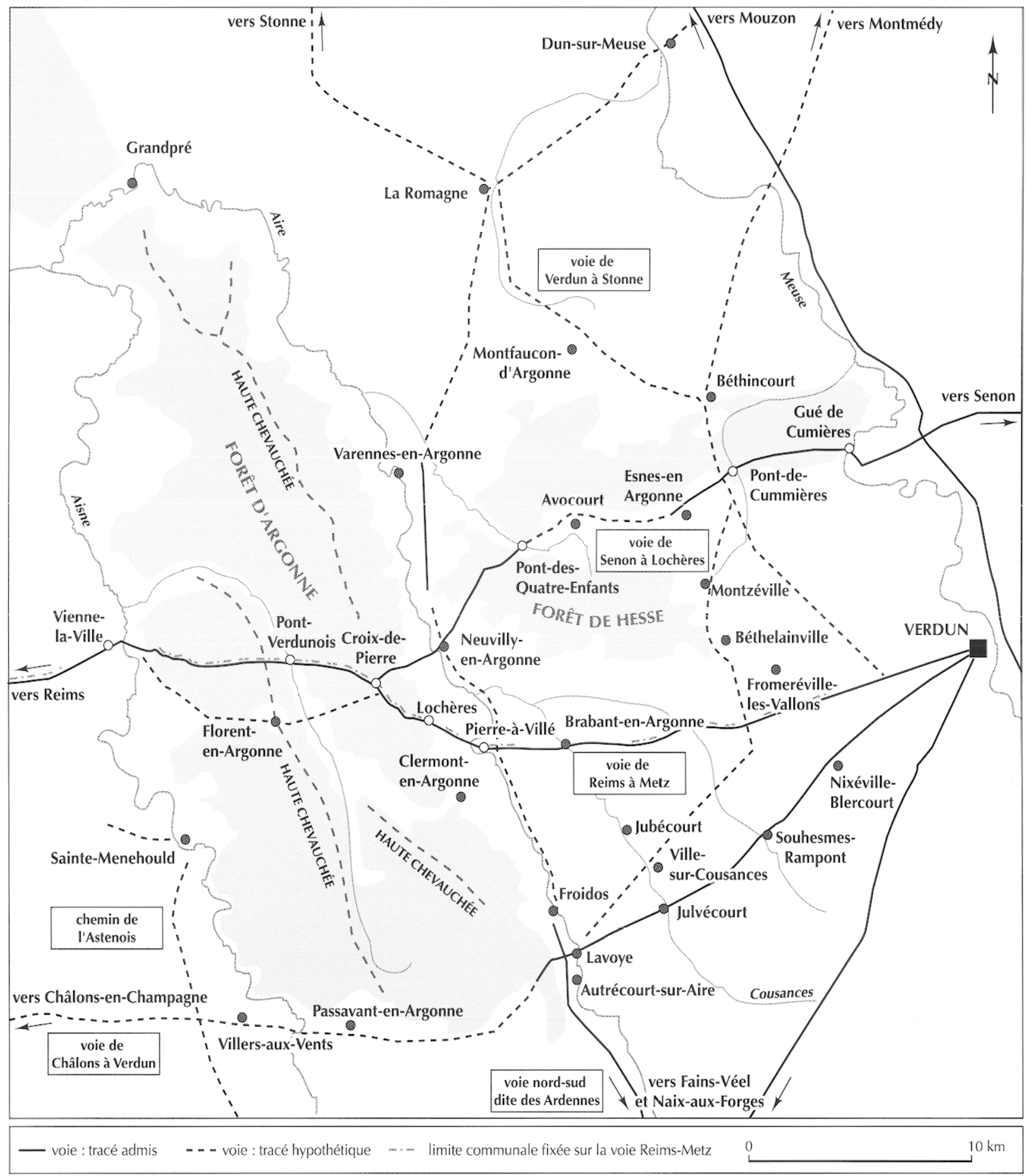

Fig. 7 - Réseau des routes antiques de l'Argonne (DAO M. Gazenbeek, INRAP). 
(où des structures antiques importantes subsistent), puis la Meuse à Mouzon. Une autre voie partait en direction du sud vers Toul ou vers Langres. Au centre, la route directe de Reims à Metz via Verdun coupait à travers l' $\Lambda$ rgonne. Cc réseau d'importance suprarégionale est complété par des voies de communication reliant des centres de rang inférieur: Verdun, Senon, Naix-aux-Forges, Châlons-enChampagne, Mouzon, etc.

La route Reims-Metz par Verdun est la voie antique de la région la mieux identifiée. Elle a laissé une forte empreinte dans le paysage. Sur de très longs segments, elle a servi à fixer les limites territoriales des paroisses. Par conséquent, elle se trouve à l'écart de tous les centres de peuplement médiévaux, excepté les villages de Vienne-la-Ville et de Brabant-en-Argonne. Cette voie, construite dès le départ en remblai au-dessus du sol, est composée de couches successives de pierres, de sables et de graviers ${ }^{7}$. Parfaitement conservée sous forme de digue sur les plateaux boisés, cette chaussée a subi une forte usure sur les versants, ce qui atteste l'intensité et surtout la durée de son utilisation. Les montées dans le massif de l'Argonne (rive droite de l'Aisne, les deux rivès de la Biesme, descente de Lochères, rive gauche de l'Aire) ont été transformées en chemins creux. Pour les montées les plus importantes, plusieurs tracés parallèles, profondément découpés dans le versant, se sont développés comme sur la rive gauche de la Biesme, où ces creux atteignent plus de $10 \mathrm{~m}$ de profondeur et prennent l'aspect de ravins.

Près de Lochères, cet axe se dédouble : une route part en direction de Senon et traverse la Meuse à une dizaine de kilomètres au nord de Verdun, au gué de Cumières. Son parcours a été relativement bien reconnu par F. Liénard (1881-1885, III, p. 103-116). La route part, selon toute vraisemblance, de la voie Reims-Metz au lieu-dit La Croixde-Pierre, situé sur la crête de l'Argonne, pour descendre sur les rives de l'Aire qu'elle atteint quelque part en face de Neuvilly-en-Argonne. C'est entre Neuvilly-en-Argonne et la Buanthe, où elle traverse Le Pont-des-Quatre-Enfants, que son tracé est assez bien identifié. Sur les cadastres du $\mathrm{XIX}^{\mathrm{e}}$ s., différents segments de chemins anciens portent les noms de "voie verte " ou de " chemin des Ferrons » ou encore de " chemin des Romains », d'après F. Liénard, qui lui assigne ensuite un trajet contournant le village d'Avocourt par le nord. Mais entre Le Pont-des-QuatreEnfants et Esnes-en-Argonne, à l'est, peu d'indications sur le terrain ou sur les cadastres du XIX ${ }^{\mathrm{e}} \mathrm{s}$. permettent d'étayer cette hypothèse. Toutefois, un officier allemand avait reconnu un chemin antique est-ouest au nord d'Avocourt,

7. Sur cette voie, différentes coupes sont décrites par Liénard (18811885, II, p. 5-15) et dans Gallia (XXVTII, 2, 1970, p. 294). recoupé par les tranchées allemandes de la Grande Guerre (Unverzagt, 1919, p. 8), qui pourrait appartenir à ce tracé. Après Esnes, son tracé suit la cote 285 et L'Homme-Mort en dircction dc Cumières, où la Meuse est traversée à gué. Près du village détruit de Cumières, la route avait également été mise au jour à l'occasion du creusement des tranchées allemandes de la Première Guerre mondiale ${ }^{8}$.

Le troisième axe est-ouest pourrait être une voie de Verdun à Châlons-en-Champagne. Ce tracé est proposé par F. Liénard (1881-1885, II, p. 105-114), qui fait passer cette route par Nixéville-Blercourt, Les Souhesmes-Rampont, Julvécourt, Lavoye, Passavant-en-Argonne, puis Villers-enArgonne, avant la traversée de la Champagne crayeuse. Cet auteur ne donne cependant pas d'indication de terrain permettant de confirmer ce tracé, excepté le toponyme "vieux chemin de Verdun à Châlons » entre les villages de Julvécourt et Lavoye. Le toponyme même de Lavoye, qui dérive de lou wué pour le gué, est une indication de l'importance et de l'ancienneté du franchissement de l'Aire à cet endroit (Widranges, 1862, p. 38-39). Notons qu'au Moyen Âge, cette voie faisait partie de l'une des routes de pèlerinage vers Saint-Jacques-de-Compostelle. Des photographies aériennes ont apporté quelques précisions et modifications au tracé proposé, notamment au sud et à l'ouest de Passavant (Tilloy, 1979).

Dans la vallée de l'Aire, ces routes sont recoupées par un axe sud-nord, dont le tracé n'est pas clairement défini dans la partie nord de la région. Pour les uns, il s'agit d'une voie allant de Caturrices (Fains-Véel, près de Bar-le-Duc), dans la vallée de l'Ornain, à Dun-sur-Meuse ; pour d'autres, elle venait des Ardennes et remontait la vallée de l'Aire jusqu'à sa jonction avec la route de Caturrices à Verdun (Liénard, 1881-1885, II, p. 85-93 ; Meunier, 1905). Jusqu'au siècle dernier, cette voie en remblai existe encore en divers endroits dans la vallée de l'Aire où elle est connue sous le nom de Haut-Chemin. Entre le village de Beauzée-sur-Aire et Froidos, il semble que cette route suivait un parcours rectiligne à mi-pente sur le versant ouest de la vallée de l'Mire, où plusicurs structurcs linéaires lui sont peut-être liées. Cette voie traverserait l'Aire à Froidos pour remonter ensuite la rive droite jusqu'au nord de Vraincourt, au lieudit La Pierre-à-Villé où elle recoupe la grande chaussée Reims-Metz (Liénard, 1881-1885, II, p. 95-103) 9. L'axe

8. Couche bétonnée bombée de calcaire concassé sur $4 \mathrm{~m}$ de large et entre $0,12 \mathrm{~m}$ et $0,30 \mathrm{~m}$ d'épaisseur au centre (Chenet, 1922a, p. 141, n. 1). Lors de nos prospections nous avons remarqué ce même profil sur les berges du ruisseau de Montzéville au Pont-de-Cumières (Esnesen-Argonne).

9. Selon F. Liénard (et les auteurs qui lui ont succédé), cet axe rejoint sur quelques kilomètres la voie Reims-Metz à partir de La Picrre-à-Villé pour remonter jusqu'au massif de l'Argonne, puis suit la crête princi- 
antique nord-sud de la vallée de l'Aire continuait ensuite sur la rive droite de la rivière, comme semblent l'indiquer plusieurs structures linéaires à l'est de Varennes-enArgonne.

Un deuxième axe nord-sud est représenté par la voie Verdun-Stonne par Montfaucon-d'Argonne, qui se détacherait près de Fromeréville-les-Vallons, à l'oucst de Verdun, de la route Reims-Metz. Selon F. Liénard, ce chemin est bien conservé sur le territoire de cette commune et sur celui de Montzéville. Son cheminement peut être suivi sur les cartes comme une succession discontinue de portions de routes. Cette voie aurait été reconnue en 1844 lors du défrichement d'un bois au lieu-dit La Pièce-des-Moines entre Béthincourt et Montfaucon-d'Argonne, où elle était empierrée. Elle descendrait ensuite la vallée de l'Andon jusqu'à Romagnesous-Montfaucon, puis elle se dirigerait sur Buzancy et Stonne; cette dernière localité étant située sur la voie romaine Reims-Trèves. Le tracé et l'existence même de cette voie sont donc peu assurés, à l'exception du trajet Fromeréville-les-Vallons - Béthincourt.

Enfin, H. de Widranges évoque une voie antique allant de Lavoye vers Montmédy (Widranges, 1862, p. 42). Cette route passerait par Ville-sur-Cousances et au-dessus de Jubécourt. L'auteur pense en avoir trouvé des traces sur les communes de Béthelainville, le hameau de Vignéville et Montzéville où ce chemin est appelé Chemin des Roullieux. $\grave{\Lambda}$ Béthincourt, il prend le nom de Chemin des Romains.

Comme souvent, l'antiquité de toutes ces voies n'est pas assurée. Soulignons le grand nombre de tracés proposés pour le versant meusien de l'Argonne. En Argonne marnaise, seul le Chemin de l'Astenois, entre la voie ReimsToul et l'agglomération de Sainte-Menehould, pourrait être d'origine antique ${ }^{10}$.

pale du relief en direction du nord. La carte de Cassini, qui indique le tracé de cette voie dans la forêt, lui donne le nom de Chemin de Grandpré. Mais elle est également connue sous le nom de La Haute Chevauchée. Sur cette partie du territoire, l'origine romaine du tracé est incertaine. En effet, on trouve dans la forêt d'Argonne plusieurs chemins appelés Haute Chevauchée précisément ceux qui suivent les crêtes des plateaux de gaize selon un tracé nord-sud. Une Haute Chevauchée relie les bois de Beaulieu-en-Argonne, dans le sud, à Vienne-le-Château, au nord, et une autre Chevauchée existe au sud-est des Islettes. Le tracé de ces chemins appartient plus sûrement à l'époque médiévale comme en témoignent les textes qui mentionnent des " hautes chevauchées" dès le XII' $\mathbf{s}$. : via quae dicitur Equitata en 1150, "Chevauchier " en 1228, "Haute-Chevauché " en 1551 (Barthélemy, 1865, p. 95).

10. Cette route passerait par Sommeilles, La Neuville-aux-Bois et Le Vieil-Dampierre. Peut-être faut-il mettre en rapport ce tracé hypothétique et les indications d'un gué antique sur l'Aisne au pied de la butte de Sainte-Menehould au Pont-Rouge (Brouillon, 1909, p. 6).

\section{LE RÉSEAU FLUVIAL}

Située à l'écart des grands fleuves, l'Argonne est pourtant avantageusement placée par rapport aux itinéraires de portage qui relient la Marne, la Meuse et la Moselle. Le transport des produits se faisait dans un premier temps obligatoirement par la route, dans la mesure où les rivières et les ruisseaux du centre de l'Argonne n'étaient pas navigables ${ }^{11}$. Un transbordement sur bateau était possible aux marges de la région, sur l'Aisne à l'ouest (SainteMenehould, Vienne-la-Ville, Voncq) et sur la Meuse à l'est (Verdun, gué de Cumières), ou plus loin sur la Moselle (Metz) ou sur la Marne (Châlons-en-Champagne). Les avantages de cette situation étaient encore sensibles au milieu du XIX ${ }^{\mathrm{e}}$ s. lorsque les bouteilles produites par les verriers du Four de Paris à Lachalade sur la Biesme étaient transportées à dos de mulet jusqu'à Châlons-en-Champagne à une distance d'environ $80 \mathrm{~km}$ et, de là, à Paris.

\section{LES FORMES D'HABITAT ET LEUR CHRONOLOGIE}

Nous avons classć l'habitat antique selon la superficie des sites et leurs caractéristiques architecturales. Le croisement des termes de cette classification architecturale (ville, habitat groupé, villa, petit site ou ferme) avec les durées d'occupation autorise une analyse assez fine de l'organisation de l'espace antique dans lequel s'insère la production de céramique.

\section{LES VILLES}

La région n'a pas connu de développement de type urbain. Située aux marges de cités importantes, elle reste à l'écart des grands centres politiques et administratifs (une configuration qui perdurera sous différentes formes jusqu'à la fin de l'Ancien Régime). Verdun (Virodunum) est le centre urbain le plus proche. L'agglomération antique est largement inconnue ${ }^{12}$. Les maigres vestiges du HautEmpire sont ëparpillës sur 25 ha environ autour de l'éperon de la vieille ville, entre la Meuse et son affluent la Scance. À la fin de l'Antiquité et pendant le haut Moyen Âge, l'importance de la ville s'affirme, tout au moins selon les sources textuelles. Elle devient chef-lieu de cité au IV $\mathrm{s}$. Au début $\mathrm{du} \mathrm{VI}^{\mathrm{c}}$ s., un marché important et un castrum sont attestés mais les informations archéologiques relatives à cette époque sont très pauvres. La situation administrative de Verdun durant l'Antiquité est peu claire : mentionnée

11. Nous n'avons pas trouvé d'indication de navigation sur l'Aire dans les monographies d'histoire locale.

12. Un état de la question a été dressé par F. Gama en 1997. 


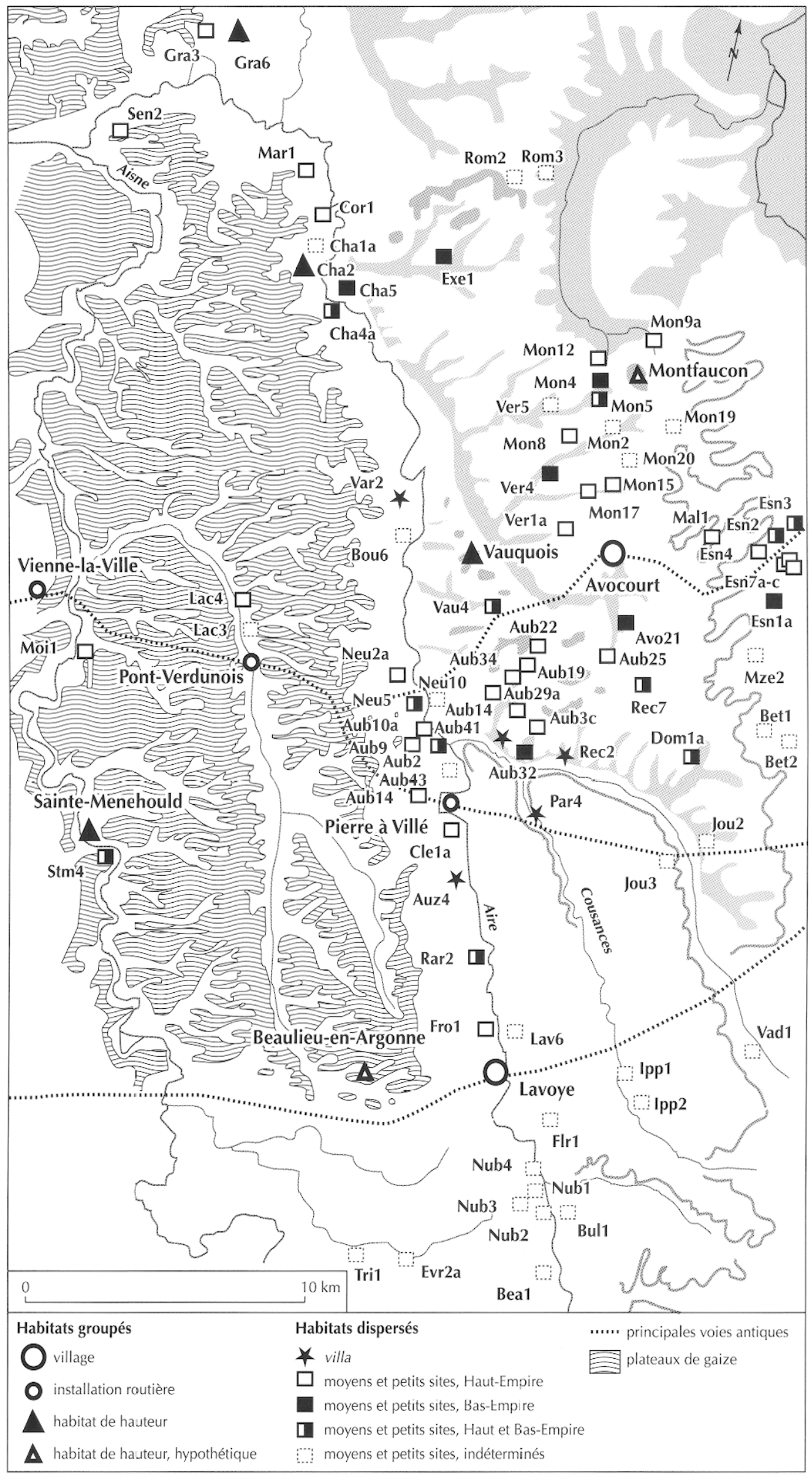

Fig. 8 - Occupation du sol, répartition de l'habitat antique (DAO M. Gazenbeek, INRAP). 
comme civitas au $\mathrm{V}^{\mathrm{c}}$ s., nous ne savons pas s'il s'agit d'une entité détachée de la cité des Mediomatrices ou si cette mention renvoie à un état plus ancien et mal connu du fait de la pauvreté des sources littéraires et épigraphiques du Haut-Empire ${ }^{13}$

\section{LES HABITATS GROUPÉS}

Si les villes, à part Verdun, sont absentes de la région et de ses marges, les petites agglomérations sont bien attestées sur le terrain. En fait, il s'agit d'ensembles très diversifiés, qui n'ont en commun que le caractère groupé de l'habitat. Pour l'Argonne, nous avons distingué trois types d'implantations groupées : le vicus, l'installation routière et le site de hauteur (fig. 8).

\section{Le vicus}

Deux sites, Lavoye et Avocourt, correspondent pour nous à la notion de vicus.

Pour Lavoye, c'est le baron $\mathrm{H}$. de Widranges qui nous donne, vers le milieu du XIX $^{e}$ s., l'une des premières descriptions des vestiges romains qui s'étendent autour de ce site (fig. 9) (Beaulieu, 1843 ; Widranges, 1862). Il s'agissait de la découverte, en 1832 et 1834, de blocs d'un basrelief au Chauffour, en limite du village de Lavoye, et d'un four de potier qui produisait de la sigillée moulée dans le quartier de La Vérine. Les blocs avaient été trouvés lors de la démolition des fondations d'une " habitation » romaine au sol en béton. Ces blocs furent rapidement brisés et détruits. Des $t u b u l i$, des fûts et bases de colonnes d'ordre dorique ont également été mis au jour mais aussitôt détruits. $H$. de Widranges écrit avoir reconnu une rue bordée de maisons antiques dans les fouilles du Chauffour. Il conclut sa description par un inventaire des monnaies provenant du site et conservées dans différentes collections privées, dont la sienne. La série s'échelonne entre des monnaies consulaires jusqu'aux pièces d'Honorius.

13. La plupart des auteurs considèrent que la région de l'Argonne était probablement partagée entre les cités des Rèmes, des Catalaunes et des Médiomatrices. Ainsi, la civitas Verodunensium (Verdun), connue par la Notice des provinces de la Gaule du V's., aurait été détachée de la zone d'influence de la cité des Médiomatrices vers le III $^{c}$ ou le IV $^{e}$ s. La possibilité d'une séparation politique et administrative entre Verdun et Metz durant toute l'Antiquité, ou du moins dès le III' $\mathrm{s}$., est attestée par l'existence d'une station routière Ad Fïnes dans le Woëvre entre Verdun et Metz, signalée par l'Itinéraire d'Antonin. Or, le toponyme Fines se trouve habituellement en limite de cité. Verdun aurait alors été rattachée à la zone d'influence de la cité des Rèmes comme semble l'indiquer la distribution des monnaies de bronze gauloises du $\mathrm{I}^{\mathrm{er}} \mathrm{s}$. avant notre ère : la monnaie coulée LT 8124, attribuée à ce peuple, se retrouve à Verdun dans la proportion de 6 sur 10 (Scheers, 1977, p. 170 et p. 750, fig. 207).
À partir de 1878 et jusqu'au début des années 1920, le $\mathrm{D}^{r}$ Meunier s'intéresse au site (Meunier, 1905, 1908 ; Chenet, 1941 ; Chenet, Gaudron, 1955 ; archives départementales de la Meuse, série 71.J, fonds G. Chenet). Aidé, vers la fin de son activité, par G. Chenet, il entreprend de nombreuses fouilles, " toutes faites au couteau, afin de ne rien briser et de recueillir aussi méthodiquement que possible les divers fragments appartenant à un même vase "; méthode qui lui permet de mettre au jour de nombreux fours et dépotoirs.

Il prend rapidement conscience de la situation exceptionnelle de Lavoye pour la production de la céramique en raison de la proximité de la matière première, du combustible et de la gaize réfractaire, mais aussi de son emplacement au croisement de deux routes antiques. Les fouilles du $\mathrm{D}^{\mathrm{r}}$ Meunier ont permis de découvrir d'autres activités artisanales: un four à chaux du III $^{\mathrm{e}}$ s., un établissement de bronzier du $\mathrm{I}^{\text {er }} \mathrm{s}$. et des vestiges liés à la fabrication du verre au $\mathrm{IV}^{\mathrm{c}}$ s. Le $\mathrm{D}^{\mathrm{r}}$ Meunier et G. Chenet fouillent un grand nombre de " trous noirs » (en fait, des tombes à incinération) entre les quartiers de La Vérine et du Chauffour.

Le $\mathrm{D}^{\mathrm{r}}$ Meunier fouille également une nécropole mérovingienne de 367 tombes, utilisée dès la fin du Ve s. jusqu'au VIII $^{\text {e }}$ s. comme l'indique la découverte d'une fausse monnaie en or. Ce cimetière " franc " semble s'organiser autour d'une tombe de "chef " et recouvre différentes constructions romaines, dont une installation thermale (Chenet, 1935 ; Joffroy, 1974 ; Young, 1984).

Les fouilles ont mis en évidence une vaste zone artisanale avec des fours de potiers de différentes époques entre la rivière et le quartier de La Vérine. Ces fours s'intercalent assez souvent avec des aires funéraires recelant des incinérations. Nous notons l'absence de sépultures à inhumation. Les vestiges de l'habitat antique et de plusieurs installations thermales se trouvent soit sous le village actuel, soit directement à l'ouest de celui-ci, parallèlement au Chemin de La Haie aux Vaches. Une partie de ces constructions est recouverte par la nécropole mérovingienne.

Le site d'Avocourt (fig. 10) a été étudié moins systématiquement que Lavoye. Connu dès le XVIII ${ }^{\mathrm{e}}$ s., un premier inventaire des vestiges a été dressé au milieu du XIX ${ }^{\mathrm{e}} \mathrm{s}$. par F. Liénard. Celui-ci a évalué la superficie du site à $2 \mathrm{~km}$ de longueur sur $1 \mathrm{~km}$ de largeur et il a noté avoir reconnu parmi d'autres vestiges d'habitations une " avenue pavée " et un hypocauste en briques (Liénard, 1853, p. 166-171). Une cinquantaine d'années plus tard, G. Chenet entreprend des prospections et des fouilles assez étendues sur le site. Ces recherches sont toutefois arrêtées par la déclaration de la guerre de 1914-1918. C'est pendant les hostilités qu'il rédige (" pour mémoire ") une notice résumant l'ensemble de ses recherches faites à cet endroit 


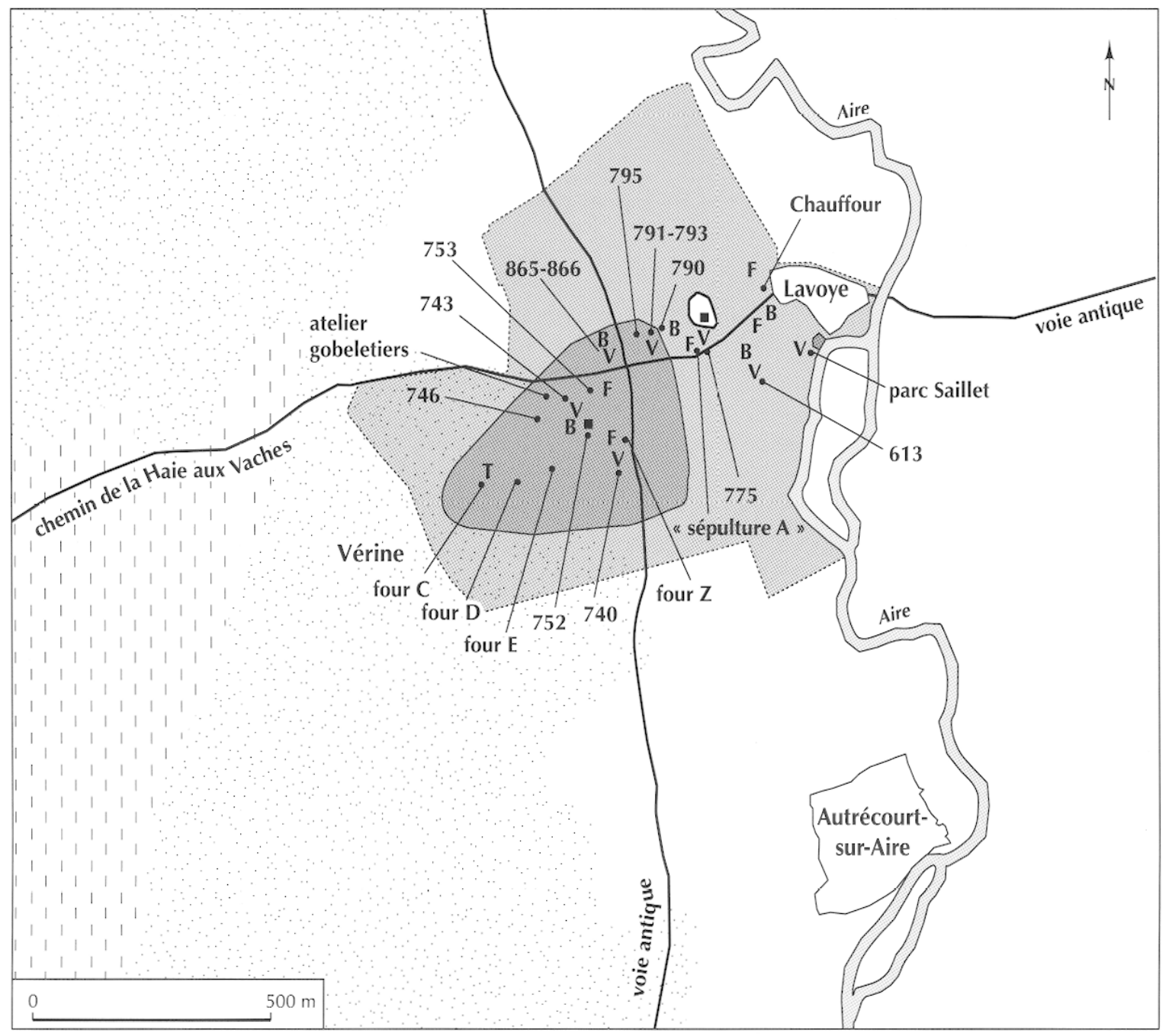

\begin{tabular}{|lll|}
\hline B & vestiges de bronzier & zone de fours de potier \\
$\mathrm{T}$ & tuilerie & quartiers cadastraux ayant livré des vestiges antiques \\
$\mathrm{V}$ & vestiges de verrier & sables verts \\
$\mathrm{F}$ & vestiges de forges de fer \\
- hypocaustes & \\
nécropole mérovingienne & \\
\hline
\end{tabular}

Fig. 9 - Le site de Lavoye (fond de carte d'après des cadastres du XIX's. ; DAO M. Gazenbeek, INRAP).

(Chenet, 1917). Il distingue neuf secteurs entre Le Moustier à l'est et Le Prix-des-Blanches à l'ouest, qui concernent tous des fours de céramique du Haut- et du Bas-Empire. Ses renseignements sont utilement complétés par les observations d'un officier allemand, G. Strohm, faites lors des combats dans les tranchées (cité in extenso par Unverzagt, 1919 , p. 8-9). Ce dernier note que les vestiges antiques s'arrêtent au nord à la lisière de la forêt, tandis que vers le sud, les lignes françaises l'empêchent de reconnaître la limite méridionale. Toutefois, dans cette direction, les niveaux recelant des tuiles deviennent plus denses et des fondations maçonnées apparaissent. Pour G. Strohm, il s'agirait d'une zone d'habitation. Il note également l'existence de deux voies empierrées à environ $0,30 \mathrm{~m}$ sous la surface. L'une est orientée est-ouest, l'autre nord-sud et suit plus ou moins le tracé d'un chemin de terre actuel. Les tranchées allemandes recoupent à plusieurs endroits des fours de potiers. 


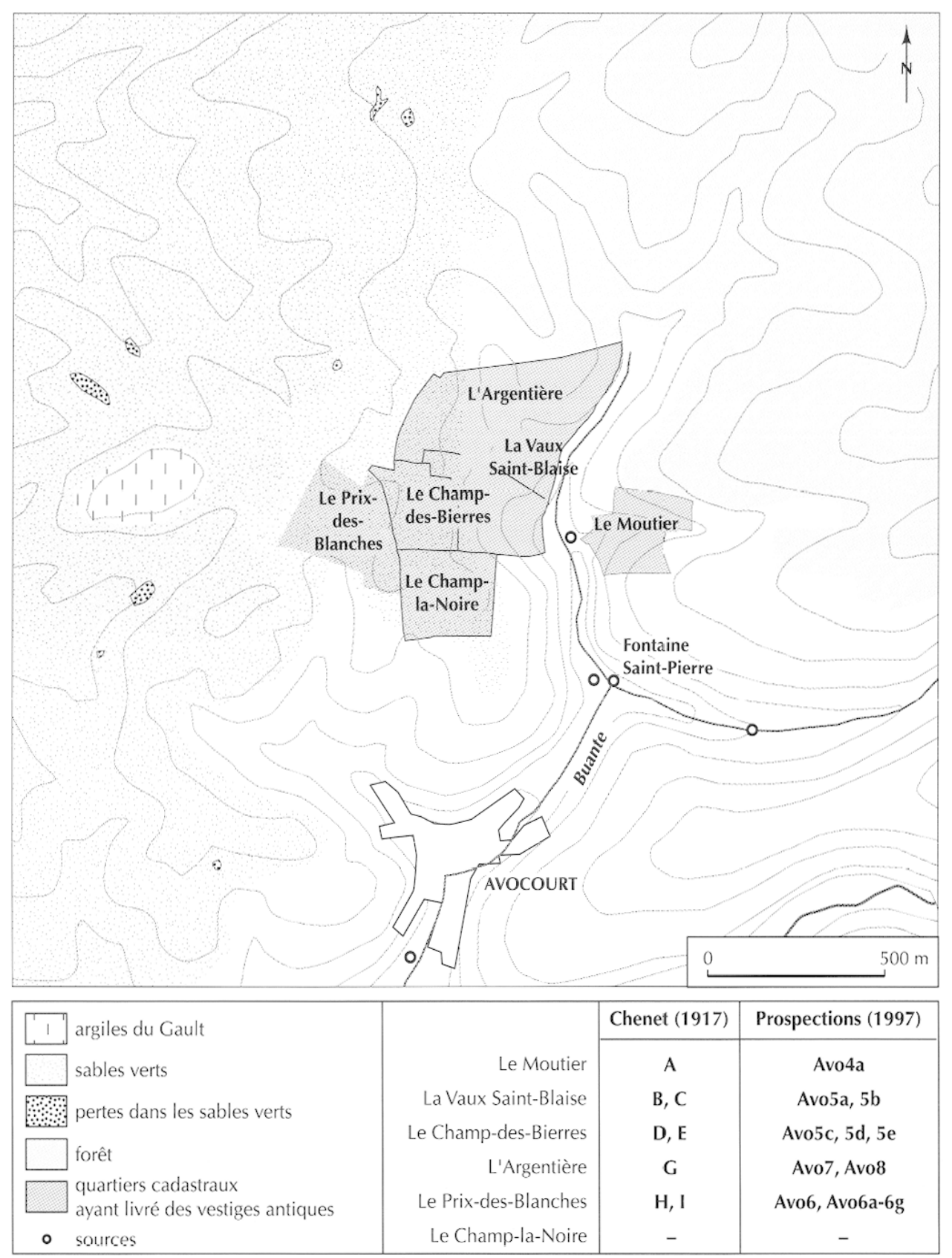

Fig. 10 - Le site d'Avocourt (DAO M. Gazenbeek, INRAP).

Le site d'Avocourt fut en partie transformé en nécropole à l'époque mérovingienne. Le cimetière, couvrant une superficie d'environ 0,50 ha au quartier du Champ-des-Bierres, a été détruit vers 1812 quand "on entreprit de débarrasser le sol de ces tombes qui faisaient obstacle à la culture " (Liénard, 1881-1885, III, p. 111). Mais encore au milieu du $\mathrm{XIX}^{\mathrm{e}}$ s., les labours découvraient de nouvelles tombes.

Les recherches plus récentes, commencées après le déclassement en zone rouge du site dans les années 1960, contribuent peu à notre connaissance de la topographie du site. Les prospections et les fouilles concernent la zone d'ateliers qui était déjà repérée par G. Chenet au Prix-desBlanches (Gallia, 1968, XXVI, 2, p. 380 ; 1978, p. 334 ; Feller, 1989 ; Gallia Informations, 1992, 2, p. 94).

Les deux sites de Lavoye et d'Avocourt ont en commun l'importance de leur superficie, la longue durée de leur occupation et un grand nombre d'installations artisanales. Dans les deux cas, la production de céramiques est 
fortement développée. C'est souvent ce seul aspect qui a retenu l'attention des différents chercheurs. Sur cet espace considérable, couvrant 35 ha à Avocourt et 40 ha à Lavoye, une partie importante est occupée par des ateliers de potiers, accompagnés d'autres activités artisanales telles que fours de bronziers, forges de fer et fours de verriers. Sur les deux sites, des vestiges d'hypocaustes (au moins deux à Lavoye et un à Avocourt) indiquent l'existence d'installations thermales collectives ou privées.

Les deux petites agglomérations sont occupées dès le $\mathrm{I}^{\mathrm{er}} \mathrm{s}$., voire avant, car un important matériel de La Tène a été trouvé à Lavoye. Leur occupation semble avoir été continue jusqu'au début du $\mathrm{V}^{\mathrm{e}} \mathrm{s}$., et même plus tardivement si l'on considère la présence des deux nécropoles mérovingiennes qui se développent à leur emplacement à partir du $\mathrm{VI}^{\mathrm{e}} \mathrm{s}$.

Les deux sites se trouvent aux croisements de voies antiques secondaires. Lavoye est placé au carrefour de la voie de la vallée de l'Aire et de celle de Châlons à Verdun, à l'endroit où cette dernière traverse la rivière à gué. À Avocourt, la voie de Lochères vers Senon croise un chemin nord-sud. Dans les deux cas, nous remarquons que la zone artisanale se développe autour du croisement proprement dit, tandis que les quartiers d'habitations sont situés à l'écart de celui-ci (près du gué à Lavoye).

\section{L'installation routière}

Le lien entre la route et l'habitat est également très net pour certains sites regroupés le long de la voie Reims-Metz (fig. 8) : c'est le cas de la station routière d'Axvenna dans la vallée de l'Aisne, signalée par l'Itinéraire d'Antonin ${ }^{14}$, de celle du Pont-Verdunois dans la vallée de la Biesme, en partie fouillée par G. Chenet au début du siècle (Chenet, 1922b, 1928b, 1946) (fig. 11), et de celle de La Pierre-à-Villé sur un méandre de l'Aire. Les trois sites se trouvent à des franchissements de cours d'eau. De surface assez restreinte (10 ha au Pont-Verdunois, 15 ha à La Pierre-à-Villé), ils ont néanmoins une activité artisanale importante signalée par des forges et des ateliers de potiers attestés dans les deux cas. G. Chenet écrit aussi avoir fouillé un fanum au PontVerdunois. L'occupation de ces habitats s'inscrit dans la longue durée, au moins du $\mathrm{I}^{\mathrm{er}}$ au IV $\mathrm{IV}^{\mathrm{e}} \mathrm{s}$. En marge, le long de la voie, des nécropoles ont pu se développer, comme aux abords du Pont-Verdunois. Là, G. Chenet a fouillé des tombes à incinération et deux tombes à inhumation du $\mathrm{II}^{\mathrm{e}}$ ou du $\mathrm{III}^{\mathrm{e}} \mathrm{s}$. Ce type d'installation a aussi été repéré sur

14. La localisation exacte de la station d'Axvenna est difficile à établir. Il pourrait s'agir du site du Bois de Charmeresse, à l'ouest de Vienne-laVille, où un " établissement romain assez important " est signalé dès le XIX`s. (Barthélemy, 1865, p. 9).

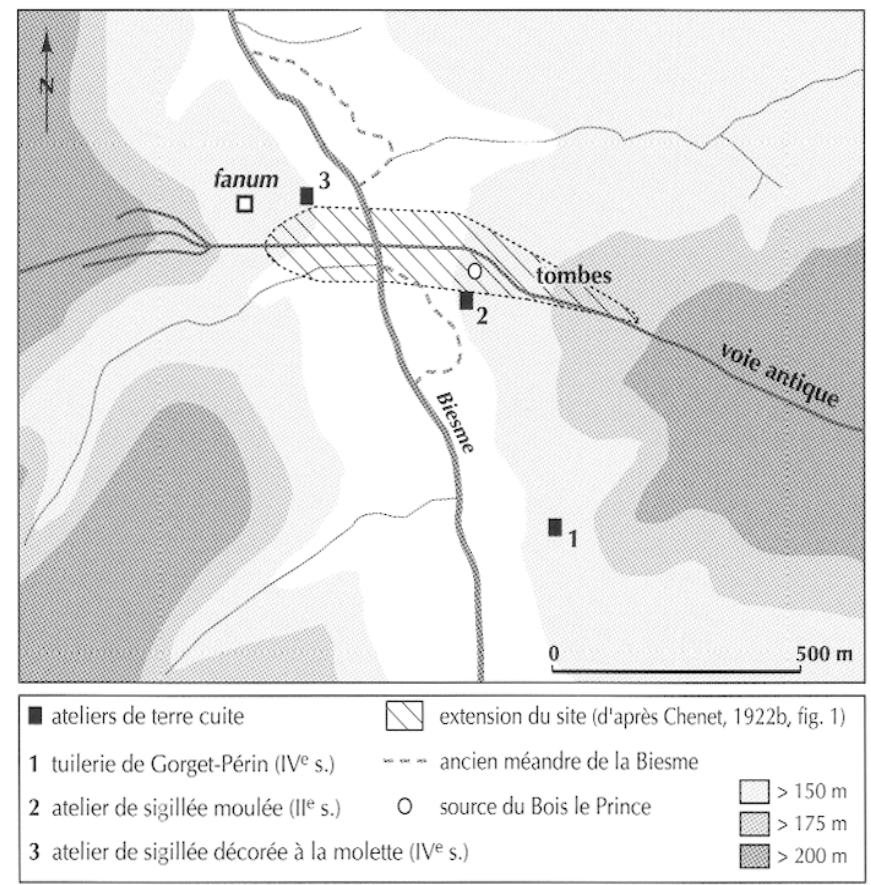

Fig. 11 - Le site du Pont-Verdunois (DAO M. Gazenbeek, INRAP).

des routes d'importance secondaire comme sur la voie Senon-Lochères, où le site du Pont-de-Cumières (Esn3) et les concentrations associées (Esn2, 4, 5, 7) se répartissent autour de la voie. Les prospections autour du site du Pontde-Cumières ont mis en évidence au moins une installation thermale.

\section{Les sites de hauteur}

La dernière catégorie d'habitat groupé est constituée par les sites de hauteur associés à des occupations de versant (fig. 8). Deux d'entre eux ont été explorés, respectivement à Châtel-Chéhéry (Cha2) et à Grandpré (Gra6). Dans les deux cas, l'occupation localisée sur le sommet plat d'une butte tëmoin de gaize est doublée par une occupation contemporaine en bas du versant. À Grandpré, l'occupation au sommet de la colline couvre 1 ha et l'habitat situé sur le versant (Gra7) 1,5 ha. Le constat est le même à ChâtelChéhéry où le sommet de 2,5 ha est entièrement occupé tandis qu'un second habitat, d'une superficie comparable, est situé sur le versant est. Depuis les années 1930, des vestiges sont trouvés à cet endroit (Chenet, 1941, p. 39-41). Sur ces deux sites, l'activité artisanale est apparemment moins développée que sur les précédents. Grandpré a livré des traces de forges, tandis que des fours de potiers sont les seuls vestiges d'activité artisanale attestés à Châtel-Chéhéry. Ces petits habitats groupés (respectivement 2,5 ha et 5 ha 
environ) ont en commun leur position topographique ainsi que leur création tardive. Tous deux sont occupés aux $I^{\mathrm{e}}$ et $\mathrm{V}^{\mathrm{c}} \mathrm{s}$.

Il est probable que Châtel-Chéhéry et Grandpré ne soient pas les seuls sites de hauteur de l'Argonne à cette période. À Sainte-Menehould, la découverte de monnaies du Bas-Empire et de céramique au sommet de la butte témoin de gaize sur laquelle a été implantée la ville du haut Moyen Âge (Mauget, 1906-1907, p. 385) invite à y voir (avec prudence) un site analogue. De même, la mise au jour de céramiques tardives sur la butte de Vauquois, par $\mathrm{G}$. Chenet ${ }^{15}$ après la guerre de $1914-1918$, peut être une indication sur l'existence d'un site du même type à cet endroit. Le lieu a par la suite été occupé par un village médiéval, avant d'être détruit par la guerre des mines durant la Première Guerre mondiale. Une occupation de l'Antiquité tardive sur d'autres buttes de la région, comme celles de Montfaucon et de Beaulieu, occupées à la fin $d u V{ }^{e} s$. par des abbayes bénédictines ${ }^{16}$, n'est pas impossible.

Ces vici et installations routières peuvent être aisément comparés avec les classes morphologiques ou fonctionncllcs d'agglomérations secondaires définies pour la Lorraine (Massy, 1994) ou la Wallonie (Brulet, 1994). Les sites de Lavoye et d'Avocourt font indubitablement partie des groupements liés à l'exploitation agricole et ils témoignent de l'essor engendré par les activités de production. Comme c'est le cas ailleurs en Lorraine, il est difficile de reconnaître les vestiges des habitations au sol, tandis que les traces artisanales sont partout présentes. D'autres sites d'Argonne, notamment les grands groupements d'ateliers de céramiques des Allieux et de la forêt de Hesse (cf. infra), entrent également dans cette catégorie. Les installations routières sur la voie Reims-Metz, dans les vallées de la Biesme et de l'Aire, doivent être comparées avec les «villages-rues " du nord de la Gaule et les modestes groupements lorrains (moins de $10 \mathrm{ha}$ ) engendrés par la création des grands axes routiers, probablement à l'époque augustéenne.

Pour ce qui concerne les sites de hauteur de l'Antiquité tardive, une comparaison s'impose avec ceux du pays trévire, où ce phénomène a été le mieux étudié (Gilles, 1985). Plus proche de l'Argonne, le site fortifié du Mont Vireux à Vireux-Molhain dans les Ardennes, situé sur un éperon dominant la Meuse, livre des repères chronologiques utiles : créé vers 260 , il est doté d'un rempart en

15. Voir Chenet, 1941, p. 38. L'association des Amis de Vauquois et de sa région, qui assure l'entretien des vestiges de la guerre de 1914-1918 sur la butte, découvre encore de la sigillée sur ce site.

16. Montfaucon-d'Argonne en 597, Beaulieu-en-Argonne en 542, Moiremont au VIII ${ }^{\mathrm{e}}$ s. (Cottineau, 1939-1970). pierre après 380 et est abandonné au milieu du Ve $\mathrm{s}$. Des activités de forge et de fonderie de bronze y sont attestées (Lémant, 1992, p. 133-135). Ce type de site est courant dans les Ardennes à celte période. Certes, il ne s'agit pas là d'habitats groupés permanents puisque, d'après les auteurs, de tels sites ne remplissent que des fonctions de refuge et de cantonnement militaire. C'est l'association avec une occupation de bas de pente qui leur confère le plus souvent l'aspect d'habitat groupé.

\section{LES VILLAE}

Plusieurs sites antiques installés dans les vallées de l'Aire et de ses affluents orientaux (fig. 8) correspondent à des villae. Ils ont en effet livré des vestiges architecturaux correspondant à des aménagements luxueux, notamment des éléments de thermes, des marbres et des enduits peints. Plusieurs de ces habitats ont été fouillés au siècle dernier ou ont fait l'objet d'observations de la part de G. Chenet.

À Auzéville-en-Argonne, au lieu-dit Sur le Moulin (Auz4), divers travaux d'épierrement de murs antiques ont permis de dégager une enfilade d'au moins trois pièces ${ }^{17}$ avec des murs épais revêtus d'enduits peints et des sols aux dallages en briques. Des tubuli étaient appliqués contre l'un des murs. Le bâtiment a connu au moins deux états: G. Chenet note en effet l'existence de deux sols superposés dans une pièce.. Plusieurs fragments d'éléments architecturaux et des bas-reliefs ont été inventoriés. Un fragment de colonne et un bas-relief en calcaire représentant un personnage étaient mêlés aux décombres et un bloc avec deux bas-reliefs figurant des personnages était réutilisé dans l'un des murs, tandis que dans une des niches ce sont des éléments d'un autel ou des fragments d'un monument funéraire qui furent remployés. La datation de cette villa reste incertaine : les fouilles ont livré très peu de céramiques et aucune monnaie. G. Chenet suggère que la réutilisation de bas-reliefs romains implique une construction postérieure au I ${ }^{\mathrm{er}} \mathrm{s}$. Il constate l'absence de sigillées du IV $\mathrm{V}^{\mathrm{c}} \mathrm{s}$., ce qui lui permet de situer l'occupation autour des II ${ }^{\mathrm{e}}$ et III $^{\mathrm{e}} \mathrm{s}$. Une réoccupation tardive de l'habitat est possible, car G. Chenet signale en effet, dans les déblais, des tessons d'une céramique noire carénée qu'il pense être mérovingienne. La superficie du site est grande. Selon J.-B. Gillant, les vestiges antiques s'étendent depuis le presbytère d'Auzéville jusqu'au lieu-dit Sur le Moulin, sur une distance de $200 \mathrm{~m}$ environ (Gillant, 1886-1887).

17. Ces activités de carrière ont été attentivement suivies en 1886-1887 par le curé du village, J.-B. Gillant, qui a noté ses observations au fur et à mesure que le terrassier mettait au jour les murs et les démolissait (Gillant, 1886-1887; Chenet, 1929). 
La villa du Pré-Marquet (Var2) ou de La Verte Voie près de Varennes a été partiellement fouillée en 1889. Ces recherches ne sont connues que par de très courtes notices dans différentes publications régionales (dont Liénard, 1891). On retient surtout la mise au jour d'un hypocauste. Sur les cinq monnaies trouvées dans ces fouilles, une seule est identifiée (Vérus: 161-169). Nos prospections ont permis d'identifier le site sur plus de 1 ha. Le matériel de surface, dont des enduits peints, montre une occupation longue $d u I^{\text {er }}$ au IV ${ }^{e}$ s. au moins. Cette datation tardive permet de rattacher à cette villa la petite nécropole découverte en 1906 tout près du site, contre le vieux chemin de La Verte Voie. Le mobilier funéraire en verre et en sigillée, dont un bol Chenet 320 décoré à la molette, $n^{\circ} 172$ de la classification d'Unverzagt, était du dernier quart du $\mathrm{IV}^{\mathrm{e}} \mathrm{s}$. (Chenet, 1936).

La villa de Champ-la-Gaye (Par4), sur la rive droite de la Cousances, a été découverte lors de l'ouverture d'une carrière en 1865. Les vestiges se situent sur la limite communale entre Parois et Brabant-en-Argonne (Liénard, 1881-1885, II, p. 9). Les constructions s'étendaient sur au moins $800 \mathrm{~m}^{2}$ au bord de la rivière. Elles étaient composées de pièces de 2 à $4 \mathrm{~m}$ de côté dont les murs, encore conservés sur $1 \mathrm{~m}$ de hauteur, étaient construits de briques recouvertes d'enduits peints, sur fondations en pierre. Les sols étaient également en briques. Un trésor d'une trentaine de monnaies, découvert dans l'une des pièces, fut aussitôt partagé entre les ouvriers et seulement 12 d'entre elles sont parvenues au musée de Verdun. En dehors d'un potin gaulois des Lingones, ces monnaies s'échelonnent entre la seconde moitié du I ${ }^{\mathrm{cr}} \mathrm{s}$. (Titus) et la seconde moitié du IVe $s$. (Valens).

La villa de Genhoux à Récicourt (Rec2), également découverte fortuitement au siècle dernier (Liénard, 18811885, II, p. 10), a livré en prospection des tesselles de mosaique, du béton de tuileau et des enduits peints, évoquant un aménagement architectural soigné. La céramique trouvée en prospection indique une occupation qui s'étend du I ${ }^{\mathrm{er}}$ au IIIc $\mathrm{s}$. Une absence marquée de sigillées décorées à la molette suggère un abandon avant le $\mathrm{IV}^{\mathrm{e}} \mathrm{s}$.

De même, les structures fouillées par G. Chenet au Champ-Colas (Aub4l) à Aubréville après la Première Guerre mondiale (Toussaint, 1946, p. 149-150), avec la présence d'enduits peints et de tubuli, dénotent un certain luxe.

Ces cinq sites ont en commun leur position topographique, leur superficie et leur durée d'occupation. Les vestiges, qui s'étendent sur plus de 1 ha, lorsque la superficie a pu être définie (Auzéville, Pré-Marquet, Genhoux), sont situés sur les versants ou les rebords des terrasses le long des vallées principales de l'Argonne orientale et ne sont donc jamais très éloignés de l'axe de la vallée. Ces habitats apparemment assez luxueux sont occupés pendant une période longue couvrant le Haut- et le Bas-Empire, du $\mathrm{I}^{\mathrm{er}}$ au III $^{\mathrm{e}}$ s. à Genhoux et $\Lambda$ uzćvillc, ct au moins jusqu'au $I^{\mathrm{c}}$ s. au Pré-Marquet et à Champ-la-Gaye.

L'absence de documents épigraphiques est remarquable, aussi bien dans les villae que dans les habitats groupés. Ils auraient pu nous renseigner sur l'origine et le statut de leurs habitants. Il semble que cette lacune ne soit pas due à une absence réelle d'inscriptions dans la région. En effet, par deux fois, leur existence est signalée. F. Liénard rapporte qu'au cimetière du Champ-des-Bierres sur le site d'Avocourt une pierre, qui était encore visible au village au début du XIX ${ }^{e}$ s., avait été trouvée avec l'inscription Paseus ou Paseas (Liénard, 1853, p. 166-171). À Lavoye, des inscriptions, aussitôt détruites, ont été signalées au XIX ${ }^{\mathrm{e}} \mathrm{s}$. (Beaulieu, 1843, p. 58). Certains sites ou plutôt certains de leurs habitants occupaient sans doute une place importante dans la hiérarchie sociale comme en témoignent les basreliefs trouvés en remploi dans les murs antiques de la villa d'Auzéville ainsi que dans les fondations d'un bâtiment romain à Lavoye et qui peuvent provenir de deux monuments funéraires.

\section{LES SITES MOYENS ET PETITS}

Une cinquantaine de sites, définis en prospection comme des habitats par la composition des indices de surface (matériaux de construction, mobilier céramique diversifié), entrent dans la catégorie des sites moyens et petits. Généralement, ce groupe correspond aux habitats de moins de 1 ha, sans aménagements particuliers. On les trouve tout le long de la vallée de l'Aire, dans la vallée de la Biesme, sur les plateaux de calcaire portlandien autour de Montfaucon et au pied de la cuesta d'Esnes. On peut ajouter à cette catégorie des lieux de découvertes marqués par de petites concentrations de céramique, dont on connaît mal la fonction : dépotoir, habitat érodé, etc.

À Senuc, le site de La Croix-Haumont (Scn2) sc singularise par sa position sur un éperon aux versants très abrupts, dominant de quelque $60 \mathrm{~m}$ le confluent de l'Aire et de l'Aisne. Cet habitat perché, sans aménagements architecturaux particuliers, qui date du $\operatorname{III}^{\mathrm{e}}$ s., a très probablement livré un trésor ${ }^{18}$.

Dans l'étroite vallée de la Biesme, connue avant la canalisation de la rivière au $\mathrm{XVIII}^{\mathrm{e}} \mathrm{s}$. pour son fond marécageux,

18. Trésor d'environ 300 pièces découvert en 1838 au nord-est du village dans une crevasse, et qui aurait été semblable à celui de Gallo (Ardennes) qui recelait des pièces de l'époque de Septime Sévère à Volutien : première moitié et milieu du III' ${ }^{\mathrm{s}}$ s. (Beaulieu, 1843, p. 60). 
les habitats sont rares et modestes, en dépit des affleurements d'argile et de sables verts qui ont pourtant attiré les potiers antiques dans ce vallon (voir infra). Les deux sites découverts en prospection au nord du Pont-Verdunois (Lac3, Lac4) sont de petites dimensions, proches d'une source et implantés sur le bas de versant, juste au-dessus du fond plat de la vallée. Seul le site de Lac4 a pu être daté (II ${ }^{\mathrm{c}} \mathrm{s}$.).

Sur les hautes terrasses de la rive gauche de l'Aire, les habitats de ce groupe sont nombreux : Corl, Marl (I ${ }^{\mathrm{cr}}$ -

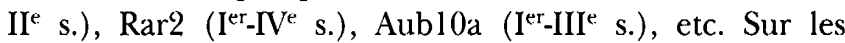
plateaux de Montfaucon, la prospection a permis de recenser plusieurs autres habitats de ce genre: Mon8,

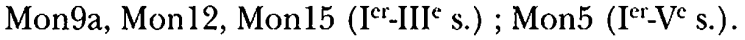

La prospection extensive des affleurements de marnes aux pieds de la cuesta orientale de l'Argonne, dans un secteur s'étendant à l'est des grands centres de production d'Avocourt jusqu'à la forêt de Hesse, avait pour but de vérifier l'importance de ce contexte géologique dans la distribution des ateliers de potiers antiques. Excepté les indices d'un four de céramique gallo-belge à Esn $7 \mathrm{~b}$, aucun four de potier n'a été découvert avec certitude. Néanmoins un grand nombre d'autres structures a pu être repéré, notamment des habitats (Domla, Esnla, le groupe d'Esn2, Esn3, Esn4, Esn7a et Esn7c) et même une installation liée à une source avec des constructions en grand appareil : sanctuaire et/ou thermes? (Mal1).

Plus au sud, sur les vastes plateaux de calcaires portlandiens du sud-est de l'Argonne, la prospection s'est concentrée essentiellement sur les versants dominant la rive droite de l'Aire entre Aubréville et Lavoye, et sur des secteurs situés de part et d'autre de la voie romaine Reims-Metz. Seuls des indices de site (Jou2, Lav6) ont été repérés, toujours dans une zone qui domine directement une vallée. En revanche, sur les plateaux, des zones étendues d'épandage de matériel antique existent, montrant une mise en culture ancienne, mais il n'y a apparemment pas d'habitat.

Les vastes plateaux de gaize entre l'Aire à l'est et l'Aisne à l'ouest sont aujourd'hui presque intégralement couverts de forêts, à l'exception des marges occidentales largement mises en culture autour des villages. Des secteurs boisés étendus ont été prospectés avec des résultats remarquables pour la Protohistoire et le Moyen Âge. Une attention particulière a été portée sur une zone entre Vienne-le-Château et Florent-en-Argonne, composée de labours en marge de la forêt. En dépit de conditions de visibilité optimales pour la prospection pédestre, aucun site d'habitat antique ni même des zones d'épandage de matériel antique n'ont été repérés sur cette partie du plateau.

Aux abords de la voie Reims-Metz, des tombes ont été repérées sur ces plateaux. Il s'agit d'un tumulus en haut du versant est de la vallée de l'Aisne, d'une possible tombe tardive sous tuiles en haut de la côte de Lochères et enfin, en plein milieu du plateau et de la forêt d'Argonne, d'une tombe à inhumation avec un plat en sigillée Chenet 304 (Chenet, 1941, p. 61). Ce modèle d'occupation, qui met en évidence de vastes zones sans habitats de l'époque gallo-romaine, mais seulement des tombes en bordure de la voie antique, semble identique pour l'ensemble de ces plateaux.

Cela ne veut pas dire que la forêt d'Argonne soit réellement vide. En effet, l'existence de deux groupes de puits probablement antiques (Stm5, Vch5) (fig. 15) montre que ces plateaux ont été le théâtre d'autres activités, liées notamment à l'industrie du verre (voir infra).

\section{LES SITES MÉROVINGIENS}

Peu d'habitats mérovingiens sont connus dans la région (fig. 12). Cette pauvreté contraste avec le nombre de nécropoles de la même période découvertes notamment au $\mathrm{XIX}^{\mathrm{e}}$ s. dans cette partie de l'Argonne. La prospection a révélé trois sites d'habitats seulement (Avol6b, Ver4 et Exel). À Exel, le gisement recouvre en partie un habitat antique du $I^{c} \mathrm{~s}$. La présence de céramiques mérovingiennes sur des habitats antiques a aussi été constatée dans les villae de Genhoux (Rec2) et d'Auzéville (Auz4), ainsi que sur les sites de hauteur et de piémont de Grandpré (Gra6) et de Châtel-Chéhéry (Cha2). Ceci semble être également le cas pour les sites de Châtel-Chéhéry 4a, de Châtel-Chéhéry 5 et de Montfaucon 5.

Près d'une dizaine de nécropoles mérovingiennes sont connues dans la région. Plusieurs ont été découvertes à l'emplacement de sites romains, montrant que leur réoccupation ou la continuité de leur occupation durant la période de transition entre l'Antiquité tardive et le haut Moyen Âge n'était pas rare. Le cas est attesté à Vaux-Bona (Aub14) sur la voie Reims-Metz (Liénard, 1881-1885, II, p. 8) et dans les villages antiques de Lavoye et d'Avocourt.

D'autres nécropoles de la période "franque "sont situées le long des vallées de l'Aire et de la Cousances: cimetière de La Quemine à Nubécourt, sépultures de Fleury-sur-Aire, tombes de L'Homme-Mort près de Varennes, cimetière à Fléville, nécropole du Châtelet à Senuc. Dans la vallée de la Cousances, on dénombre une nécropole à Julvécourt, des sépultures au lieu-dit FosséReignier à Ville-sur-Cousances et une tombe à Jubécourt. Enfin, à Nixéville-Blercourt un groupe de sept ou huit sépultures a été repéré au sommet de la colline surplombant le village. Sur le versant, à $500 \mathrm{~m}$ du même village, une nécropole de 150 tombes a été fouillée en 1884. Près d'Esnes, on trouve la petite nécropole de La Côte la Hoche. 


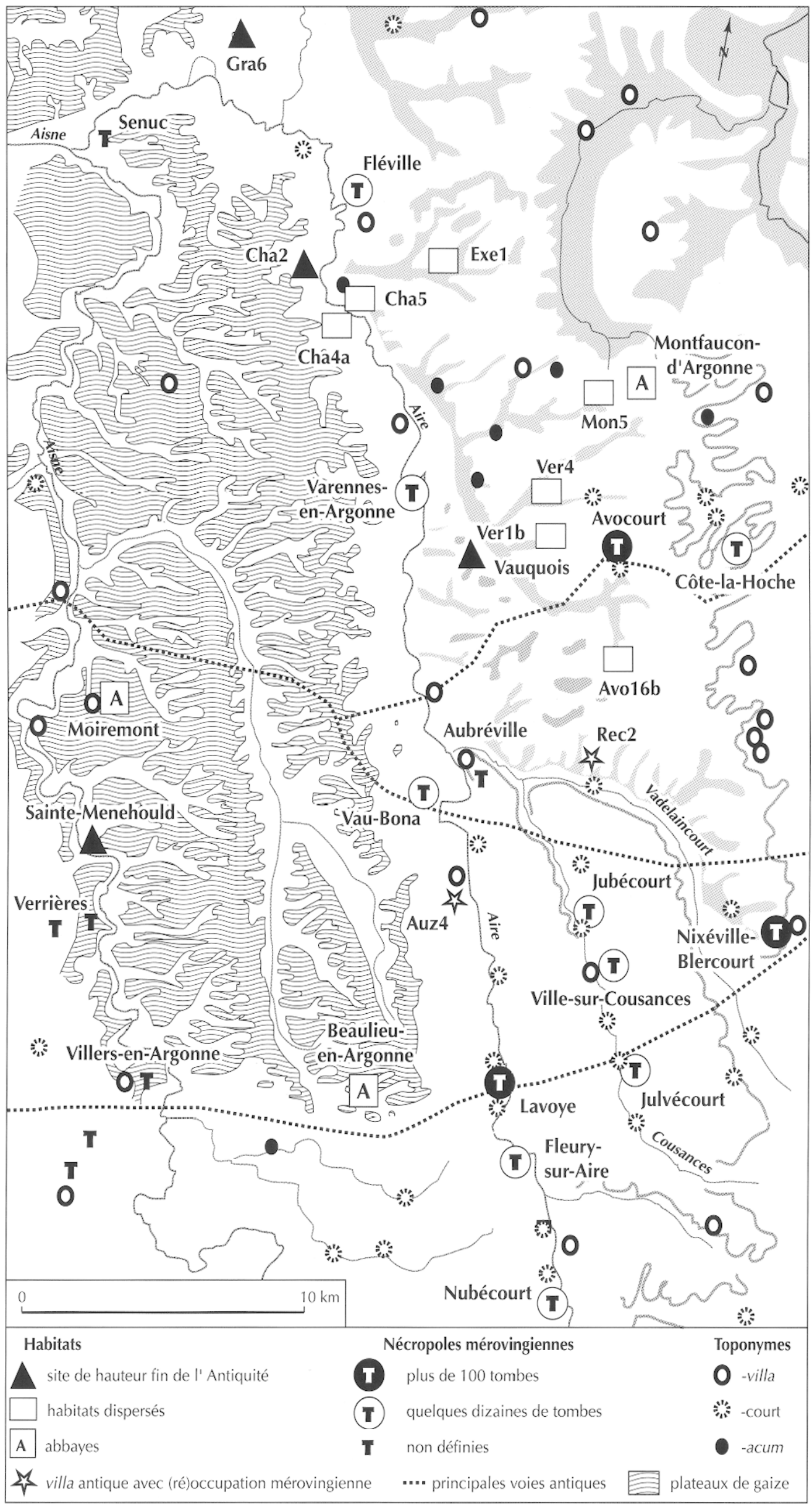

Fig. 12 - Occupation du sol, distribution des sites mérovingiens el du haut Moyen Âge (DAO M. Gazenbeek, INRAP). 
Sur le versant ouest de l'Argonne, des cimetières sont signalés à Verrières et à Villers-en-Argonne ${ }^{19}$.

Le nombre de tombes signalées dans les différentes nécropoles varie considérablement. Certains cimetiëres dépassent largement la centaine d'inhumations. C'est le cas en particulier à Nixéville-Blercourt, à Lavoye et à Avocourt, où ces cimetières soulignent ainsi le rôle important que ces deux derniers sites continuent à avoir à la fin de l'Antiquité. Mais la plupart des nécropoles ne renferment qu'un nombre limité de tombes (environ 20 à Julvécourt, 7 à Esnes, 15 à Fléville) et doivent correspondre à des aires funéraires associées à des habitats dispersés.

La disproportion entre le nombre d'habitats connus (10) et le nombre de nécropoles (14) peut avoir une double origine. D'une part, les vestiges des habitats mérovingiens sont très discrets et se limitent souvent à une concentration de céramiques. Ils sont donc moins faciles à repérer en prospection que les habitats romains. D'autre part, un certain nombre de ces sites a pu par la suite évoluer en village médiéval. C'est par exemple ce modèle que nous proposons pour Lavoye, mais aussi pour Aubréville, connu par une charte de Pépin (Herbereci villa, voir Dauzat, Rostaing, 1983) et où une tombe mérovingienne maçonnée a été signalée près de l'église Saint-Martin (Revue des musées, 1930 , p. 124). C'est dans ce sens aussi qu'il faut peut-être interpréter la phrase de Schmit qui signale une "station barbare sous l'église de Moiremont " (Schmit, 1926-1928, p. 205). Ceci implique une certaine continuité dans le modèle d'occupation du sol: certaines zones demeurent préférentiellement occupées. Nous remarquons d'ailleurs que les villages argonnais, dont le toponyme indique une origine ancienne (noms en - court dérivés de curtis et en ville dérivés de villa), sont implantés sur les mêmes terrains que les villae romaines : rebords de terrasses des vallées de l'Argonne occidentale et absence marquée dans l'Argonne centrale (Biesme).

\section{LES GRANDES PHASES DE L'OCCUPATION : ESSAI DE PÉRIODISATION}

Une cinquantaine de sites d'habitat ont livré assez d'éléments de datation (céramiques, monnaies) pour permettre d'établir des chronologies relativement précises. Ils correspondent à des habitats isolés ou groupés. Plusieurs

19. Voir Widranges, 1871 (La Quemine) ; archives départementales de la Meuse 71.J.29 (Fleury); Liénard, 1853, p. 171-172 (La Côte la Hoche) et p. 176-177 (L'Hornme-Mort) ; Guelliot, 1920-1929 (Fléville) ; archives SRA Champagne-Ardenne, lettre du $D^{r}$ Rozoy (Senuc); Liénard, 1881-1885, II, p. 107 (Nixéville-Blercourt) et III, p. 109-1 10 (Julvécourt, Fossé-Regnier, Jubécourt); Schmit, 1926-1928, p. 278 et 287 (Verrières, Villers-en-Argonne).

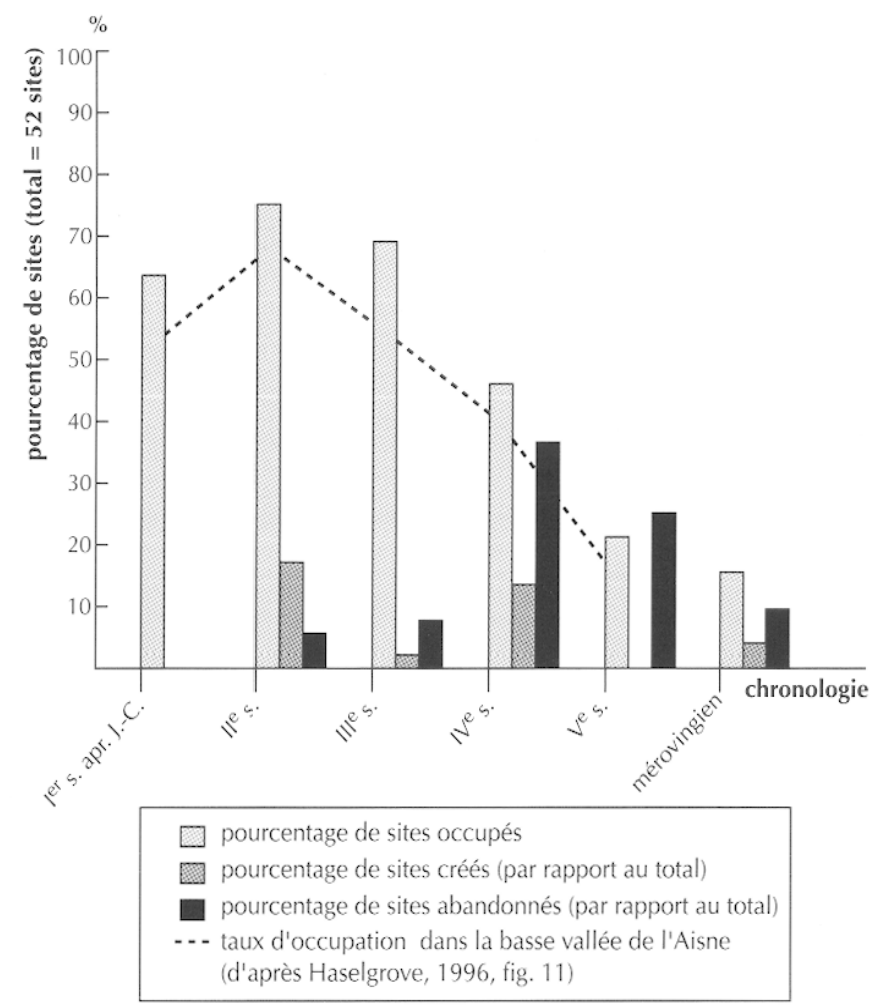

Fig. 13 - Pourcentage par siècle des sites antiques créés, occupés et abandonnés (DAO M. Gazenbeek, INRAP).

d'entre eux ont une double fonction : lieu de production de poterie et habitat. La plus grande densité de sites antiques se situe aux $\mathrm{II}^{\mathrm{e}}$ et $\mathrm{III}^{\mathrm{e}} \mathrm{s}$. (jusqu'à $75 \%$ des sites sont alors occupés), qui apparaissent comme la période la plus dynamique dans la région (fig. 13), avec l'implantation de nombreux habitats le long des vallées et sur les plateaux autour de Montfaucon à partir du $\mathrm{I}^{\text {er }} \mathrm{s}$. Un nombre important de sites est abandonné à la fin de cette période, dans tous les cas avant l'apparition de la sigillée décorée à la molette. $\mathrm{Au} \mathrm{IV} \mathrm{V}^{\mathrm{c}}$ s., un site sur deux seulement $(46 \%)$ est occupé, diminution qui s'accentue encore au Ve $\mathbf{s}$. (21\% occupes). Cette courbe de l'occupation, avec une progression entre le $\mathrm{I}^{\mathrm{er}}$ et le $\mathrm{II}^{\mathrm{e}}$ s., puis une baisse continue du nombre de sites occupés durant tout le reste de l'Antiquité, est tout à fait classique (Ouzoulias et al. dir., 2001). Dans les régions proches, des prospections systématiques sur $40 \mathrm{~km}^{2}$ dans la basse vallée de l'Aisne, au nord-ouest de Reims, ont donné exactement le même résultat (Haselgrove, 1996).

Toutefois, le IVe s. montre aussi des créations : $13 \%$ des sites apparaissent à partir d'une période située à cheval sur le $\mathrm{III}^{\mathrm{c}} \mathrm{s}$. et le $\mathrm{IV}^{\mathrm{e}} \mathrm{s}$. Il s'agit notamment des sites de hauteur (Cha2, Gra6, Vauquois), mais également de petits habitats dispersés comme Exel (Exermont), parfois liés à des ateliers de céramique, tel Verlb. Le tout donne l'image d'un 


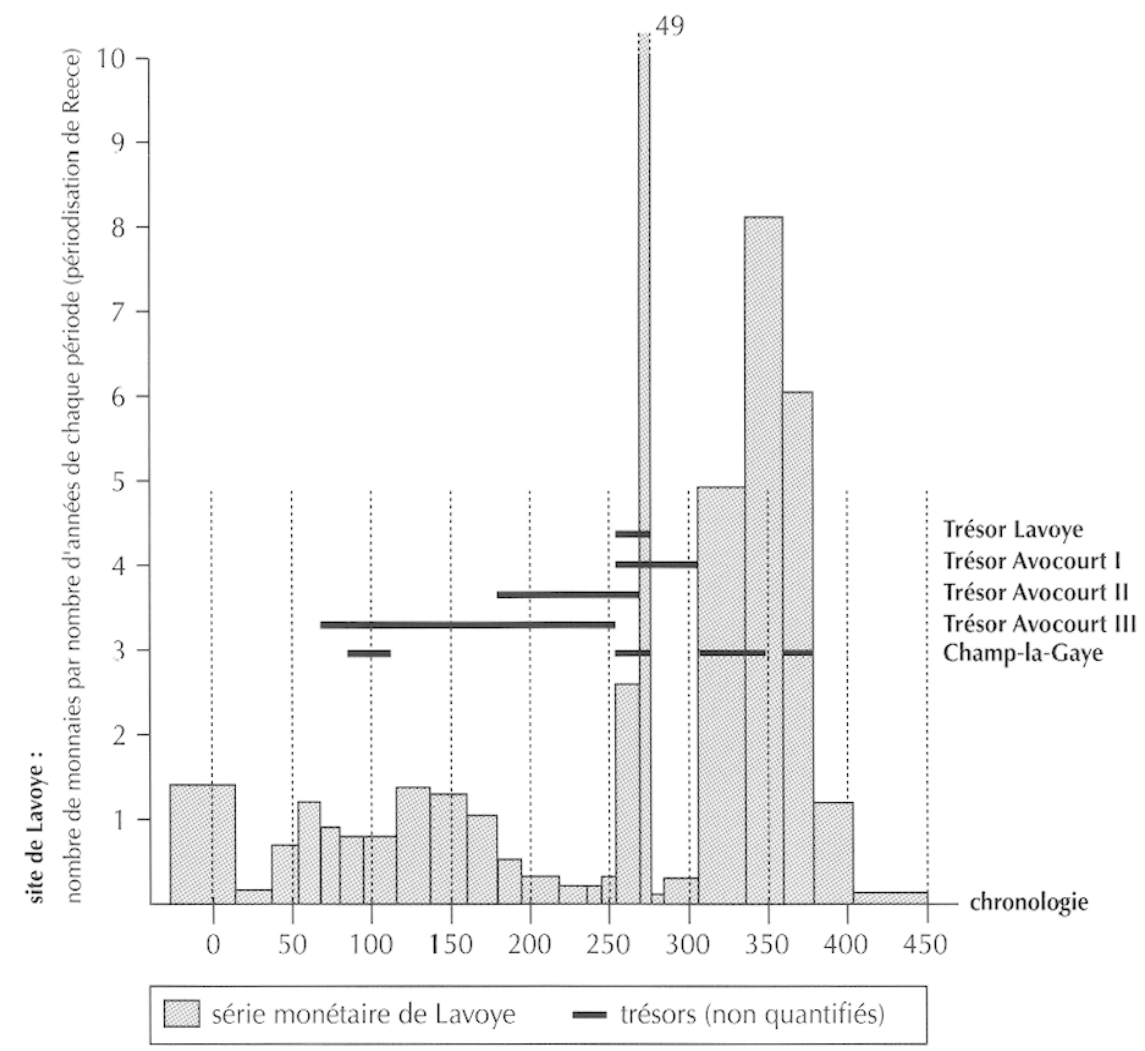

(DAO M. Gazenbeek, INRAP).

processus de changement complexe, où de multiples facteurs sont entrés en jeu ${ }^{20}$.

Le dynamisme de la région durant la seconde moitié du $\mathrm{III}^{\mathrm{e}}$ s. et durant le $\mathrm{IV}^{\mathrm{e}}$ s. est également perceptible à travers les découvertes monétaires faites dans la région depuis le $\mathrm{XIX}^{\mathrm{e}}$ s. (fig. 14). L'étude entreprise sur la série monétaire de Lavoye (hors trésors) issue des fouilles du $\mathrm{D}^{\mathrm{r}}$ Meunier et de $\mathrm{G}$. Chenet montre les dynamiques de la circulation monétaire sur ce site. Un inventaire détaillé des 1230 monnaies trouvées par le $\mathrm{D}^{r}$ Meunier en 20 ans de fouilles sur ce site permet d'appréhender l'importance de la masse monétaire dans cette agglomération durant toute l' $\Lambda$ ntiquité. Lcs pičccs couvrent la période qui s'échelonne de La Tène finale aux empereurs byzantins et indiquent une occupation continue jusqu'au Ve $\mathbf{s}$. au moins. Les variations dans l'histogramme relèvent davantage des phénomènes monétaires (refonte, thésaurisation, etc.) que de fluctuations démographiques sur le site.

Il en est de même pour les trésors monétaires de la période romaine découverts dans la région (Estiot, 1998). À Avocourt, les trois dépôts connus sont respectivement une

20. Cette complexité a été bien misc en lumière dans la synthèse faite par P. Van Ossel en 1995 sur l'habitat rural de l'Antiquité en Gaule septentrionale. amphore remplie de 400 livres de monnaies, un vase en argent contenant plusieurs monnaies et un vase en céramique avec 146 monnaies. Lavoye a livré un trésor de 1760 pièces contenues dans un vase. Du point de vue de la datation, les trésors d'Avocourt s'arrêtent avec des pièces frappées respectivement en 253, 268 et 306 tandis qu'à Lavoye, la fin de la série se situe vers 282 . Ces dates s'échelonnent sur toute la seconde moitié du III ${ }^{\mathrm{e}} \mathrm{s}$. et le début du IV $^{e}$ s., parfois au-delà comme en témoigne le trésor de la villa de Champ-la-Gaye dont la composition s'arrête aux monnaies de Valens, soit la seconde moitié du $I^{\mathrm{c}} \mathrm{s}$. (Liénard, 1881-1885, II, p. 9).

L'importance des trésors réside dans les jalons chronologiques qu'ils marquent. Ils ont longtemps servi à mesurer l'impact des invasions de la seconde moitié du III ${ }^{e}$ s., et notamment les invasions de 259-260 et de 275, sur la dynamique régionale de l'occupation. Or, aucun des trésors connus ne correspond à ces périodes d'invasions, ce qui relativise la corrélation établie traditionnellement entre le nombre des trésors et l'ampleur des invasions. Ceci vient en appui des derniers résultats de la recherche tendant à relativiser l'impact et l'importance des invasions (Van Ossel, 1992, p. 69-72 ; Whittaker, 1995) et à souligner le rôle de la thésaurisation domestique (Delmaire, 1995). On est alors en droit de mettre en doute l'idée, longtemps en vogue à la 
suite des publications de G. Chenet, selon laquelle les invasions de 275 auraient totalement remodelé la production céramique de la région (Van Ossel, 1986).

\section{L'ÉCONOMIE DE LA RÉGION : UN ARTISANAT DIVERSIFIÉ}

Les découvertes et fouilles anciennes montrent que le site de Lavoye, le plus étudié, a connu un artisanat du feu varié : bronziers, forgerons, fonderies de verre et productions céramiques sont largement attestés. Les prospections et les découvertes fortuites montrent que certaines de ces activités sont signalées dans plusieurs autres endroits de la région. Nous faisons ici le point sur l'artisanat du verre et du fer, ainsi que sur les tuileries (fig. 15) qui sont particulièrement liées à l'environnement propre à l'Argonne.

\section{L'ARTISANAT DU FER ANTIQUE EN ARGONNE}

En Argonne, le minerai de fer a été exploité dans les sables verts de l'Albien inférieur ${ }^{21}$, dont les gisements se trouvent à une faible profondeur (entre $4 \mathrm{~m}$ et $30 \mathrm{~m}$ ). Les lieux d'extraction attestés sont tous de l'époque moderne (XVI ${ }^{e}$ s. et plus récent) et sont concentrés dans la partie nord de la région, entre Grandpré et Romagne-sousMonffaucon (Hussenel, 1982, p. 403-407).

Les vestiges de forges sont nombreux au Pont-Verdunois, à Avocourt, à Lavoye et à La Pierre-à-Villé pour ne nommer que les sites majeurs. Sur ce dernier site, les prospections géophysiques ont montré que les scories de fer ont servi à l'empierrement de la voie antique. À Lavoye, on trouve des concentrations de scories de fer à neuf endroits différents au moins, dont trois pourraient être des forges (archives départementales de la Meuse 71.J.32). L'une de ces dernières a livré de nombreuses scories et loupes de grandes dimensions et des débris de briques de fourneaux, dont certaines avec les loupes encore en place. Cet ensemble date probablement du I ${ }^{\text {er }}$ s.

La présence généralisée de vestiges de métallurgie du fer dans ces habitats groupés évoque la situation mise en évidence en Bourgogne, dans l'Auxois (Mangin et al., 2000) : groupement de forges dans les agglomérations (Lavoye), peut-être des "forges routières " sur les axes de circulation (Le Pont-Verdunois, La Pierre-à-Villé), sans que l'on sache s'il s'agit seulement du travail du fer ou aussi de réduction.

21. La base de cette formation est caractérisée dans ce secteur par une présence massive de peroxydes de fer hydratés sous forme de grains répartis sur des couches de 1 à $3 \mathrm{~m}$ d'épaisseur (Notice de la carte géo logique de la France, 1/80 000, feuille $\mathrm{n}^{\circ} 35$ de Verdun).
Les études dans l'Auxois ont bien mis en évidence l'éclatement de la chaine opératoire de la production du fer entre, d'une part, les sites de traitement et de réduction du minerai et, d'autre part, les sites d'épuration du produit de la réduction et les sites d'élaboration d'objets en fer. Pour l'Argonne, l'absence de recherches sur les scories ne permet pas d'atteindre ce degré de précision, mais une répartition des activités similaires est probable. L'éclatement de la chaîne opératoire ne paraît d'ailleurs pas limité à la métallurgie du fer. Le même modèle semble pouvoir être proposé pour l'artisanat du verre.

\section{LA PRODUCTION DU VERRE ANTIQUE EN ARGONNE}

La fabrication du verre en Argonne est bien documentée pour le Moyen Âge et l'époque moderne (Chenet, 1920a ; Jannin, 1980, 1989, 1990). Les recherches et les prospections ont mis en évidence un grand nombre d'ateliers de verriers de ces époques dans les vallons qui entaillent les plateaux de gaize de l'Argonne. La découverte d'ateliers de verrerie romains aux Houis, près de Sainte-Menehould, et à Lavoye au début du $\mathrm{XX}^{\mathrm{e}}$ s., montre toutefois que l'origine de cette industrie dans la région remonte à l'Antiquité. Mais la fabrication régionale du verre dans l'Antiquité a une ampleur plus grande que ne le laisseraient supposer les vestiges découverts sur ces deux sites.

La verrerie des Houis, située sur une butte de la rive gauche de l'Aire au sud-est de Sainte-Menehould, a été prospectée et fouillée pendant plusieurs années par L. Mauget, un érudit local (Mauget, 1906-1907 ; Chaw, 1989). Ses travaux ont mis en évidence des vestiges sur environ $200 \mathrm{~m}$ de longueur. Un seul four a été découvert, mais on peut penser que la masse du matériel en verre recueilli implique l'existence d'un nombre de fours plus important. La production semble très variée : verre à vitre, verre soufflé, petits objets de parure (bracelets, bagues, perles, épingles, pions, etc.) et des milliers de tesselles de mosaique. Ce site a certainement été occupé durant une partie du III' $s$. (16 monnaies de Gallien, Tetricus, Claude le Gothique et Probus) et du IV $v^{\text {ee }}$ s. (3 monnaies de Constance Chlore et de Constantin I, bol en sigillée Chenet 320 avec décor à la molette UC 149, mortier Chenet 330). Le début de l'occupation peut cependant se situer au $\mathrm{II}^{\mathrm{e}} \mathrm{s}$. (sigillées moulées, gobelets moulés, deux monnaies d'Antonin le Pieux).

Sur le site du village antique de Lavoye, plusieurs vestiges liés à la production du verre ont été découverts par le $\mathrm{D}^{\mathrm{r}}$ Meunier (Chenet, 1920a, p. 258 ; archives départementales de la Meuse 71.J.15 et 71.J.32). Il a notamment fouillé un petit four de verrier dans la partie la plus occidentale du site (La Clairière). La production semble limitée unique- 


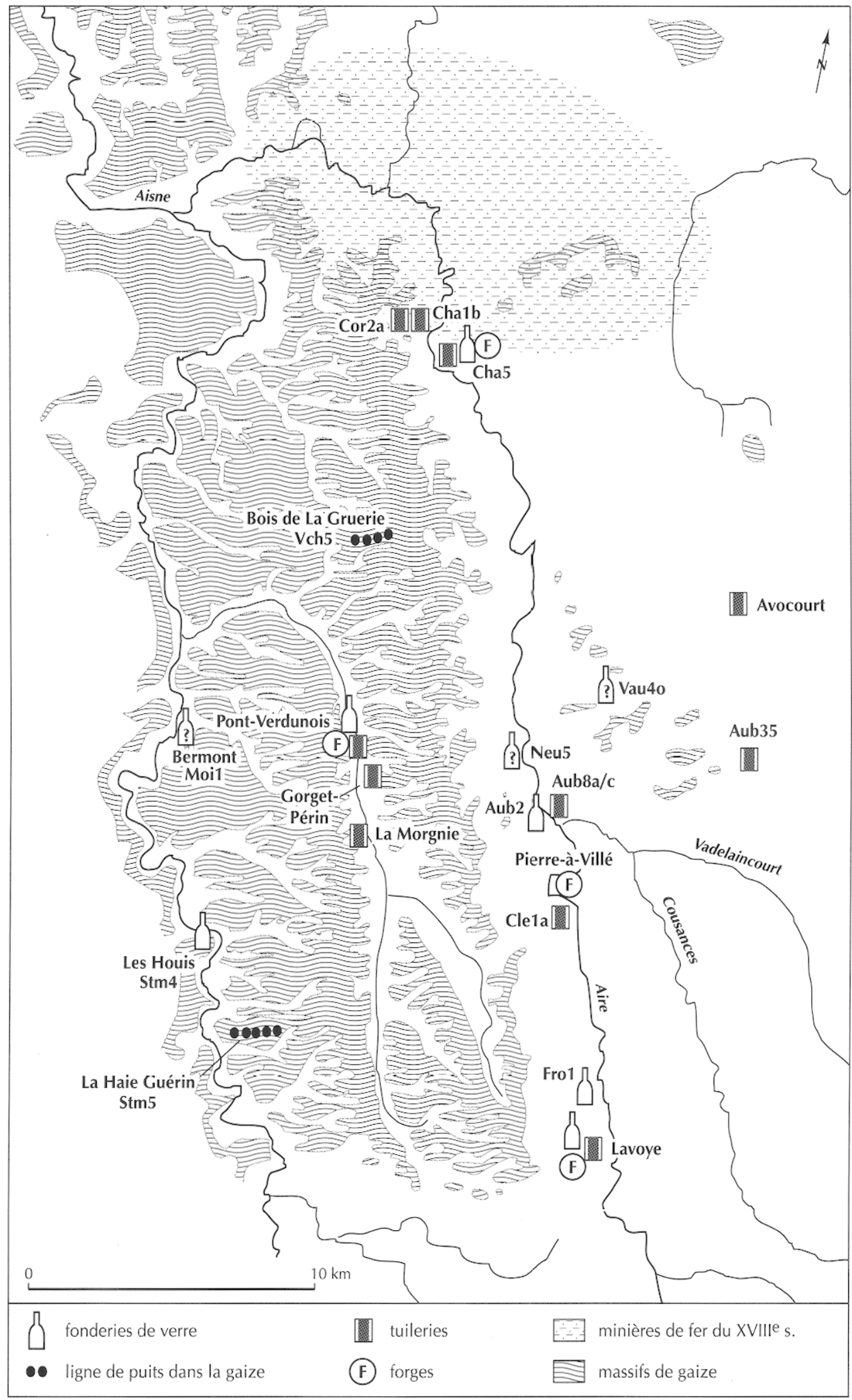

Fig. 15 - L'artisanat diversifié de l'Argonne durant l'Antiquité (DAO M. Gazenbeek, INRAP). 
ment à des vases. Selon G. Chenet, la céramique associée permet de dater le four de la seconde moitié du III ${ }^{\mathrm{e}} \mathrm{s}$. Le dépouillement des archives de cet auteur a mis en évidence sept autres fours ou dépotoirs liés à l'industrie du verre sur ce site. Il a aussi identifié un four avec des débris de creusets près de la rivière (Parc Saillet). Ce four n'est pas datable avec précision. D'autres débris de creusets ont été découverts en relation avec des sigillées décorées à la molette dans le comblement d'un puits, dans un dépotoir (accompagnés de trois monnaies de Valens et Valentinien, soit de la seconde moitié du IV ${ }^{\mathrm{e}} \mathrm{s}$.) et dans une couche de destruction en association avec de nombreuses monnaies du IV ${ }^{e}$ s. Les creusets étaient aussi nombreux dans trois dépotoirs, où ils étaient associés à des moules et des bols de sigillées. Un de ces dépotoirs a livré une monnaie de Commode (dernier quart du II $\mathrm{s}$.) et un deuxième une monnaie en argent de Gallien (soit du troisième quart du III ${ }^{c} \mathrm{~s}$.). L'ensemble de ces découvertes s'étend sur tout le site, avec au moins deux fours situés à ses extrémités est et ouest.

$\mathrm{Au}$ nord de Lavoye, en marge de l'habitat antique de Froidos, le $\mathrm{D}^{\mathrm{r}}$ Meunier a également fouillé un dépotoir de verrier datable du III $^{c}$ s. par des sigillées moulées et une monnaie de Macrin des années 217-218 (Chenet, 1920a, p. 258-259 ; archives départementales de la Meuse 71.J.32). La fabrication englobait des vitres, du verre soufflé, des éléments de verre millefiori, des petits objets de parure (bagues, bracelets, boutons, épinglcs, pcrlcs) ct dcs tcsscllcs dc mosaïquc. Les creusets, présents en grand nombre, sont, comme à Lavoye, des marmites en céramique bleutée craquelée.

Dans la vallée de l'Aire, nos prospections ont également mis en évidence de très grands fours de verriers en marge des sites d'Aub2, de Vau4 et de Cha5. Ces deux derniers ont notamment livré des blocs de verre. G. Chenet a signalé aussi une production de verre au Pont-Verdunois, dans la vallée de la Biesme. Le site de Bermont (Moil, II $^{\mathrm{c}}-\mathrm{III}^{\mathrm{e}} \mathrm{s}$.), implanté sur une terrasse de l'Aisne, résiste plus à l'interprétation. Le gisement couvre environ 5 ha. Tout dans la composition du matériel de surface invite à y voir autre chose qu'une villa. Le mobilier se caractérise par une forte proportion de céramiques bleutées craquelées (plus de $50 \%$ des tessons). Aucun élément architectural autre que des moellons et des tuiles n'a été recensé. La composition spécifique des céramiques du site sous-entend une activité particulière, peut-être justement la production de verre (creusets). Ce même cas de figure a été noté sur le site de Breuil (Neu5), dans la vallée de l'Aire, où $47 \%$ de la céramique découverte est de type bleuté craquelé. Ce site a également livré des tesselles de mosaïque en pâte de verre.

Il est probable que les séries de puits signalées depuis longtemps sur les plateaux de gaize entre l'Aisne et l'Aire soient en relation avec la production de verre antique dans la région. Actuellement, deux ensembles sont connus. Un premier, avec au moins cinq puits identifiés sur une longueur de $2 \mathrm{~km}$, est situé dans le bois de La Gruerie à l'ouest de Varennes. Un seul puits, profond de $20 \mathrm{~m}$, a été exploré (Liénard, 1853, p. 164165). Son ouverture est étroite ( $1 \mathrm{~m}$ de diamètre seulement) et son cuvelage construit en petit appareil. Ses parois s'évasent progressivement vers le bas pour atteindre entre 4 et $5 \mathrm{~m}$ de diamètre au maximum. Le second groupe de puits se situe à l'est de Verrières, dans le bois de La Haie-Guérin (Hussenet, 1990 , p. 16-20). Un ensemble de 22 puits s'échelonne le long d'un chemin creux sur environ $1,5 \mathrm{~km}$. L'un de ces puits, profond de $23 \mathrm{~m}$, a été fouillé récemment (Jannin, 2001). Comme pour le puits du bois de La Gruerie, il présente un profil en forme de bouteille avec une ouverture en petit appareil de $1 \mathrm{~m}$ de diamètre, puis un cuvelage de $2 \mathrm{~m}$ de diamètre. Au fond, un important mobilier antique a été mis au jour. En dehors de très nombreux fragments de creusets de verre en céramique bleutée craquelée, les quelques tessons de sigillée moulée et de céramique engobée noire permettent de dater le comblement du fond du II' s. ou du III' s.

Tous les fours de verriers antiques connus actuellement dans la région se situent donc à l'extérieur des massifs de gaize, dans les vallées de l'Aisne, de l'Aire et de la Biesme. C'est une situation inverse aux verreries plus récentes, généralcmcnt situćcs dans les vallons incisant les plateaux de gaize, à la source de la matière première. En revanche, pour la période romaine, les puits creusés dans la gaize peuvent indiquer une exploitation très organisée de la matière première, sous réserve que leur attribution à l'Antiquité soit confirmée. La gaize extraite était alors acheminée vers les fours des Houis, de Lavoye et d'autres sites de transformation, peut-être après une première opération de trituration. L'extraction souterraine de la gaize assure évidemment une grande pureté de la matière première. Cette activité semble connaître son apogée au III ${ }^{\mathrm{e}}$ et au IV $\mathrm{s}$.

Nous ne savons rien sur la diffusion des produits en dehors de l'Argonne et un seul échantillon de la production, en l'occurrence des tesselles en pâte de verre du site des Houis, a été analysé à ce jour. Cette analyse, élémentaire et globale, montre que ce sont des vases dont le fondant est à base de soude (environ $13 \%$ ) tandis que la potasse est quasi absente (moins de $1 \%$ ) (Brun et al., 1991), ce qui est tout à fait typique du verre romain.

\section{LES TUILERIES}

Les tuileries sont un élément important de l'industrie antique de la terre cuite en Argonne. Dans la vallée de la Biesme, les fours à tuiles occupent les zones intermédiaires 
entre les trois officines de céramique connues, sans être forcément contemporains de ces dernières. Une tuilerie est connue à La Morgnie au sud du Pont-des-Rèmes et une autre à Gorget-Périn (IV ${ }^{\mathrm{e}} \mathrm{s}$.) au sud du Pont-Verdunois. La troisième se trouve au Pont-Verdunois même, en association avec des rebuts de cuisson de sigillées décorées à la molette et des moutons d'imbrices (Chenet, 1927a, p. 86, 88-90, 94-95). Cette association existe aussi à Lavoye dans le four $\mathrm{E}$.

Dans la vallée de l'Aire, les prospections montrent l'existence d'un nombre important de tuileries, quelquefois associées à des ateliers de céramiques communes (PoirierMignon: Aub8a/c, I ${ }^{\text {er }}$ s.), voire à des habitats (Châtelet : Clela, II s.). Autour de Châtel-Chéhéry, plusieurs tuileries très rapprochées indiquent un lieu de production important. À La Forge, sur la rive droite de l'Aire, la tuilerie s'inscrit dans le contexte d'un habitat du IVe s. (Cha5). Sur la rive gauche de la rivière, deux autres tuileries se font face de chaque côté d'un ruisseau au nord de la butte de Châtel (Chalb, Cor2a). Le matériel de surface ne permet pas une datation précise.

À l'est de l'Aire et à l'exception d'une production attestée à Avocourt, un four de tuilier parfaitement isolé dans le paysage a été repéré à quelques centaines de mètres au nord-ouest de Verrières dans la forêt de Hesse (Aub35).

Une dizaine de structures sont donc confirmées. Leurs conditions d'implantation sont assez diversifiées : tuileries insérées dans des structures artisanales (Le Pont-Verdunois, Aubréville, Lavoye, Avocourt), côtoyant un habitat (Châtelet, La Forge) ou situées à l'écart d'un habitat proche (Pont-Verdunois dans le cas de la tuilerie de Gorget-Périn ; site de Verrières dans le cas d'Aub35). Leur fonctionnement $s^{\prime}$ 'échelonne entre le $\mathrm{I}^{\mathrm{cr}}$ et le $\mathrm{IV}^{\mathrm{c}} \mathrm{s}$. au moins. Mêlées aux officines de céramique, elles participent à la même dynamique économique que celles-ci. En profitant des mêmes conditions favorables au développement que la céramique, les tuileries se sont multipliées dans la région. Elles complètent et densifient la carte de répartition des ateliers de terre cuite argonnais et contribuent à la diversification de leur production.

\section{L'INDUSTRIE DE LA CÉRAMIQUE EN ARGONNE}

C'est dans ce contexte général que s'inscrit la fabrication de céramiques, longtemps définie par les seules sigillées trouvées sur un nombre limité de sites ${ }^{22}$. Une première chronologie de la production argonnaise a été proposée par le $\mathrm{D}^{\mathrm{r}}$ Meunier au début du $\mathrm{XX}^{\mathrm{e}}$ s. (Meunier, 1908). La fouille d'une fosse à Lavoye a mis au jour un lot de 200 vases

22. Il s'agit des sites d'Avocourt, Lavoye, Pont-des-Rèmes, Pont-desQuatre-Enfants, Les Allieux et Châtel-Chéhéry. totalement différents des céramiques qu'il avait rencontrées jusqu'alors dans les ateliers de sigillées du site. En l'interprétant comme une sépulture à incinération, le $\mathrm{D}^{\mathrm{r}}$ Meunier la désigne sous le nom de "Sépulture A ». Les nombreuses monnaies qu'il trouve dans le comblement datent de la période allant de Claude le Gothique à Constance II, soit entre 267 et 361. Il émet alors l'hypothc̀se que le site a connu deux périodes de fonctionnement: la première, entre 100 et 270 , caractérisée par l'utilisation d'estampilles et de moules dans les ateliers de sigillées, et la seconde, vers 360 , où ces deux caractéristiques n'existent plus. Une époque intermédiaire entre les deux phases lui semble probable, peut-être à mettre en relation avec la guerre des Bagaudes en $282{ }^{23}$. La fin de la première époque lui est suggérée par les vestiges d'un habitat incendié daté de 270 environ, où les sigillées moulées côtoient deux bronzes de Commode et de Postume (Meunier, 1905, p. 139).

Cette chronologie fut adoptée par les auteurs successifs. E. Fölzer détermine le début de la production sigillée en Argonne (vers 125) d'après ses fouilles dans des forts du limes rhénan (fortin en terre du Saalburg, GrossKrotzenburg). Elle n'avance cependant pas de date pour l'arrêt de la fabrication, étant donné que celle-ci avait été évincée sur le limes par les ateliers de Rheinzabern et de Trèves durant la seconde moitié du II ${ }^{\mathrm{e}}$ s. (Fölzer, 1913, p. 40). Toutefois, la production de la sigillée moulée est par la suite cantonnée au $\mathrm{II}^{\mathrm{c}} \mathrm{s}$. et au début du $\mathrm{III}^{\mathrm{e}} \mathrm{s}$. Les auteurs évoquent un remplacement de la sigillée moulée par d'autres productions au III ${ }^{c}$ s. (Chenet, Gaudron, 1955 [basé sur F. Oswald] ; Hofmann, 1979 ; Feller, Brulet, 1998), tout en soulignant la nature insatisfaisante de cette datation. La deuxième époque du $\mathrm{D}^{\mathrm{r}}$ Meunier se trouve ainsi sensiblement rallongée. Les recherches sur les sites de consommation de Metz et de Maastricht indiquent que la production de sigillées tardives se prolonge jusqu'au V's., ou même au VI' s. (Bayard, 1990 ; Dijkman, 1992a et b).

\section{LES PRODUCTIONS}

En raison de la durée de l'activité des ateliers de l'Argonne, la production est à la fois typologiquement et technologiquement variée. De façon générale, on peut distinguer quatre groupes principaux (fig. 16) : les céramiques gallo-belges (groupe 1), les céramiques communes (groupe 2), les gobelets (groupe 3) et les sigillées (groupe 4). Dans ce dernier groupe, on distingue deux sousgroupes selon le mode de décor, soit moulé soit tracé avec une molette; ces deux formes sont accompagnées de

23. Par la suite, l'invasion de 276 sera également une cause évooquée (Chenet, Gaudron, 1955, p. 233). 


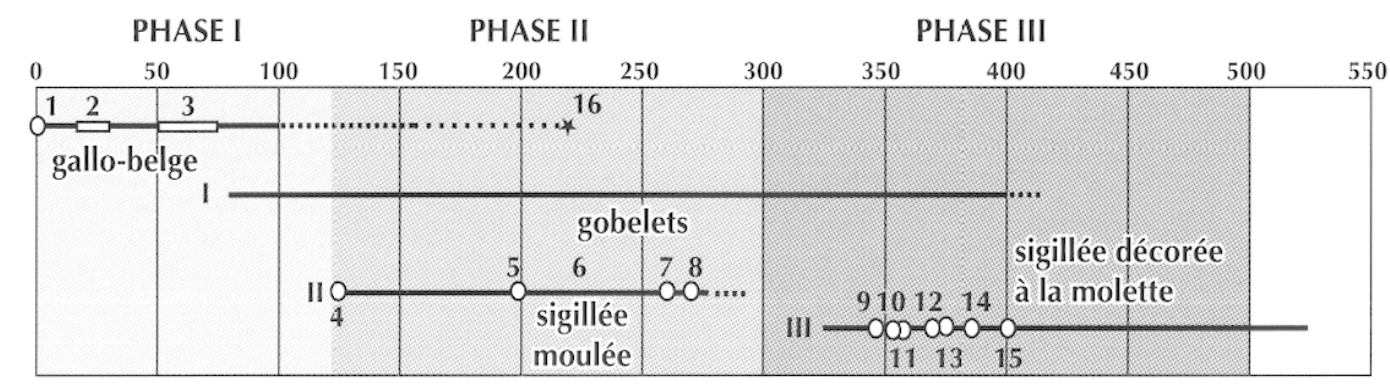

\begin{tabular}{|lcc|}
\hline O datations par monnaies & $\square$ datations typologiques & * datations archéomagnétiques \\
1 «trous noirs » (Lavoye) & 7 entrepôt (Châlons) & 12 puits champ 790 (Lavoye) \\
2 Aub8 (Aubréville) & 8 habitat incendié, fouille Meunier (Lavoye) & 13 fours A/B (Avocourt) \\
3 La Fontaine aux Chênes (Aubréville) & 9 hypocauste champ 752 (Lavoye) & 14 four A (Allieux-Clairière) \\
4 chambre P (Lavoye) & 10 sépulture A (Lavoye) & 15 fosse 8 champ 613 (Lavoye) \\
5 dépotoir four D (Lavoye) & 11 four C (Avocourt) & 16 four Prix-des-Blanches (Avocourt) \\
6 Prix-des-Blanches (Avocourt) & & \\
\hline
\end{tabular}

Fig. 16 - Les différentes phases de la production céramique d'exportation en Argonne: I, apparition des gobelets d'Argonne dans des contextes normands (d'après Blaszkiewicz, Dufournier, 1989); II, début de la sigillée moulée d'Argonne sur le limes de Germanie (d'après Fölzer, 1913); III, début et fin de la sigillée décorée à la molette (d'après Unverzagt, 1919; Hübener, 1968; Dijkman, 1992a el b).

sigillées lisses. Ces groupes sont associés ou se succèdent dans les mêmes ateliers. De ce fait, la production massive de céramique en Argonne est caractérisée par une grande continuité, sans moments de rupture marqués dans le processus de fabrication. Les différentes phases de production, fondées sur la succession de produits gallo-belges, de gobelets, de sigillées moulées et de sigillées décorées à la molette, se chevauchent.

\section{Phase I : les céramiques gallo-belges}

La production de céramique à grande échelle commence en Argonne avec la fabrication de la poterie gallo-belge au début du ${ }^{\text {cr }}$ s. de notre ère. Il s'agit d'une céramique fine qui ressemble à de la vaisselle de table imitant les formes celtiques et italiques. La typo-chronologie de la production de la céramique gallo-belge a ëté reprise par X. Deru en 1996. Les auteurs s'accordent en général pour faire débuter la production à l'époque augustéenne mais leurs avis divergent lorsqu'il s'agit de dater son extinction : le courant de la seconde moitié du $I^{\text {er }} \mathbf{s}$. ou plus tard au II $^{\mathrm{e}}$, voire au III ${ }^{\mathrm{c}}$ s. $^{24}$.

Les découvertes anciennes sur le site de Lavoye et les différentes prospections dans la région ont souligné

24. Provisoirement le milieu du II $\mathrm{e}$ s. d'après Deru (1996, p. 198). Mais certains indices, comme la présence d'un four à Avocourt (voir infra, ainsi que Deru, 1996, p. 267-268 qui qualifie cette production tardive de " dérivée de terra nigra "), pourraient donner une datation plus tardive vers le début du III $s$. l'étendue de la zone de production et la densité des implantations d'ateliers (fig. 9 et 18). L'essentiel de l'information sur les productions gallo-belges de la région vient de la fouille de trois fours à Lavoye par G. Chenet et le $\mathrm{D}^{\mathrm{r}}$ Meunier (Chenet, 1928a). À cela s'ajoutent deux sites fouillés dans la forêt de Hesse et à Avocourt (Deru, Feller, 1992 ; Deru, in Feller, Brulet, 1998, p. 270-273).

À Lavoye, trois fours qui avaient conservé leur double alandier et leur chaufferie ont été explorés en détail. Ces fours étaient construits en argile et seuls les murets de séparation des alandiers et les couloirs des foyers étaient en moellons de gaize enrobés d'argile rubéfiée. L'un de ces fours possédait encore sa sole.

Dans celui de la parcelle 753, un important dépôt de céramiques occupait la partie ouest de la chaufferie, l'avant du foyer (en partie détruit) et une partie des alandiers. L'essentiel du matériel était constitué de gobelets du $\mathrm{I}^{\mathrm{cr}} \mathrm{s}$. de type Gurtbecher (Gose, types 338-339) et Schlauchurnen (Gose, types 342-345) de fabrication locale (fig. 17). L'alandier de l'un des deux fours de la parcelle 795 était rempli de tessons de vases carénés et en accordéon (Gose, types 315-319). Dans le troisième four (parcelle 795), le foyer était fermé par un bouchon d'argile jaune. Dans ses alandiers et son foyer, il n'y avait pas d'amoncellement de céramiques. Rien ne permettait d'identifier l'éventuelle production de ce four, que seule la similitude de construction rapproche des deux autres. Mais la production gallo-belge ne se limite certainement pas à ces trois fours. G. Chenet et le $\mathrm{D}^{\mathrm{r}}$ Meunier en mentionnent aussi un, très arasé, dans la 

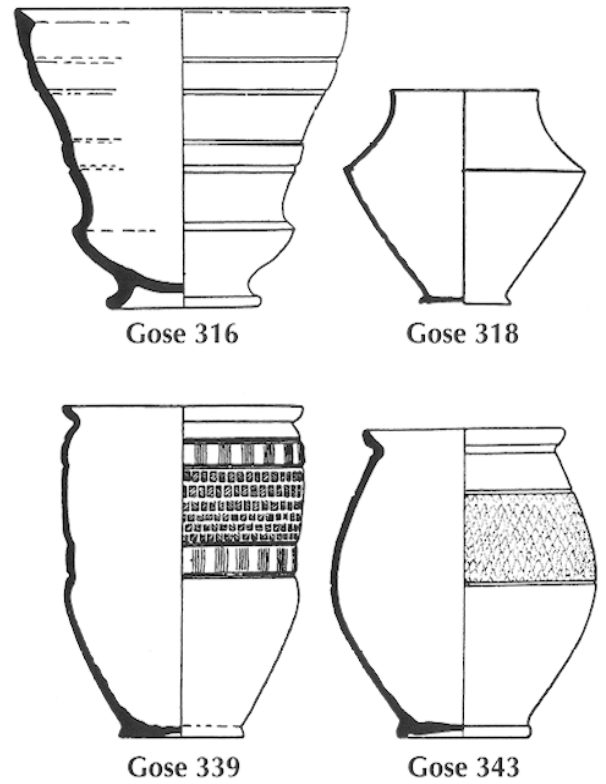

Fig. 17 - Productions gallo-belges inédites de Lavoye d'après les indications et croquis de $G$. Chenet (archives départementales de la Meuse). Échelle: 1/3.

parcelle 753 (archives départementales de la Meuse 71.J.32 [Aut. Son. A. 753, trou 2]) dont ne subsistait que la chaufferie ovale qui s'ouvrait sur un alandier conservé à l'état d'argile rubéfiée. Cette chaufferie était comblée par un remblai très noir composé de cendres mélangées à des tessons de vases. Ce sont essentiellement des plats et assiettes en cuisson oxydante où l'on reconnaît les plats gallo-belges de la première moitié du $\mathrm{I}^{\mathrm{er}} \mathrm{s}$. Un fragment de sigillée sudgauloise Drag. 29 confirme cette datation.

Sur le site, ces productions sont nombreuses dans des contextes datant de la période augustéenne. Les Gurtbecher étaient courants dans les " trous noirs " de la parcelle 740. Le trou $n^{\circ} 13$ recelait des tessons appartenant à environ 100 vases différents. Dans le trou $n^{\circ} 18$, ces céramiques sont accompagnées d'une monnaie d'Auguste. Le trou C de la parcelle 775 a également livré des Gurlbechur ainsi qu'un potin gaulois. Ce trou était scellé par une chape de mortier sur laquelle se trouvait un demi-as de Nîmes.

La prospection a montré que dès la première moitié du $\mathrm{I}^{\mathrm{er}}$ s., une série d'ateliers s'étend entre Avocourt au nord et Lavoye au sud. Au milieu, sur la rive gauche de l'Aire de part et d'autre de la voie antique Reims-Metz, se situe une zone importante de production avec plusieurs fours (Aub14). La production englobe des formes typiques du $\mathrm{I}^{\mathrm{er}} \mathrm{s}$. Le matériel de surface indique une occupation du $\mathrm{I}^{\mathrm{er}} \mathrm{s}$. à la fin du $\mathrm{II}^{\mathrm{e}} \mathrm{s}$. de notre ère. Plus au nord, en direction d'Avocourt, de nombreux sites à céramiques gallo-belges, très souvent des fours, se succèdent. Ils se situent à la fois sur l'Aire (Aub2,
Aub8a/c, Aubl0b) et dans la vallée du Mergevau (Aub3a, Aub18, Aub24, Aub28, Aub29, Aub34), qui draine une partie de la forêt de Hesse. Tous ces sites sont répartis sur de petites surfaces (moins de 1 ha) et ont un mobilier très homogène composé presque exclusivement de céramiques à cuisson réductrice. Ils datent tous du $\mathrm{I}^{\mathrm{er}} \mathrm{s}$.

Un atelier du groupe de Mergevau, le site de La Fontaine-aux-Chênes, a fait l'objet d'une fouille de sauvetage par M. Feller (Deru, Feller, 1992). Trois fours ont été découverts et neuf types de céramique gallo-belge ont été identifiés (Deru, 1996, p. 288-289). La production de céramiques communes, également attestée sur le site, comprend des marmites et des cruches engobées blanches datées du milieu et du troisième quart du $\mathrm{I}^{\mathrm{cr}} \mathrm{s}$. L'ensemble de cet atelier représente un repère important dans la mise en place de la production céramique en forêt de Hesse et nous renseigne sur les caractéristiques de la production gallo-belge dans un atelier de petite taille.

Un autre jalon se situe dans la vallée de la Buanthe, près du Moulin de la Cour, où les vestiges d'un atelier gallo-belge furent repérés en pleine guerre par un officier allemand (Unverzagt, 1919, p. 6-7). Il s'agit, d'après l'échantillon analysé au musée de Strasbourg, de productions gallo-belges datant probablement de la seconde moitié du $\mathrm{I}^{\mathrm{er}} \mathbf{s}$. Cet atelier n'a pas été localisé plus précisément.

Les productions les plus tardives sont attestées sur le site d'Avocourt. En 1988, M. Feller et R. Brulet ont entrepris une prospection électro-magnétique dans le quartier du Prix-des-Blanches, doublée d'une prospection fine sur une superficie de 2 ha, d'une série de sondages et d'une fouille sur $900 \mathrm{~m}^{2}$ (Gallia Informations, 1992, 2, p. 94). Cette prospection à mis en évidence les fondations d'un bâtiment rectangulaire $\left(86 \mathrm{~m}^{2}\right)$, précédé d'un empierrement et d'un puits, ainsi que deux fours. L'un des fours contenait encore une partie de sa charge. Les rebuts de cuisson attestent une production de céramiques de type gallo-belge: grandes cruches à deux anses et des grandes bouteilles décorées à la molette type Hofheim 120. Une datation archéomagnétique fixe la dernière cuisson aux années 200-220. Cette date est corroborée par la sigillée associée : productions argonnaises du II ${ }^{e}$ s. des formes Drag. 31, Drag. 37 et Curle 15. Autour du four, les céramiques, gallo-belges par leur technique, représentent des formes répertoriées, mais aussi d'autres déjà plus éloignées des typologies traditionnelles: des formes simplement apparentées à la classification gallobelge ou imitant des formes sigillées (coupe à marli proche de Drag. 35/36).

D'autres ateliers produisent également de la céramique commune oxydante. Ces fours sont en activité dès la première moitié du $\mathrm{I}^{\mathrm{er}} \mathrm{s}$. $\left(\right.$ Aub8a/c) ou le milieu du $\mathrm{I}^{\mathrm{cr}} \mathrm{s}$. (La Fontaine-aux-Chênes). Cette production continue au 
moins jusqu'à la fin du II $^{\mathrm{e}}$ s., voire pendant le III ${ }^{\mathrm{e}} \mathrm{s}$. Lors d'un diagnostic pour l'ouverture d'une carrière à Moncel près d'Aubréville, un four rectangulaire à deux canaux et banquette centrale a été découvert. Le mobilier recueilli à la surface de cette structure non fouillée était de la céramique commune oxydante de la fin du $\mathrm{II}^{\mathrm{c}} \mathrm{s}$. ou du début du $\mathrm{III}^{\mathrm{e}} \mathrm{s}$. (F. Boura, in Bilan scientifique, Lorraine, 1994, p. 36).

La production de céramiques gallo-belges dans l'Argonne commence donc au moins dès le début du I ${ }^{\text {er }} \mathbf{s}$. de notre ère. Dans l'état actuel de nos recherches, il semble que les formes les plus anciennes aient été produites à Lavoye. La production s'étend toutefois rapidement vers le nord et, dans le courant de la première moitié $\mathrm{du} \mathrm{I}^{\mathrm{er}} \mathrm{s}$., des ateliers couvrent une zone s'étendant sur un axe nord-sud entre Avocourt au nord et la voie Reims-Metz au sud (fig. 18). D'après les résultats de la fouille d'un four à Avocourt, la fabrication se prolonge, avec une évolution sensible dans les formes, jusqu'au II $^{c}$ s., voire l'extrême fin du $\mathrm{II}^{\mathrm{e}} \mathrm{s}$. ou le début du III ${ }^{\mathrm{e}}$ s., pour autant que la production puisse encore être définie comme gallo-belge. Ceci n'est pas une question de technique mais de typologie.

Une comparaison avec la zone de production gallo-belge de la vallée de la Vesle, dans la Marne, au coeur de la région où ce type de céramique a été développé (Deru, 1996, p. 235) (région située à $70 \mathrm{~km}$ à l'ouest de la vallée de l'Aire), est intéressante à plus d'un titre. Les ateliers de la Vesle s'étendent, comme en Argonne, sur une grande distance, une trentaine de kilomètres au moins, et ils sont également desservis par un réseau routier important. En revanche, la durée de fabrication est plus courte et se limite $\mathrm{au}$ dernier quart du $\mathrm{I}^{\mathrm{er}} \mathrm{s}$. avant notre ère et à la première moitié du $\mathrm{I}^{\text {er }} \mathrm{s}$. de notre ère, sans que cette production soit remplacée par un autre type de céramique. Leur essor peut être lié au développement urbain de Reims. L'arrivée massive de la sigillée dans la région vers le milieu du $\mathrm{I}^{\mathrm{er}} \mathbf{s}$., que la céramique gallo-belge cherchait à imiter, peut avoir favorisé l'arrêt des ateliers de la Vesle ${ }^{25}$. La comparaison s'arrête là puisque dans l'Argonne l'expansion de la production se prolonge. Deux facteurs peuvent avoir contribué à ces évolutions contraires : l'éloignement de l'Argonne de tout centre urbain important et une plus grande abondance de matière première de qualité dans cette région. En effet, les potiers de la vallée de la Vesle ne disposaient que de l'argile déposée sur les bords des cours d'eau, ce qui est une différence notable avec l'Argonne où la géologie offrait de nombreux sites de prélèvement d'argile de qualité, comme l'argile du Gault par exemple. Par ailleurs, les marchés urbains se sont détournés rapidement de la céramique gallobelge au profit des productions sigillées de la Gaule du Sud

25. Ces arguments ont déjà été évoqués par M. et D. Chossenot en 1987.

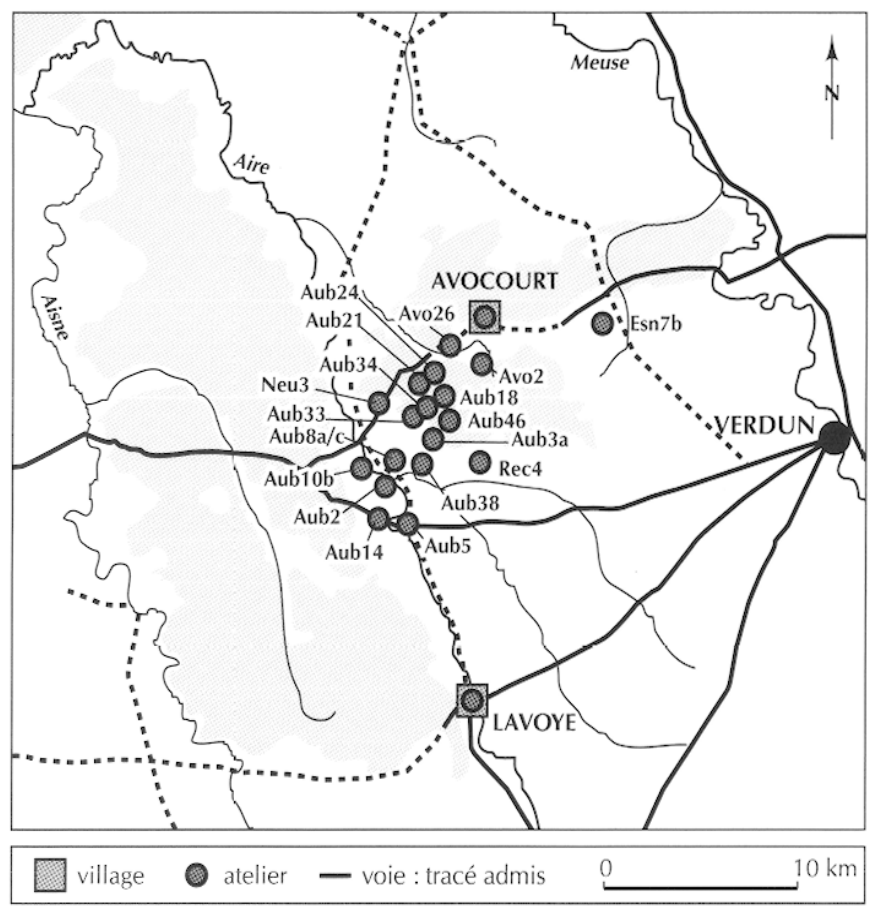

Fig. 18 - Les ateliers de céramique gallo-belge : phase I de la céramique argonnaise (DAO M. Gazenbeek, INRAP).

et du Centre. Ainsi, à Amiens, la proportion de la céramique gallo-belge chute de $42 \%$ à $23 \%$ entre le premier tiers et le milieu du ${ }^{\text {er }}$ s., pour ne plus représenter que $15 \%$ à la fin du siècle (Ben Redjeb, 1987). Il est possible que l'Argonne ait été, en raison de sa position, orientée dès le début vers une production destinée à des marchés ruraux, où la pénétration des sigillées était plus lente ${ }^{26}$, tandis que les ateliers de la Vesle dépendaient plus fortement de l'évolution socioéconomique de la ville voisine de Reims.

Une commercialisation suprarégionale de la céramique gallo-belge de la Marne, en direction de la Bretagne notamment, a été proposée à plusieurs reprises (en dernier lieu : Deru, 1996, p. 235). Cette argumentation est essentiellement fondée sur l'étude des estampilles (voir par exemple Rigby, 1981). En revanche, les ateliers de l'Argonne, situés aux marges de la région marnaise, n'auraient pas beaucoup diffusé leurs produits vers les villes. En tout cas, ils sont absents des villes de Reims et Metz, selon Deru (1996, p. 235). Mais en l'absence d'analyses pétrographiques il ne s'agit encore que d'hypothèses. Dans tous les cas, la distribution des fours gallo-belges en Argonne au

26. Voir par exemple le vicus de Bliesbruck (Moselle) où, sur les lieux du culte, la céramique gallo-belge " représente une proportion importante de l'ensemble du matériel (parfois plus de $40 \%$ ) " durant la seconde moitié du I'r s. (Petit, 1987). 


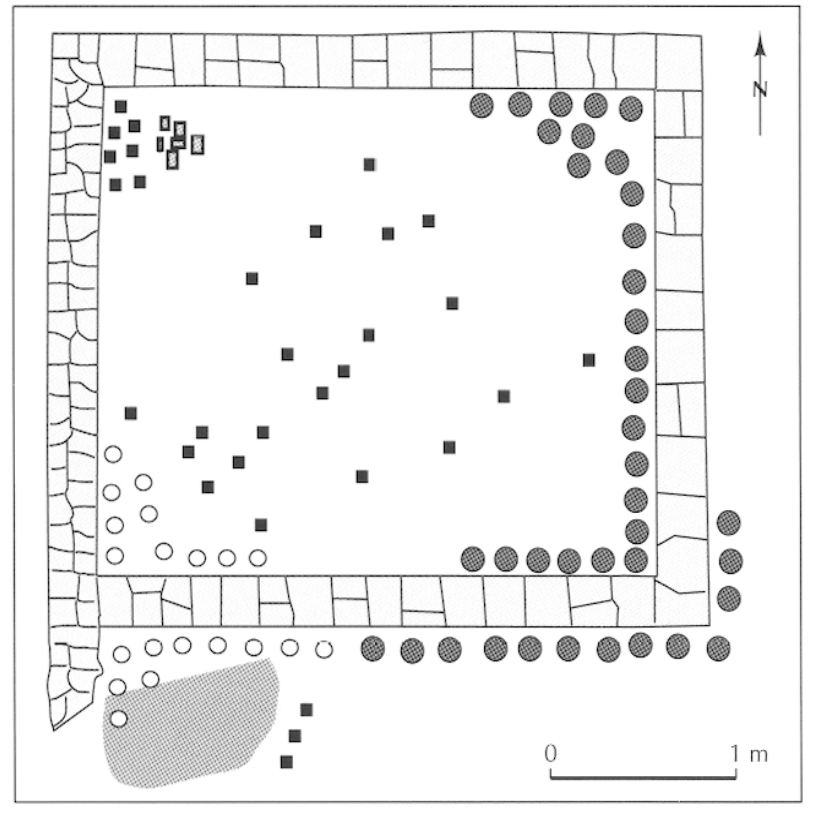

\begin{tabular}{|lll|}
\hline tasses en sigillée & rouelles de plomb \\
O pots gris et noirs & monnaies \\
& [ & silex \\
\hline
\end{tabular}

1

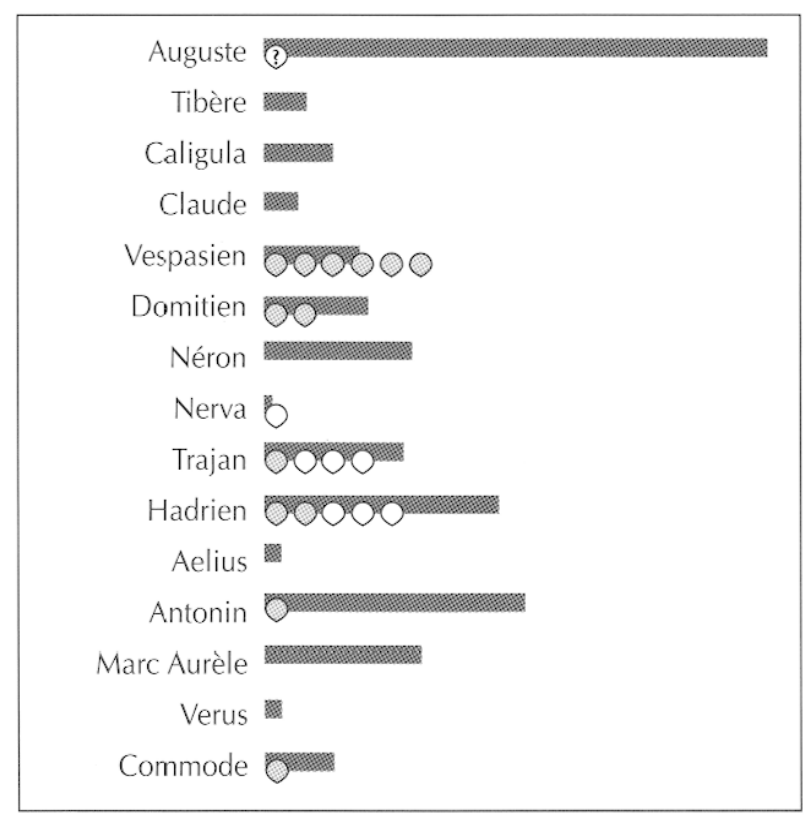

Don présence générale des monnaies sur le site

monnaies de la chambre $P$ en mauvais et très mauvais état

monnaies de la chambre $P$ en bon et très bon état

Fig. 19 - La chambre P à Lavoye: 1, répartition du mobilier (d'après Chenet, 1919); 2, répartition des monnaies (DAO M. Gazenbeek, INRAP).

$\mathrm{I}^{\mathrm{er}} \mathrm{s}$. prédit déjà très précisément l'aire de fabrication de la sigillée moulée du II $\mathrm{s}$.

\section{Phase II : la sigillée moulée et les gobelets}

À côté de ces productions qui mêlent des traditions autochtones et des imitations de modèles importés, se développe, dans le courant du II $^{\text {e }}$ s., la fabrication de sigillées moulées ou lisses. Cette phase commence en fait avec la production de gobelets engobés qui sont fabriqués et exportés massivement dès la fin du I $\mathrm{I}^{\mathrm{er}} \mathrm{s}$. (Blaszkiewicz, Dufournier, 1989). C'est seulement à partir du deuxième quart du II ${ }^{e} \mathrm{~s}$. que cette production est accompagnée de la sigillée lisse et moulée. L'association des déchets de sigillées moulées et de gobelets, notamment granités, est très fréquente et concerne la majeure partie des ateliers, mettant en lumière une évolution parallèle.

\section{Les jalons chromologiques de la production de sigillées moulées en Argonne}

La question principale concernant les ateliers de sigillées de l'Argonne réside non pas dans leur localisation mais dans leur datation. En effet, la détermination de la période de production des différentes officines est fondée avant tout sur l'étude des estampilles ou sur les critères stylistiques des décors moulés. Les potiers argonnais connus par leurs estampilles appartiennent tous au $\mathrm{II}^{\mathrm{c}} \mathrm{s}$. et plus précisément entre 120 et 210 de notre ère (Hofmann, 1972). De la disparition des estampilles après cette date, on déduit, sans doute trop rapidement, un arrêt ou une raréfaction de la production des sigillées au III ${ }^{\mathrm{e}} \mathrm{s}$. Dans cette perspective, il est utile de rappeler les différents jalons sur lesquels se fonde la chronologie de la sigillée estampillée et moulée en Argonne.

L'atelier de la chambre Pà Lavoye. La chambre Pà Lavoye, probablement une partie d'un atelier, forme le plus ancien contexte connu de fabrication de sigillée en Argonne (fig. 19) (Chenet, 1919, p. 244-247 ; archives départementales de la Meuse, catalogue des monnaies 71.J.35). Dans cette pièce de $3 \mathrm{~m}$ sur $2,50 \mathrm{~m}$ ont été trouvées une centaine de tasses en sigillée, empilées contre les murs, appartenant à cinq formes différentes, dont plusieurs portaient l'estampille de Tocca, ainsi que 37 monnaies ${ }^{27}$. Les éléments

27. Si dans ses publications Chenet ne mentionne que les monnaies appartenant à la pćriode qui s'ćtcnd d'Augustc au sixic̀mc consulat dc Commode (soit 191), nous avons retrouvé dans ses notes la trace d'une 
numismatiques permettent de dater le mobilier de la chambre $\mathrm{P}$ du règne d'Hadrien, entre 120 et 140 . Tocca et les deux potiers Cossilus et Marcellus, qui lui sont associés au sein d'un tas de surcuits dans une cour attenante à la chambre $\mathrm{P}$, sont donc actifs à Lavoye à cette période. Ces dates sont très proches de celle proposée par E. Fölzer pour le début de la production sigillée argonnaise : environ 125 de notre ère (Fölzer, 1913, p. 40).

Le dépotoir du four $D$ à Lavoye. L'une des autres rares occasions où les recherches anciennes dans les ateliers ont livré un élément de datation a été la fouille du four $\mathrm{D}$, sur le même site, en 1906 (Meunier, 1908, p. 189-192). La chaufferie du four fut comblée en deux phases après son abandon. Le fond était rempli avec les débris du four même : tuyaux, blocs de gaize et lut. Au-dessus, dans une terre très noire et cendreuse, avaient été jetés des tessons de sigillée et de nombreux fragments de moules. Entre ces deux couches, une grande monnaie de bronze de Septime Sévère, en très bon état, qui date de 197, donne à la fois un terminus ante quem pour la destruction du four et un terminus post quem pour la formation du dépotoir céramique.

Le matériel dans ce comblement, qui date donc probablement du début du III ${ }^{\mathrm{c}}$ s., est assez typé. Les bols moulés Drag. 37 aux décors empâtés sont abondants. Les fragments d'une quarantaine de moules ont été trouvés. Le $\mathrm{D}^{\mathrm{r}}$ Meunier a noté que plusieurs d'entre eux n'ont pour tout décor que des lignes en zigzag disposées symétriquement et tracées à la roulette. Aucune marque de potier n'a été observée sur ce lot de sigillées. Le four même a probablement servi pour la fabrication de vases globuleux et ovoïdes à pied étroit et élevé, à engobe rouge lustrée et à décor incisé ou à la barbotine ${ }^{28}$.

Un "entrepôt " à Châlons-en-Champagne. En 1981, une fouille de sauvetage dans le centre ville de Châlons-enChampagne a permis la découverte d'un ensemble important de sigillées argonnaises, regroupé dans une construction légère, que les fouilleurs proposent d'interpréter comme un entrepôt ou un magasin (Lenoble, 1986). Cinq formes de céramique composent le mobilier: les terrines à collerette de type Chenet $326 \quad(16 \%$ des 331 bords), les terrines à déversoirs ornés de mufles de lions

vingtaine de monnaies de cette fouille, probablement les seules qu'il ait pu identifier. Ces pièces nous montrent que la série s'arrête cn fait à Hadrien. Scules dcux monnaies sont plus tardives mais elles semblent n'avoir aucun rapport avec le reste du lot. L'absence d'antonins et de pièces de Marc Aurèle, pourtant bien représentées sur le site de Lavoye, est claire à cet égard. Les monnaies qui ont peu circulé se cantonnent à la période Nerva/Hadrien, tandis que les pièces plus anciennes (et les deux plus récentes) montrent des traces d'une circulation longue.

28. Selon Chenct (1911, fig. 31 et p. 85), c'est le prototype du gobelet Ch. 335 .

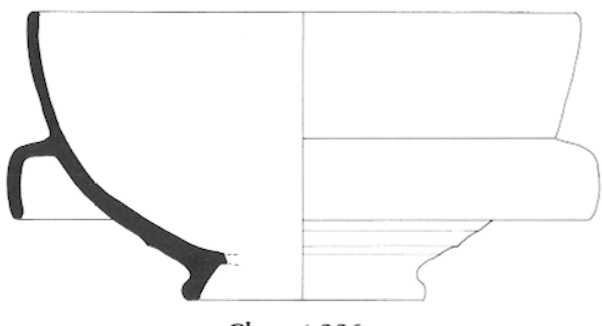

Chenet 326

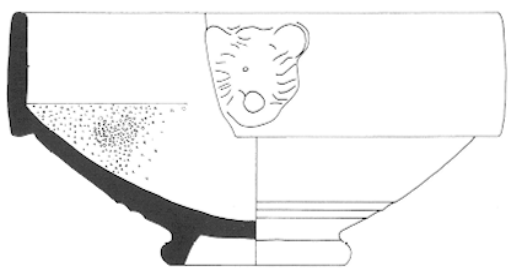

Drag. 45

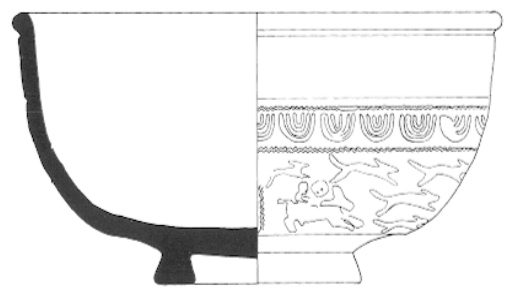

Drag. 37

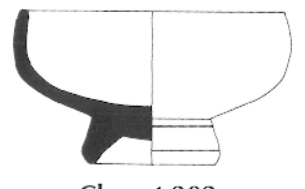

Chenet 302

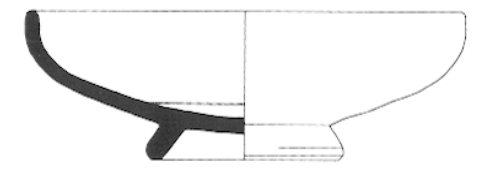

Chenet 303
Fig. 20 - Sigillées de l'entrepôt de Châlons-en-Champagne (d'après Lenoble, 1986, fig. 3 et 4). Échelle: 1/4.

type Drag. 45 ou Chenet 330 (39\%), les coupes et coupelles Chenet 302-303 (21\%) et enfin les bols moulés Drag. 37 (24\%) (fig. 20). Les décors de ceux-ci sont « de mauvaise facture et présentent le plus souvent des traits indistincts dus sans doute à des surmoulages et à l'usure des moules ». Les motifs sont attribuables notamment à Tocca, Tribunus, Africanus et Germanus, soit des décorateurs dont l'activité couvre l'ensemble du II $^{\mathrm{e}} \mathrm{s}$. Ce lot était accompagné de six monnaies en bronze de Postume. Cet ensemble date donc des dernières décennies du $\mathrm{III}^{\mathrm{e}}$ s., après 260 en tout cas, et implique une production de sigillée moulée avec une reprise de motifs antérieurs durant la seconde moitié du III $^{\text {e }}$ s. En cela, l'Argonne suit la même évolution que les ateliers de Lezoux, qui continuent également à produire des bols Drag. 37 moulés durant le III ${ }^{\mathrm{e}} \mathrm{s}$. et même le $\mathrm{IV}^{\mathrm{c}} \mathrm{s}$. (Rogers, 1999, vol. 1, p. 22). 


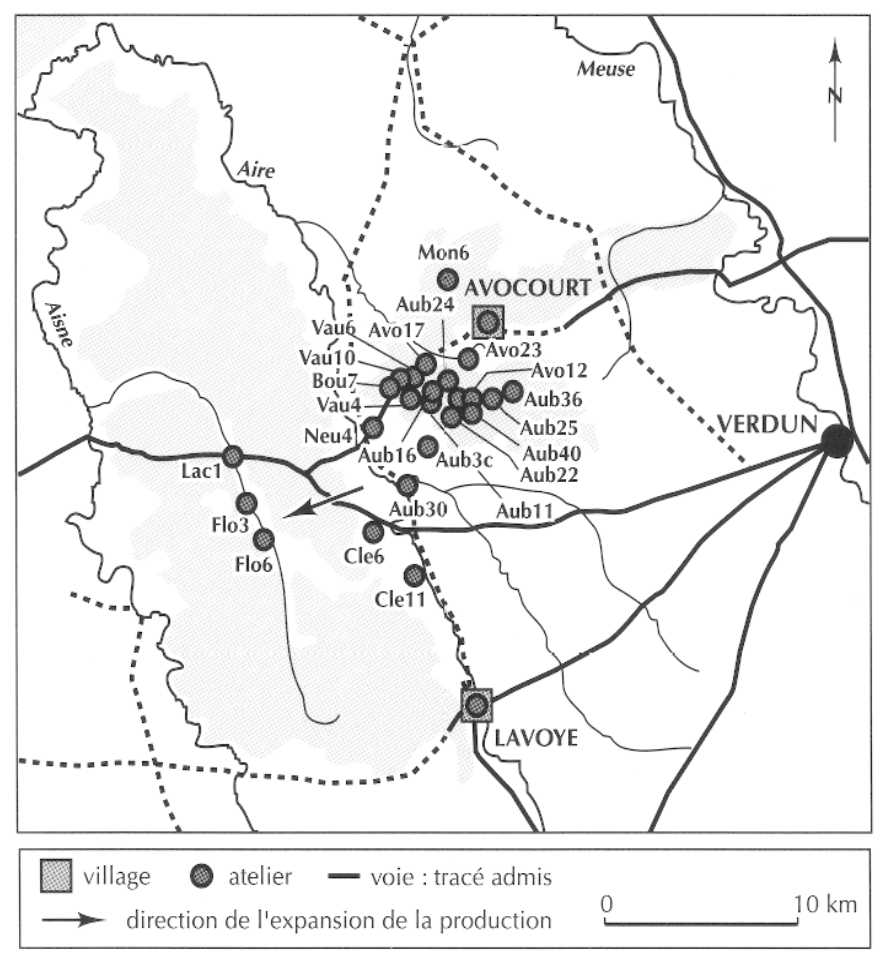

Fig. 21 - Les ateliers de sigillées moulées: phase II de la céramique argonnaise (DAO M. Gazenbeek, INRAP).

\section{Les ateliers de sigillées moulées}

Le centre de production exploré de la façon la plus étendue est celui de Lavoye. En dehors de l'atelier de la chambre $\mathrm{P}$ et $\mathrm{du}$ four $\mathrm{D}$, cités ci-dessus, les fouilles anciennes ont concerné une dizaine de fours de sigillées moulées (fig. 21). Malheureusement, les notes du $\mathrm{D}^{\mathrm{r}}$ Meunier ont été perdues pendant la guerre 1914-1918.

Le village antique d'Avocourt a également livré un grand nombre de fours appartenant à cette période. Les recherches de G. Chenet montrent que les fours de sigillées moulées s'étendent depuis le quartier du Moustier à l'est jusqu'à celui du Prix-des-Blanches à l'ouest ${ }^{29}$. C'est ce dernier secteur qui a été le plus étudié, d'abord par G. Chenet, puis par R. Brulet et M. Feller, qui y ont fouillé un four de sigillées dont l'arrêt du fonctionnement est daté par archéomagnétisme vers 260-270 (Gallia Informations, 1992, 2, p. 94).

C'est lors de la deuxième phase de production en Argonne que le nouveau centre de production des Allieux est créé dans la forêt de Hesse (fig. 22). Même si F. Liénard suppose déjà que c'est un lieu de fabrication de poterie

29. Les informations concernant les fours d'Avocourt découverts par Chenet se trouvent essentiellement dans Chenet, 1917 et 1941, p. 31.
(Liénard, 1853, p. 173-174), ce sont seulement les recherches de G. Chenet, à partir de 1905, qui marquent le début de l'étude de ce groupement d'ateliers (Chenet, 1917, p. 157 ; 1941, p. 35-38). Les poinçons des sigillées et des moules issus des fouilles de Chenet sur ce site forment un ensemble particulier. Sur les 40 poinçons, 27 sont anonymes, et 6 existent sur des moules des potiers Germanus et Africanus (Hofmann, 1968). Les autres sont d'attribution incertaine. Les poinçons anonymes définissent un style typique des Allieux et ne se rencontrent que rarement à Lavoye ${ }^{30}$. Sur la foi de ces décors et de leur association avec Germanus et Africanus, on peut proposer une datation assez tardive du début de la production de sigillée moulée aux Allieux, c'est-à-dire pas avant le dernier tiers du $\mathrm{II}^{\mathrm{e}}$ s. Les recherches récentes ont largement confirmé l'extension et la densité des ateliers de sigillée sur le site (Feller, Brulet, 1998, p. 298-363). Toutefois, les fours de sigillées décorées au moule ne concernent qu'une petite partie des structures.

Il existe un phénomène d'essaimage de petits ateliers autour du centre de production des Allieux. Il est même difficile de saisir la limite entre ce centre et les ateliers qui l'entourent: une concentration très dense de fours et de dépotoirs est auréolée de vestiges progressivement plus espacés. La prospection a permis de localiser un atelier de sigillée moulée (Bou4) près de la fontaine de La Gaille, résurgence dans le calcaire portlandien. Un autre atelier est connu sur la rive gauche du ruisseau de la Branière, à $700 \mathrm{~m}$ en aval de la source (Bou7). Vers le nord et le nord-est, en direction des pentes du mont des Allieux, plusieurs autres lieux de fabrication de sigillées moulées ont pu être identifiés (Vau6, Vau7, Vau 10).

Dans la forêt de Hesse, les ateliers de sigillée moulée sont nombreux (fig. 23). Ils s'échelonnent, en l'état actuel des recherches, entre la clairière des Allieux à l'ouest et le plateau de La Croix-des-Prêcheurs à l'est. En dehors des Allieux, deux autres sites regroupent un grand nombre de fours et de dépotoirs. Ils se situent de part et d'autre du massif de gaize du Hermont, sur le plateau d'argiles du Gault: à l'ouest, se trouve Le Vaux-Mulard et, à l'est, La Croix-des-Prêcheurs.

Le Vaux-Mulard correspond à un vaste semis de fours et de structures variées. Nous y avons comptabilisé une vingtaine de concentrations de matériel des $\mathrm{II}^{\mathrm{e}}$ et $\mathrm{III}^{\mathrm{e}} \mathrm{s}$. sur environ 8 ha (Aub21, Aub22, Aub23). L'ensemble de la zone a livré des vestiges de production de sigillées moulées. Vers l'est, cette zone de production se termine avec l'officine du Rendez-vous de chasse (Aub40) inventoriée une première fois par G. Chenet (1917, p. 156). Avant la guerre

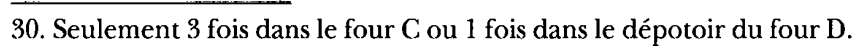




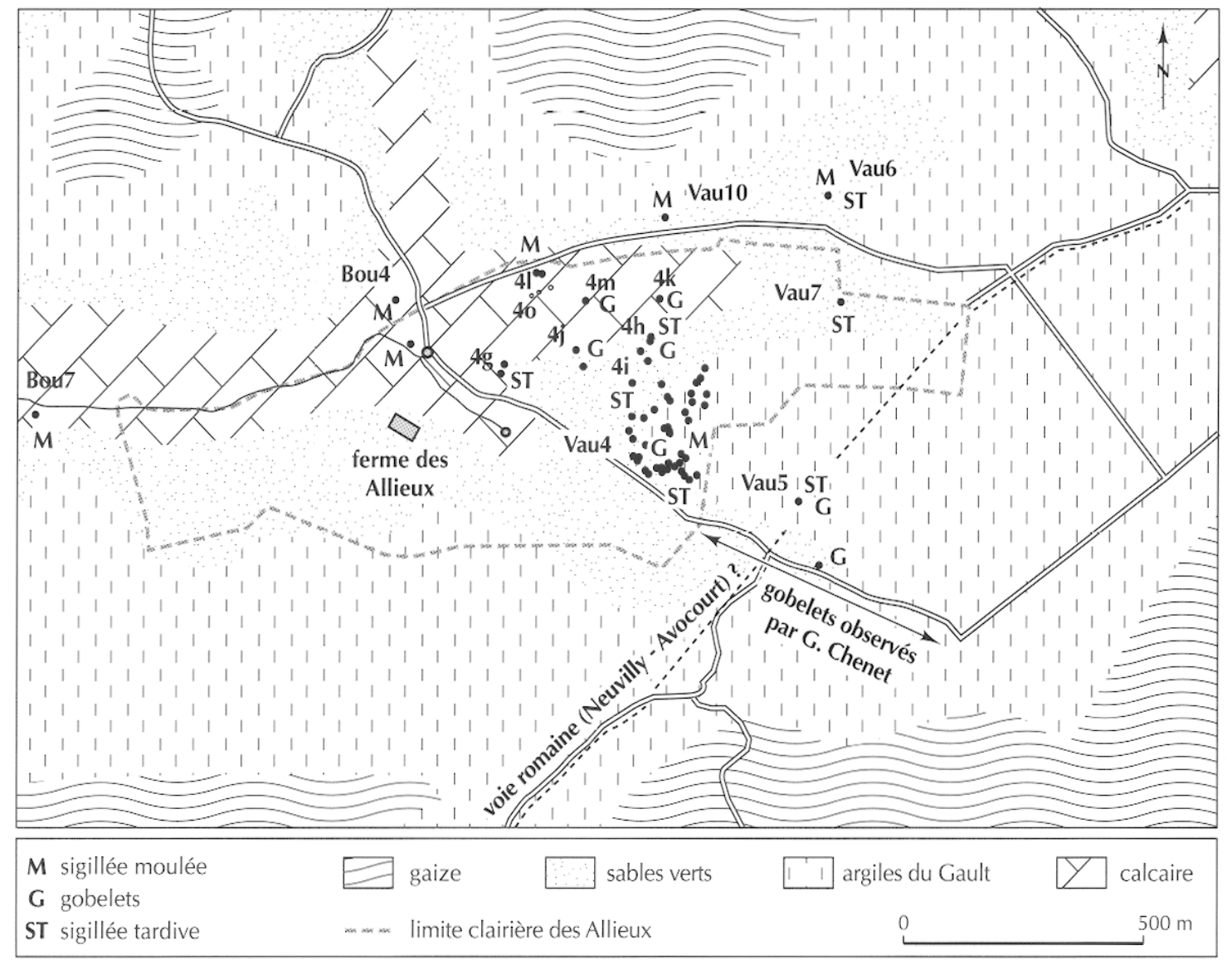

Fig. 22 - Les ateliers des Allieux (Vauquois) (DAO M. Gazenbeek, INRAP).

de 1914-1918, le creusement d'un puits d'extraction de phosphate contre le bâtiment avait entraîné la destruction d'un dépotoir de vases sigillés moulés et unis, parmi lesquels des ratés de cuisson.

Le deuxième site, découvert lors de travaux forestiers, couvre le quartier de La Croix-des-Prêcheurs (Aub25, environ $14 \mathrm{ha}$ ). Un dépotoir et un four, distants de $200 \mathrm{~m}$, ont été fouillés en 1978 (Gallia, 1980, 38, 2, p. 416 ; Mitard, 1986, p. 206-207). La production comprend de la sigillée lisse et moulée, ainsi que de la céramique commune. Dans la chaufferie du four, des vases entiers ont été trouvés, principalement des Drag. 40, des Drag. 32 et des mortiers avec gueule de lion, dont certains sont surcuits. Les formes recueillies et notamment les mortiers de type Curle 21 et Drag. 45 indiquent comme période d'activité le dernier quart $\mathrm{du} \mathrm{II}^{\mathrm{e}} \mathrm{s}$. et le $\mathrm{III}^{\mathrm{e}} \mathrm{s}$. Une étude stylistique des décors moulés trouvés dans ce dépotoir a permis d'attribuer une partie importante de ceux-ci à Gesatus, potier actif vers la fin du $\mathrm{II}^{\mathrm{e}}$ s. (Bücher, 1988).

Autour de res deux grandes aires de production, un semis de fours isolés ou de petites officines parsèment les étendues d'argiles du Gault et de sables verts qui entourent les buttes témoins de gaize de la forêt de Hesse. Au nord du Vaux-Mulard, la prospection a permis de repérer deux concentrations de sigillées moulées, dont des ratés de cuisson (Aub24). Entre Le Vaux-Mulard et La Croix-desPrêcheurs, un petit atelier isolé de céramiques oxydantes (sigillées? céramique commune ?) a été trouvé près d'une source sur le versant sud du massif du Hermont (Avol2). D'autres ateliers de sigillée existent au bas du versant du massif de gaize des Quatre-Bornes. En 1991, une fouille de sauvetage, sur la seule partie alors repérée de ce dernier atelier ${ }^{31}$, a permis de dégager un four et une partie de sa chaufferie. Dans celle-ci, qui dessert également un deuxième four, des quantités importantes de différentes céramiques (sigillée, craquelée bleutée, dérivée de gallobelge, commune), de cales et de supports de cuisson ont été récoltées. Le fouilleur place le dépotoir dans le courant du

31. Connu sous le nom de "four de la coupe $n^{\circ} 11$ de la forêt

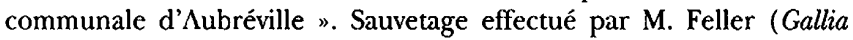
Informations, 1992, 2, p. 94). 


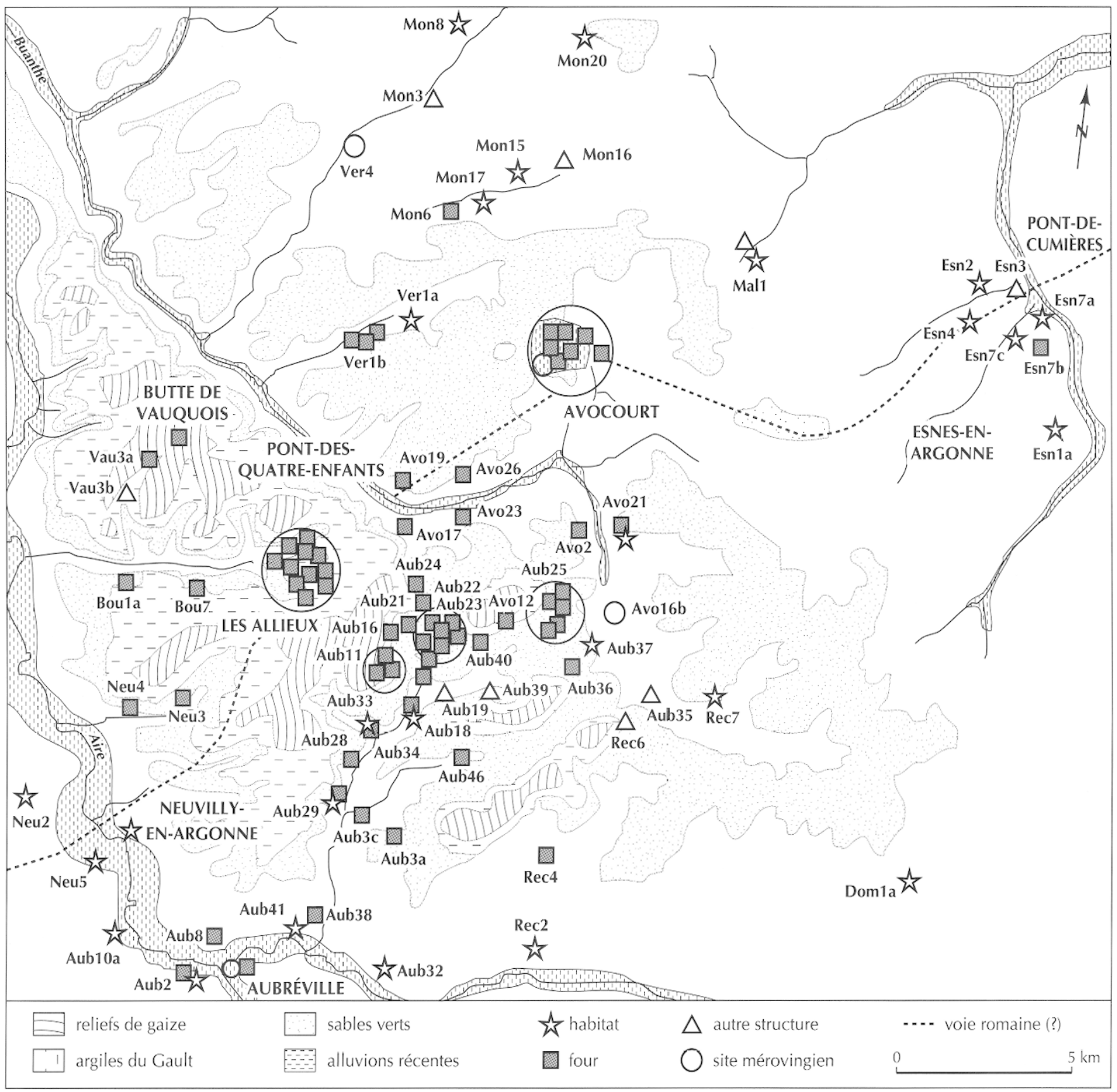

Fig. 23 - Siles antiques de la forêt de Hesse et du bassin d'Avocourt (DAO M. Gazenbeek, INRAP).

III ${ }^{\mathrm{e}}$ s., mais ne précise pas quelles céramiques ont été fabriquées sur place. La prospection a montré que ce four n'est pas isolé : d'autres vestiges, dont des fours, existent un peu plus haut sur la pente et autour d'une source au pied du versant (Aub11 et Aub16). Les céramiques recueillies indiquent une activité synchrone de ces différentes structures durant la seconde moitié du II ${ }^{\mathrm{e}} \mathrm{s}$. et/ou le $\mathrm{III}^{\mathrm{e}} \mathrm{s}$. La prospection montre également que la production concerne essentiellement des sigillées (dont des Drag. 33, 37 et 45) et sans doute des grandes cruches de céramique commune à cuisson oxydante.

Le site de La Caouette (Avo17), sur la rive gauche de la Buanthe, a été découvert par G. Chenet en 1914, mais la guerre mit un terme à ses recherches sur ce site qui resta pendant quatre ans sur la ligne de front (Chenet, 1917, p. 156). Cependant, il eut le temps de découvrir une série de 
ratés de cuisson au nom du potier Tocca. Les poinçons de La Caouette sont absolument neufs, à fleur de coin, et G. Chenet a pensé que cet atelier est entré en production avant ceux de Lavoye, où 'Tocca aurait exercé par la suite (cf. la chambre P). Le site possédait au moins trois fours. Nos prospections ont donné de nombreux fragments de sigillées Drag. 27 et Drag. 18/31 ainsi que des formes Drag. 37, dont certains avec l'estampille de Tocca. Notons également la présence d'un décor moulé avec un poinçon de Germanus (fin du II ${ }^{\mathrm{e}}$ s.). Au Moulin de la Cour (Avo23), également situé sur la rive gauche de la Buanthe, nos recherches ont permis de localiser près de l'emplacement du moulin un petit atelier qui a produit à la fois des sigillées et des gobelets fouettés Chenet 332.

Plusieurs ateliers de sigillées lisses et moulées ont été identifiés dans la vallée de l'Aire. Celui de Lochères a été découvert vers 1900 par des ouvriers qui extrayaient des nodules de phosphate. Notre prospection a permis de le localiser à $200 \mathrm{~m}$ au sud de la voie romaine Reims-Metz, au bord d'un ruisseau (Cle8). Il cst composé de plusicurs fours de sigillée et a livré des supports de cuisson ainsi que des vases unis du $\mathrm{II}^{\mathrm{c}} \mathrm{s}$. (Chenet, Gaudron, 1955, p. 23). Les prospections ont également permis d'inventorier des ateliers inédits dans la vallée de l'Aire : près d'Auzéville, l'atelier du Chaude-Coq (Clel1) en bordure de la rivière; au nord de Neuvilly-en-Argonne, le dépotoir du Riau de Russe (Neu4b), dont le matériel très homogìnc (sigillćcs, cćramiques à pâtes oxydantes fines, supports de cuisson) indique la présence proche d'un ou de plusieurs fours.

$\mathrm{Au}$ cœur du massif argonnais de gaize, dans la vallée de la Biesme, trois ateliers ont été anciennement reconnus, formant une zone de production cohérente au sud de la voie Reims-Metz.

L'atelier le plus éloigné de cette route, au Pont-desRèmes (Flo6, voir fig. 21), a été fouillé en 1912 par G. Chenet (Chenet, 1913). L'exploration, sur $200 \mathrm{~m}^{2}$, a mis au jour un four, sa chaufferie, une fosse à tremper l'argile et une tranchée de drainage. Dans les environs immédiats de ce four d'autres sondages n'ont pas donné de résultat. Les fosses d'extraction d'argile semblent se situer sur la rive opposée du ruisseau qui borde l'atelier au nord. La tranchée et la fosse à tremper l'argile étaient en partie remblayées avec des déchets de fabrication (vases manqués, moules) ainsi qu'avec les débris d'un mouton. Ces derniers étaient coiffés par des matériaux de démolition du four et des tessons variés. La production comprend principalement de la sigillée, représentée par une vingtaine de formes. Au total, 14 fragments de moules pour bols Drag. 37 ont été trouvés. G. Chenet supposait que les décors moulés étaient tous du même décorateur, sauf six fragments de vases et de moules qui seraient plus récents et qui ont été trouvés à la surface du remplissage de la tranchée et de la fosse. Certains ensembles décoratifs, avec des poinçons similaires, sont connus à Avocourt (four de L'Argentière) et aux Allieux, mais surtout à Lavoye où ils sont très abondants et ont été identifiés comme étant ceux des potiers Tribunus et Gesatus.

À mi-chemin entre Le Pont-des-Rèmes et la voie antique, l'atelier du Vaux-Régnier (Flo3, voir fig. 21) a été fouillé par G. Chenet en 1914, mais les résultats de ses recherches n'ont malheureusement pas pu être publiés. Toutes les notes concernant cet atelier ont été détruites en 1914-1915 et il n'est connu que par des informations disparates (Chenet, Gaudron, 1955, p. 28 et fig. 56-57). Le four était du même type qu'au Pont-des-Rèmes, mais plus petit: il présente un plan ovale allongé avec, de part et d'autre de la bouche de l'alandier, un mur servant de contrefort. Il n'y avait pas d'autres aménagements et le matériel recueilli était peu abondant : un moule, des tessons décorés et des vases lisses du même type qu'au Pont-des-Rèmes. Sur les 50 estampilles trouvées sur le site, 7 seulement ont pu être déchiffrées, mais la liste des noms a été perdue pendant la guerre. Un décor de moule constitue le seul élément de datation. La production de gobelets à engobe noir est également attestée pour cet atelier. G. Chenet a récolté à La Côte du Claon, en face du four de sigillée, des objets appartenant à un atelier à gobelets globuleux granités. Le matériel recueilli en prospection, sigillées Drag. 15 et Chenet 303 ainsi que des gobelets godronnés, confirme cette double production.

Le troisième atelier se situe en bordure de l'installation routière du Pont-Verdunois (Lacl, voir fig. 21) sur la voie romaine Reims-Metz. G. Chenet a recueilli à deux reprises, autour de la petite fontaine du Bois-le-Prince, deux fragments de moules pour bol Drag. 37, tous deux du style de Tribunus: un dans la " partie supérieure d'une cavité funéraire " et un autre à quelques mètres. Enfin, lors de la pose de la ligne téléphonique le long de la route départementale, un amas de gaize calcinée a été mis au jour. Mais l'état du terrain, bouleversé par l'extraction de l'argile au $\mathrm{XIX}^{\mathrm{e}}$ s., a interdit à G. Chenet toute exploration plus poussée (Chenet, 1927a, p. 86-88).

Sur les trois ateliers connus de la vallée de la Biesme, seul celui du Pont-des-Rèmes a pu être daté avec une assez. grande précision, puisque sa production a été étudiée en détail. Pour G. Chenet, le début de son activité, apparemment de courte durée, s'établit vers 150 (Chenet, 1913). Cette hypothèse est confirmée par la présence de terrines Curle 21 et Drag. 44, productions typiques de Lezoux de la seconde moitié du II ${ }^{e}$ s. (Bet et al., 1989). Pour Le VauxRégnier et Le Bois-le-Prince, les choses sont moins simples, puisque le matériel et les notes de G. Chenet ont été perdus lors de la guerre de 1914-1918. Dans les deux cas, la datation 
proposée par cet auteur repose sur les critères stylistiques des décors moulés des bols Drag. 37. Au Vaux-Régnier, les poinçons d'un tesson décoré sont proches de ceux de Germanus et d'Africanus (Chenet, 1927a, p. 87, fig. 4F et p. 90-92) et peuvent être situés dans le dernier tiers du II $^{\mathrm{c}} \mathbf{s}$. ou au début du III $^{\mathrm{e}}$ s. Au Bois-le-Prince, le décor des deux fragments de moule trouvés par G. Chenet sont, selon lui, du style de Tribunus dont la période d'activité se situe, selon B. Hofmann, dans les années 140-170 (Hofmann, 1968, p. 275). Ce sont donc des datations très incertaines, car elles sont fondées sur un ou deux tessons seulement. En outre, dans le cas du Bois-le-Prince, les poinçons ne sont pas de Tribunus (au moins pour le moule figuré), mais sont seulement proches des siens. Pour ces deux ateliers, nous ne pouvons donc qu'avancer une datation peu précise, qui se situerait dans la seconde moitié du II $^{\mathrm{e}} \mathrm{s}$.

\section{Les gobelets}

La production de gobelets concerne tous les grands ateliers : Les Allieux, Le Vaux-Mulard, Avocourt et Lavoye. Tout en étant régulièrement associés à la production de sigillée, les gobelets peuvent également être produits par des officines totalement spécialisées. À Moty (Aub14, voir fig. 25), sur la voie Reims-Metz dans la vallée de l'Aire, cette production succède directement (ou est contemporaine) aux ateliers gallo-belges, sans traces de fabrication de sigillée.

L'association entre les gobelets et les sigillées est le mieux illustrée par les gobelets moulés, étudiés sur le seul site de Lavoye. Les fouilles de G. Chenet et du $\mathrm{D}^{\mathrm{r}}$ Meunier ont mis au jour un atelier qui a livré 50 moules au total (Chenet, 1920b). Mais d'autres fours et dépotoirs sur ce site montrent que la production de ces gobelets était assez généralisée (dépôts près du four $\mathrm{C}$, dans la chambre $\mathrm{P}$, dans le trou $\mathrm{C5}$ et dans le trou $\mathrm{S}$; fosse de gobelets dans la parcelle 746: four $\mathrm{V}$ comblé avec une cinquantaine de gobelets). D'après une marque incluse dans la décoration, nous savons que l'un des décorateurs de ces vases moulés est Eburus. Au moins une partie des poinçons utilisés pour les moules est attribuée par G. Chenet à Tribunus, Germanus, Africanus et Amenus. La production des gobelets moulés semble typique du $\mathrm{II}^{\mathrm{e}} \mathrm{s}$.

La production la plus ancienne et la plus répandue comprend les gobelets Chenet 332. Le début de la fabrication en Argonne n'est pas défini. Notons que la forme existe au moins dès le milieu du I $^{\text {er }}$ s. (Hawkes, Hull, 1947 : type $94 \mathrm{~A}-\mathrm{B})$.

G. Chenet a établi une quinzaine de types différents pour l'Argonne : pour les $\mathrm{II}^{\mathrm{e}}$ et $\mathrm{III}^{\mathrm{e}} \mathbf{s}$. (Chenet, 1941, fig. 29 et 31 ) et pour le IV ${ }^{\mathrm{e}}$ s., les formes Chenet $333-342$. Tous ces gobelets présentent les mêmes caractéristiques malgré quelques variantes. Il s'agit de vases à pied rétréci et à panse globuleuse qui se terminent par un col tronconique bordé d'une étroite lèvre moulurée. Ils sont généralement en terre commune rouge à engobe noirâtre ou métallisée, parfois aussi en pâte brune, jaunâtre ou grise, avec ou sans engobe. Les décors sont le plus souvent constitués par un simple effet granité obtenu en fouettant de l'argile fluide (Chenet 332), mais on y trouve également des décors à la molette et à la barbotine, des lignes de guillochis, parfois des incisions, des panses godronnées (type Chenet 333-340), ainsi que des décors moulés utilisant la technique des moules dits "à valves ", comme pour les sigillées. La longue durée de la production de ces gobelets est soulignée par la diversité des techniques de décoration.

Dans tous les cas, la production est massive : à Lavoye, le dépotoir de la parcelle 746 rassemble toutes les variétés de ce type de céramique dont plusieurs milliers de gobelets simples ou à dépressions, avec un décor granité (les plus nombreux), des lignes guillochées, un décor à la barbotine ou un décor moulé (les plus rares). Le matériel associé - un grand bronze d'Hadrien et quatre fonds de tasses coniques en sigillée avec les estampilles de Cocus et de Cintugnatus permet de situer ce dépotoir dans la première moitié du II $^{\mathrm{c}}$ s. Dans certains ateliers, la production des gobelets est plus importante que la fabrication de sigillée. Ainsi, aux Allieux, $G$. Chenet note avoir vu des débris de gobelets sur plusieurs centaines de mètres, le long de l'adduction d'eau de Vauquois au sud-est de la clairière. Nos prospections et celles de M. Feller montrent que les ateliers de gobelets sont également fréquents au nord-ouest de cette zone.

Durant les $\mathrm{II}^{\mathrm{c}}$ et $\mathrm{III}^{\mathrm{e}}$ s., presque tous les ateliers produisent, en dehors des formes sigillées classiques, un large éventail d'autres poteries. Nous avons déjà mentionné plusieurs ateliers livrant à la fois de la sigillée et des gobelets engobés (Vaux-Régnier, Moulin de la Cour). Les autres fabrications les plus courantes sont les mortiers Drag. 45 (à déversoir en forme de tête de lion), les mortiers Chenet 359 , 360 ou 361 (en terre rouge orangè sans engobe) et les terrines Chenet 325 et 326 (en céramique fine oxydante, également sans engobe).

L'imbrication des différentes productions peut être totale. Au Vaux-Mulard, la plupart des vestiges sont liés à la fabrication de gobelets Chenet 332, en particulier à Aub21, Aub22a et Aub22d (fig. 23). Sur ce site, le regroupement de la production des gobelets et des sigillées moulées est confirmé par les investigations approfondies de G. Chenet sur le seul four qu'il ait identifié. Il le dégage en 1914, dans une butte circulaire d'un diamètre de $10 \mathrm{~m}$ environ et de $1 \mathrm{~m}$ de haut. Selon lui, il s'agit très probablement d'un ancien tumulus hallstattien. (Chenet, 1917, p. 156 ; archives 
départementales de la Meuse 71.J.37). Il y trouve la base d'un four de sigillée avec, dans la chaufferie, quelques fonds de tasses en sigillée et de nombreux gobelets engobés à panse globuleuse ou godronnée, unis ou décorés (barbotine, guillochés). Des petits vases, des couvercles coniques et des cruches oxydantes et réductrices sont également présents. Les gobelets et supports de cuisson associés sont extrêmement abondants et correspondent à un volume de plusieurs mètres cubes. De nouvelles recherches dans cette butte après la guerre mettent au jour un alandier ovale avec foyer, avec de nombreux débris de grandes cruches à deux anses.

\section{Phase III : la sigillée décorée à la molette}

La sigillée décorée à la molette est le successeur logique de la sigillée moulée, avec une technique de décor rationalisée permettant une production accélérée des bols décorés.

Les ateliers de référence ont été identifiés par G. Chenet (1941, p. 17-41) (fig. 24). Seuls quelques-uns de ces sites ont livré des éléments de chronologie absolue :

- la chaufferie du four A de la clairière aux Allieux (dernier quart du IV ${ }^{\mathrm{e}}$ s. : monnaies de Valens, de Valentinien II et de Théodose dans les cendres du fond) ;

- les chaufferies des fours A et B à Avocourt (troisième quart du IV $\mathrm{s}$. : monnaies de Gratien et de Valens dans l'amas de cendres près du foyer) ;

- la fosse-chaufferie du four C à Avocourt (milieu du IVe s. : monnaies de Constant et de Constance II) ;

- la sépulture $A$ (troisième quart du $I^{\mathrm{e}} \mathrm{s}$.), le puits du champ 790 (vers 375) et l'hypocauste du champ 752 (milieu du IV's.) à Lavoye.

Tous ces éléments de datation se situent dans la seconde moitié du IV ${ }^{\mathrm{e}}$ s. Des ensembles plus précoces ne sont pas attestés en Argonne, mais seulement à l'extérieur de la région, notamment une cave à Alzey dans le Rheinland-Pfalz. (Allemagne) dont le comblement est daté par des monnaies de 330-355 (Unverzagt, 1916). Des lots plus tardifs sont signalés dans le champ 791-793 ou dans la fosse $8 \mathrm{du}$ champ 613 à Lavoye, mais la stratigraphie n'est pas sûre. Le mobilier que $\mathrm{G}$. Chenet a récupéré lors de la fouille du dépotoir B des Allieux constitue une grande partie du matériel ayant servi à l'élaboration de son ouvrage fondamental sur les céramiques tardives de l'Argonne.

Ces différents sites montrent des ensembles de céramiques variées. Les productions trouvées dans le four $\mathrm{C}$ d'Avocourt ont peu de formes en commun avec Le Pont-desQuatre-Enfants ou l'hypocauste de Lavoye par exemple. De même, des différences notables existent entre la sépulture $\mathrm{A}$ et le dépotoir $\mathrm{B}$ des Allieıx, qui recèlent à eux deux presque toutes les formes de la typologie de G. Chenet. Ces nuances

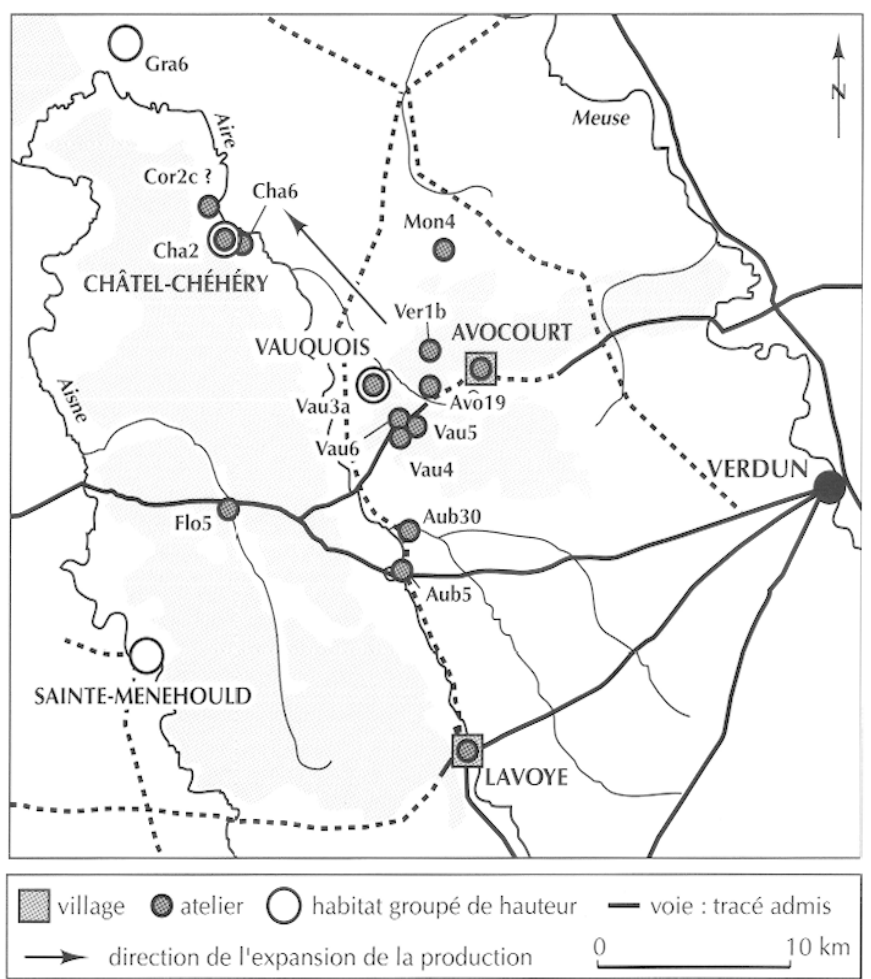

Fig. 24 - Les ateliers de sigillées décorées à la molette: phase III de la céramique argonnaise (DAO M. Gazenbeek, INRAP).

dans la composition du matériel traduisent sans doute des décalages chronologiques. De tous ces exemples, le plus particulier est celui du Pont-des-Quatre-Enfants dont la datation est probablement plus tardive. En raison des dates citées ci-dessus, l'activité de ce lieu doit se situer durant le $V^{e}$ s. - G. Chenet proposait déjà la fin du $\Gamma^{\mathrm{e}}$ et le début du $\mathrm{V}^{\mathrm{e}}$ s. (Chenet, 1927b, p. 63) -. Une datation au Ve s. d'une partie des installations des Allieux est également possible, car les monnaies de la fin du IV ${ }^{e}$ s. et de Théodose (four A) ont aussi circulé au Ves.

La sigillée décorée à la molette était rarement produite dans les mêmes ateliers que la céramique des phases précédentes. En dehors des trois pôles majeurs (Lavoye, Les Allieux, Avocourt), où ce type de céramique succède aux sigillées moulées, la production se fait aussi dans de nouveaux centres de production, comme Châtel-Chéhéry. La distribution de ces nouveaux ateliers montre une extension de l'aire de production vers le nord et la disparition d'un certain nombre d'officines dans les zones de fabrication précédentes.

Toutefois, la production des sigillées continue dans les petits habitats groupés sur la voie Reims-Metz. À la station du Pont-Verdunois, sur la rive gauche de la Biesme et en bordure de la voie antique, G. Chenet a collecté plusieurs 
supports pour bols du type 320 , qui constituent la forme la plus répandue au $\mathrm{IV}^{\mathrm{e}}$ s., ainsi que des tessons de vases décorés à la molette (Chenet, 1927a, p. 86-88). Le four associé à ce matériel n'a pas pu être mis en évidence par G. Chenet, mais notre prospection a permis de le localiser avec précision. Dans la vallée de l'Aire, un nouveau centre de production est créé sur la rive droite de la rivière, occupant une partie du méandre de La Pierre-à-Villé traversé par la voie antique.

Dans la forêt de Hesse, la production de la sigillée à la molette semble devenir ponctuelle, en dehors des environs des Allieux (atelier de Vau7). Dans la vallée de la Buanthe, entre Les Allieux et Avocourt, un atelier est actif : Le Pontdes-Quatre-Enfants.

La majorité des ateliers a été créée autour des buttes de Vauquois, de Châtel-Chéhéry et de Montfaucon, où des centres de production ont été installés sur le sommet des buttes (Vauquois, Châtel 2a) et à leur pied (Châtel 6, Montfaucon 4).

Comme dans le cas de la sigillée moulée, la fabrication de la sigillée décorée à la molette est accompagnée de la production de gobelets. Celle-ci est attestée dans la littérature uniquement dans les sites des Allieux et de Lavoye. Ainsi, le gobelet Chenet 333 en forme de tulipe à engobe rouge orangé, lisse ou à décor incisé, est bien représenté dans les sites du $I V^{e}$ s. de la région. Mais seule la fabrication d'une forme proche, plus globuleuse et au pied en bourrelet, est attestée à Lavoye, où G. Chenet a trouvé dans un puits une dizaine d'exemplaires ratés ou sous-cuits. Les autres gobelets dont la production est attestée en Argonne, soit à Lavoye, soit aux Allieux, ou sur les deux sites, sont des Chenet 334 b et $334 c, 335,339,340$ (dont la production peut commencer dès le $\mathrm{II}^{\mathrm{e}} \mathrm{s}$.), 342, ainsi que des lagènes Chenet $343,345,347,348$ et 350 .

Enfin, la production de céramiques communes continue également, comme par exemple le pot Chenet 353 en terre grise à engobe gris foncé ou noir lustré, qui imite une forme de céramique bleutée craquelée. Ce spécimen a été rencontré en plusieurs exemplaires à Lavoye, dans la sépulture A.

\section{LES ATELIERS}

Nous distinguons trois types d'ateliers selon deux critères, celui de leur superficie et celui de la durée de leur production mesurée à partir de la variété des produits : les très grands ateliers de longue durée, les grands ateliers de courte durée et les petits ateliers de courte durée (fig. 25).

Trois sites de production, Les Allieux, Lavoye et Avocourt, entrent dans la première catégorie des très grands ateliers de longue durée. Lavoye et Avocourt se singularisent par la grande variété de leur production qui s'étend de la céramique gallo-belge à la sigillée décorée à la molette, ce qui implique qu'ils ont fonctionné durant toute l'Antiquité. Aux Allieux, le début de la production, caractérisé par une absence marquée de céramique gallo-belge, semble se situer dans le courant du $\mathrm{II}^{\mathrm{e}} \mathrm{s}$. La production se pousuivra jusqu'au $\mathrm{V}^{\mathrm{c}}$ s. (en particulier celle des sigillées décorées avec la molette UC 178).

Ces sites recèlent un très grand nombre de fours. Ainsi, à la suite de la remise en culture d'une partie des Allieux dans les années 1980, une prospection par carroyage a permis de localiser une trentaine de fours (Feller, Brulet, 1998, p. 298-363), dont certains ont pu être utilisés à plusieurs époques (par exemple le four A de G. Chenet).

Les surfaces concernées couvrent des dizaines d'hectares. À Lavoye, les fours s'étendent entre la rive gauche de l'Aire au sud du village et le quartier de La Vérine à l'ouest de la route Bar-le-Duc à Clermont-en-Argonne, soit sur une distance de $800 \mathrm{~m}$. Le plus grand nombre d'entre eux se situe cependant dans ce dernier secteur, où les recherches ont été par ailleurs les plus systématiques. Par rapport à cette zone largement prospectée, le four à sigillée dit « de Messirius " apparaît comme isolé près de la rivière, mais il semble, selon nos prospections, que d'autres ateliers existaient entre cet endroit et La Vérine.

Les ateliers d'Avocourt se répartissaient sur une trentaine d'hectares sur le plateau, au nord du village actuel, et, vers l'est, dans la vallée de la Noire Fontaine. Les sondages et les fouilles de G. Chenet avant la guerre de 1914-1918 avaient déjà permis d'évaluer l'étendue de la zone de production. Nos prospections ont confirmé la densité et l'hétérogénéité des productions telles qu'elles apparaissent à travers les ramassages de surface sur les fours et les dépotoirs : sigillées moulées (Avo6a, 6c, 6g), sigillées décorées à la molette (Avo6a, 6b, 6c, 6f) et céramiques gallobelges (Avo6a, 6g). Nous notons en particulier la production de sigillées décorées à la molette associées à des mortiers Drag. 45 (Avo6b, un contexte qui livre également de très nombreux tessons de céramique réductrice rugueuse), ainsi que la présence de gobelets engobés noirs (types Chenet 333, 336-337 et 340) dans un contexte qui a livré aussi bien des sigillées moulées que des tessons décorés à la molette (Avo6c). Les vestiges s'étendent au-delà de la zone de prospection, vers la lisière de la forêt au nord et à l'ouest.

En dehors de ces trois grands groupes d'ateliers, il existe toute une gamme de centres variables par l'étendue de leurs installations et les types de leur production. Ces ateliers regroupent des dizaines de fours sur plusieurs hectares mais, contrairement à la catégorie précédente, la fabrication est le plus souvent dominée par un seul type de céramique, 


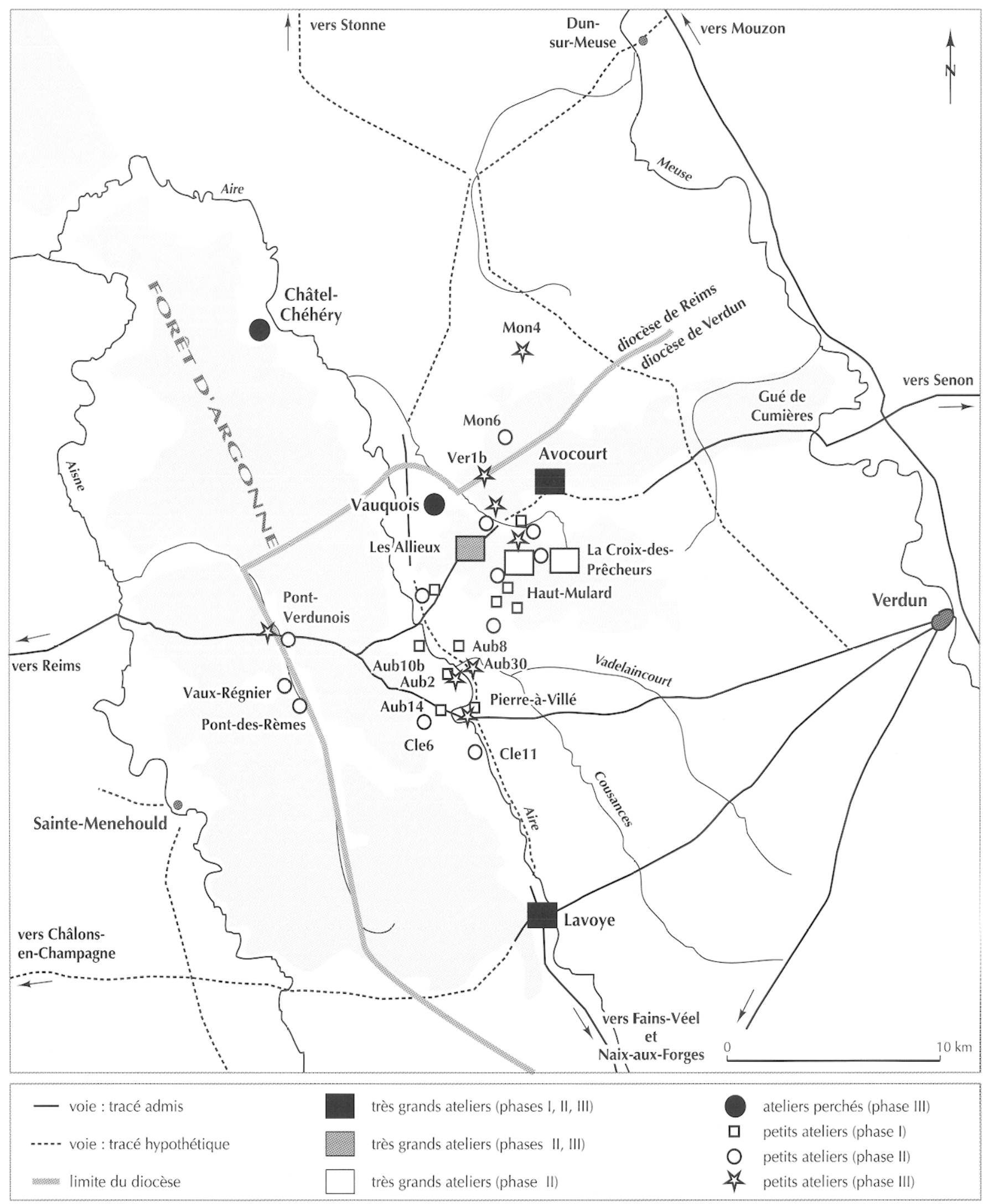

Fig. 25 - Hiérarchie des ateliers de céramique en Argonne (DAO M. Gazenbeek, INRAP). 
plus rarement deux. Ces grands ateliers sont attestés pour les céramiques gallo-belges, les gobelets et les sigillées moulées ou décorées à la molette. Contrairement aux trois sites précédents, la production conccrne toujours une fourchette chronologique relativement courte (une seule phase).

Enfin, il existe des ateliers de petite superficie, composés de quelques fours, voire même d'un seul. Comme pour le groupe précédent, les fabrications sont le plus souvent d'un seul type: gallo-belge, sigillée moulée ou décorée à la molette, gobelets engobés, céramiques communes, etc. Quelquefois, des associations existent.

L'impression qui ressort des prospections est que des ateliers très importants alternaient avec d'autres, plus modestes, répartis de façon plus lâche dans l'espace. Certains de ces petits ateliers sont éloignés des zones principales de production.

\section{LE FONCTIONNEMENT DES ATELIERS : LES POTIERS ET LEURS RELATIONS}

Les relations entre les différentes officines ainsi que leur fonctionnement ont jusqu'à présent été étudiés surtout à partir des estampilles nominatives, des poinçons pour sigillées moulées et des décors à la molette.

Le recensement des estampilles a mis en évidence le fait que des noms identiques se retrouvent dans plusieurs ateliers, en Argonne, mais aussi dans d'autres centres de production de l'Est de la Gaule et sur le Rhin. Pour les différents auteurs, ceci traduit une migration des potiers entre les lieux de production. Ainsi, sur les cinq noms de potiers associés dans le mouton du Pont-des-Rèmes (Censorinus, Viducus, Sisserus, Anisatus et Tullus), deux sont également connus à Lavoye, à Avocourt et aux Allieux. De même, le potier Tocca a fabriqué de la sigillée à Lavoye et à l'atelier de La Caouette dans la vallée de la Buanthe. À l'atelier de La Croix-des-Prêcheurs en forêt de Hesse, 41 variantes d'estampilles pour 35 noms différents ont été identifiées lors des fouilles récentes. Cettc listc a ćtć comparée avec d'autres, plus anciennes, et un certain nombre d'hypothèses sur la datation du site et les relations entre les ateliers par des potiers itinérants ont été émises (Lutz, 1991).

Nous soulignons que ces rapprochements reposent uniquement sur l'homonymie. Aucune des estampilles trouvées dans l'atelier de La Croix-des-Prêcheurs n'a été mise au jour à Lavoye, au Pont-des-Rèmes, ou à Avocourt, pour ne parler que des seuls sites qui permettent une comparaison puisque leurs estampilles ont été dessinées et publiées. Comment peut-on expliquer l'existence d'estampilles similaires sur des sites différents ? Par exemple, pour le seul site de Lavoye, 24 types divers d'estampilles au nom de Tocca sont connus et, sur l'ensemble de l'Argonne, 42 variantes ont été relevées (Chenet, Gaudron, 1955, fig. 52 ; Hofmann, 1972 ; Lutz, 1991). L'explication la plus souvent avancée est l'utilisation par un même potier de plusieurs marques différentes. Mais les rapprochements nominatifs entre ces ateliers peuvent aussi refléter de vrais homonymes (contemporains ou non) ou des patronymes (de père en fils...).

Ce problème existe également pour les poinçons des moules. À notre avis, les décors sont trop rapidement associés à un seul décorateur ou potier. Le dépôt de Châlons-en-Champagne (voir supra) le montre bien : si l'on associe un poinçon à un décorateur unique, les productions du milieu ou de la fin du III ${ }^{\mathrm{e}} \mathrm{s}$. seraient attribuées à des décorateurs du $\mathrm{II}^{\mathrm{e}} \mathrm{s}$. En tenant compte de ces réserves, il devient très difficile de cerner les relations entre les ateliers et, surtout, d'y associer des potiers individuels. Ainsi, l'utilité de ces estampilles et poinçons à des fins de datation du site est remise en cause.

Les fours ou les dépotoirs de ratés de cuisson de sigillée livrent, chaque fois qu'ils sont fouillés, un nombre limité d'estampilles : quatre noms de potiers pour le four $\mathrm{A}$ fouillé par G. Chenet sur les pentes de L'Argentière à Avocourt, trois noms pour chacun des deux fours découverts par les extracteurs de nodules de phosphate au Champ-des-Bierres et encore trois estampilles pour un four situé plus au nord. Aux Allieux, un dépotoir de sigillée moulée a livré trois noms de potiers. Au Pont-des-Rèmes, seuls cinq potiers sont associés dans un même mouton. À La Caouette, G. Chenet a identifié trois fours et quatre potiers. Ces quelques exemples montrent bien que dans ces ateliers le fonctionnement du four est une œuvre collective (Chenet, 1913, 1917 et 1941, p. 36-37).

Dans une même unité de production (ici dans le sens du four et de son chargement), les estampilles permettent de soulever des questions quant à la rationalisation de la production de sigillée.

Au Pont-des-Rèmes, l'échantillon de 327 estampilles étudiées par G. Chenet et relevées sur les formes lisses correspond à 35 variétés appartenant à 25 potiers et 4 cas douteux (estampilles incomplètes). Ces 25 potiers sont représentés de façon très inégale : 4 potiers et 1 marque anépigraphique (rosette) sont présents plus de 40 fois (groupe 1), 3 potiers entre 13 et 17 fois (groupe 2) et 18 potiers entre 1 et 9 fois (groupe $3 \mathrm{a}: 7$ potiers, entre 5 et 9 fois ; groupe $3 \mathrm{~b}: 11$ potiers et 2 marques anépigraphiques, entre 1 et 4 fois). Dans les débris du mouton qui coiffait le dépotoir sont apparus 5 noms de potiers seulement. Ce sont les 4 noms du groupe 1 et 1 du groupe $3 a$. On peut donc penser que ce chargement raté a été l'œuvre de 5 potiers au minimum. Notons aussi que les estampilles se trouvent 
seulement sur quelques formes céramiques, bien que tous les vases ouverts produits par l'atelier se prêtent à l'estampillage. Cet atelier a produit cinq services comprenant chacun des tasses, des assiettes et des plats (tig. 26). La spécialisation des potiers apparaît clairement dans le choix des estampilles. L'estampille à la rosette ne concerne que deux services $\left(\mathrm{n}^{\circ} 2\right.$ : Drag. 32 et Drag. $40 ; \mathrm{n}^{\circ} 3$ : Drag. 18 et Drag. 27), les estampilles nominatives, un seul service ( ${ }^{\circ} 1:$ Drag. 31 et Drag. 33), tandis que les services $n^{\circ} 4$ (Drag. 46 et Curle 15) et $n^{\circ} 5$ (Drag. 35 et Drag. 36) sont anonymes ${ }^{32}$. Cette standardisation de la production se ressent même dans les services. Sur les cinq potiers du mouton, deux fabriquaient des Drag. 33 (Censorinus, Sisserus), deux autres des Drag. 31 (Tullus et Viducus) et un seul potier les deux formes (Anisatus). Mais à l'intérieur de cette répartition, des distinctions existent. Anisatus et Tullus fabriquaient des Drag. 31 du type Oswald et Pryce XLVI, 12, tandis que Viducus produisait des types Oswald et Pryce XLVI, 5 et 9 .

Toutefois, les productions nominatives ne forment qu'une petite partie de la production. Quatre services sur cinq portent des estampilles anépigraphiques ou bien ne sont pas estampillés, auxquels il faut ajouter des bols et terrines anonymes. Quel est alors le nombre de potiers réellement impliqués dans la fabrication d'un chargement de four? Les estampilles, qui associent de trois à cinq potiers, nc pcrmcttcnt pas d'ćvaluer précisément leur nombre. La question est de savoir si les productions anépigraphiques et celles qui sont estampillées sont faites par les mêmes potiers ou par d'autres. Les estampilles étant attachées souvent à une forme particulière de vase, il semble que, dans un atelier, cela révèle une certaine répartition de la production entre les potiers.

\section{LOCALISATION DES ATELIERS PAR RAPPORT À LEUR ENVIRONNEMENT}

Le contexte naturel de la région garantissait un accès facile aux cinq éléments de base nécessaires à la fabrication de la céramique : l'argile, le dégraissant, l'eau, le bois de combustion et la pierre réfractaire. En ce qui concerne cette dernière, en dehors de la gaize, la pierre châline du Jurassique était également disponible ${ }^{33}$.

32. Ce phénomène n'est pas propre à l'Argonne et se constate également sur les services de la Graufesenque ; sur six services identifiés, deux seulement comportent des estampilles : une série nominative et une série anépigraphique à rosettes (Vernhet, 1976) ; de même à Lezoux (Bet, 1988, p. 228-229).

33. Les fours d'Aub8a/c étaient construits avec de la châline, disponible sur place. Seules certaines parties étaient en gaize, dont la source d'approvisionnement la plus proche se trouve à $2,7 \mathrm{~km}$.

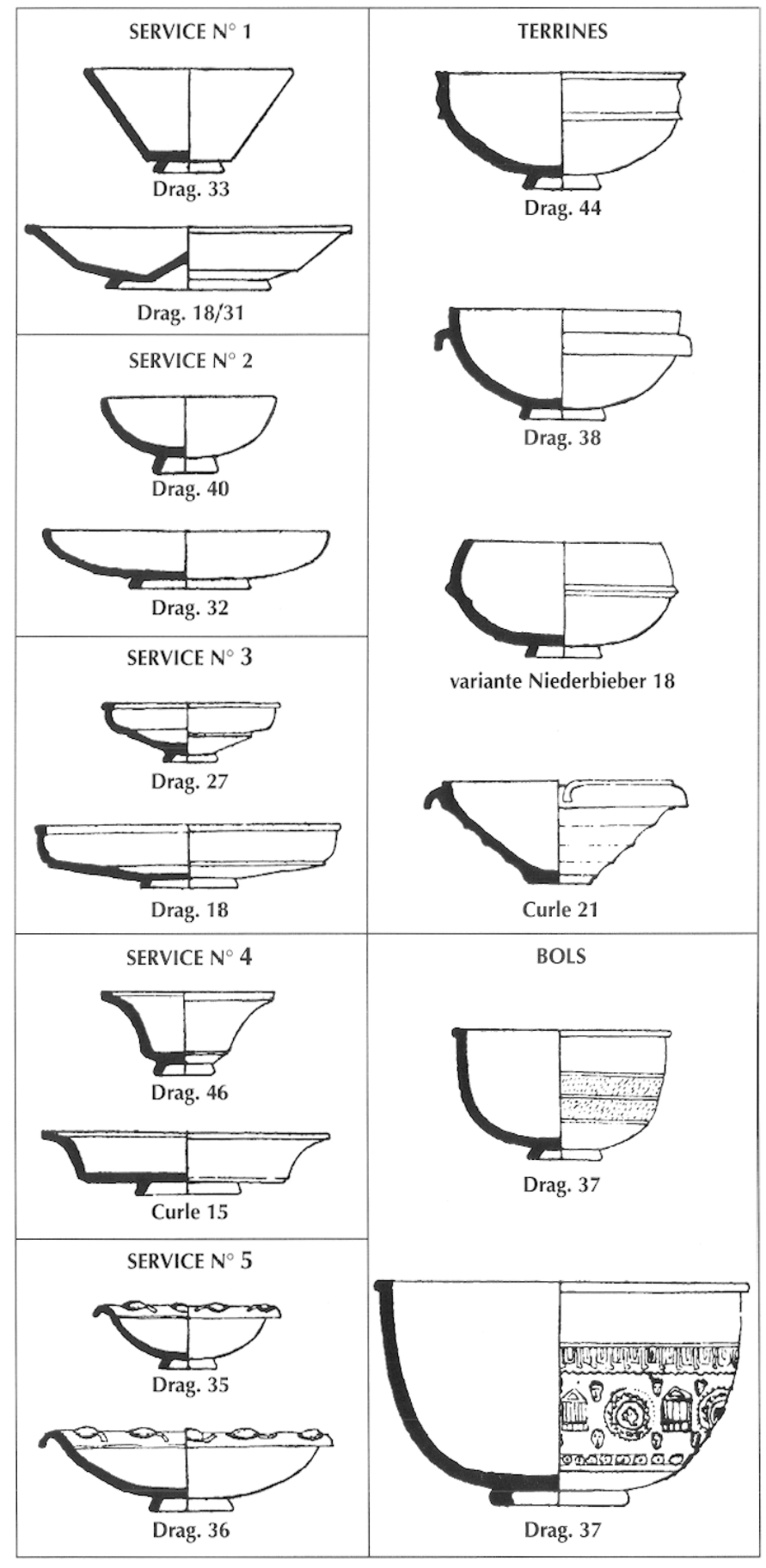

Fig. 26 - La production céramique de l'atelier du Pont-des-Rèmes (d'après Chenet, 1913).

La proximité des massifs de gaize était certainement importante pour les réserves de bois de combustion qu'ils pouvaient constituer, si l'on se réfère au développement de l'artisanat du feu au Moyen Âge et à l'époque moderne dans la région. Mais en l'absence d'études paléoenvironnemen- 
tales, nous ne connaissons pas l'impact de l'industrie céramique sur la couverture forestière de la région.

L'eau semble également avoir joué un rôle de premier plan. Deux systèmes d'approvisionnement existaient. Dans certains sites dépourvus de sources suffisamment nombreuses et abondantes, comme à Lavoye, de nombreux puits ont été creusés, permettant d'exploiter les nappes phréatiques superficielles. Ces puits ont dû exister sur d'autres sites. Les sources permanentes ont également attiré les ateliers. Un lien entre les ateliers et les sources paraît se dessiner sur les cartes de distribution, en particulier dans la forêt de Hesse. Dans ce secteur, les principaux ateliers se situent à proximité immédiate du premier palier hydrographique défini p. 274, c'est-à-dire à proximité des sources au pied des reliefs de gaize, soit Aub11, Aub16, Vau3, Avo12. Les fours installés autour des sources et ruisseaux pérennes du deuxième niveau hydrographique dans le Portlandien englobent entre autres le très grand atelier des Allieux (en particulier Bou4), ainsi que Neu3, Neu4, Aub28, Aub34, Aubl 8 et Aub46.

En ce qui concerne le dégraissant, nous constatons une très nette attraction des ateliers vers les sables verts. $40 \%$ des ateliers connus sont installés sur ces bancs, qui ne couvrent que $9 \%$ de la région, et $30 \%$ des autres ateliers se trouvent à moins de $200 \mathrm{~m}$ de ces formations, présentes essentiellement sur les calcaires portlandiens. Dans aucun de ces cas, l'argile du Gault n'a constitué un pôle d'attraction pour l'installation des ateliers.

\section{LOCALISATION DES ATELIERS PAR RAPPORT À L'HABITAT ET AUX VOIES DE COMMUNICATION}

Un problème particulier est la relation entre l'habitat et les ateliers. En général, la prospection n'a pas permis de distinguer des zones d'habitat en relation directe avec les grands ateliers de la forêt de Hesse. L'organisation spatiale des villages et hameaux antiques d'Avocourt, de Lavoye et du Pont-Verdunois est assez claire : la production céramique n'est généralement pas située au centre des agglomérations, mais dans des zones qui s'étendent au-delà du secteur habité.

Dans la vallée de l'Aire, les ateliers de petite taille sont situés à l'écart des habitats. Ils sont même toujours très éloignés des villae repérées dans la vallée. Ainsi, l'atelier de Clell se trouve à $1300 \mathrm{~m}$ au nord de la villa d'Auzéville et celui de Neu4b à $1400 \mathrm{~m}$ au nord des vestiges signalés sous le village de Neuvilly-en-Argonne. Des éléments d'enfournement isolés sont pourtant attestés sur des sites de villae, mais les prospections géophysiques n'ont jamais révélé de fours à leur emplacement. C'est notamment le cas de la villa de Varennes (Var2). Si cela peut indiquer un lien entre la production de sigillées et l'activité économique du domaine, il faut cependant remarquer que la production n'avait pas lieu dans l'environnement immédiat de l'habitation principale.

La vallée de la Biesme donne également l'impression d'une dissémination de petits ateliers isolés. Ceux du Pontdes-Rèmes, du Vaux-Régnier ainsi que les tuileries de La Morgnie ou de Gorget-Périn sont apparemment déconnectés du réseau d'habitat. Il semble qu'ils soient gérés depuis des centres plus ou moins éloignés : $500 \mathrm{~m}$ dans le cas de Gorget-Périn (site du Pont-Verdunois), tandis que pour les autres l'habitat associé n'est pas connu. Ceci est curieux, quand on songe au nombre de potiers signalés par des estampilles sur un site comme Le Pont-des-Rèmes.

Il existe une forte corrélation entre le réseau des voies de communication dans la région et les lieux d'implantation des ateliers. Les exemples les plus évidents sont les sites installés sur ou près de la voie Reims-Metz (Le PontVerdunois, zone de Lochères - La Pierre-à-Villé) et les zones artisanales des villages de Lavoye et d'Avocourt qui s'étendent autour de croisements de routes antiques.

Dans le triangle Avocourt, Lochères et La Pierre-à-Villé, situé à cheval sur la vallée de l'Aire et la forêt de Hesse, les ateliers sont particulièrement denses, notamment lors des phases de la production de céramique gallo-belge et de sigillée moulée. Il s'agit avant tout d'une zone située au croisement de plusieurs routes, celle de la vallée de l'Aire et celles qui relient d'ouest en est Reims et la Meuse. Mais le réseau devrait être plus dense. Plus au nord, autour de Montfaucon et Châtel-Chéhéry, le réseau routier antique est très mal connu et nous ne pouvons pas nous avancer sur le degré de proximité des ateliers par rapport aux voies. Nous supposons cependant que le couloir de l'Aire formait un axe de communication important au niveau régional et que Châtel-Chéhéry n'en était pas trop éloigné.

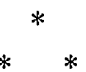

$\mathrm{Au}$ terme de ce panorama de l'Argonne à l'époque romaine, l'occupation du sol apparait comme une imbrication complexe de villages, de vastes zones artisanales et d'ateliers de céramique et de verre dispersés. Les zones artisanales de grande étendue masquent probablement un habitat associé, qu'il soit groupé comme sur le site des Houis (plus de $200 \mathrm{~m}$ de longueur) ou dispersé parmi quelques villae ou, ce qui est plus fréquent, parmi des habitats de taille plus modeste.

La production de céramiques gallo-belges dans l'Argonne commence au moins dès le début du $\mathrm{I}^{\text {er }} \mathrm{s}$. de notre ère. Dans l'état actuel de nos recherches, il semble que les formes les plus anciennes aient été produites à Lavoye. La production s'étend toutefois rapidement vers le 
nord et, dans le courant de la première moitié du $\mathrm{I}^{\mathrm{er}}$ s., des ateliers existent dans la région d'Aubréville. Dès le milieu de ce siècle, une zone étirée, parsemée d'ateliers de céramique gallo-belge, se développe le long d'un axe nord-sud entre la voie Reims-Metz au sud et Avocourt au nord-est. Ainsi, la distribution des centres de production céramique gallobelge du $I^{\text {er }} s$. préfigure déjà assez précisément l'aire de fabrication de la sigillée moulée à partir du milieu du II $^{\mathrm{c}} \mathrm{s}$.

Par rapport à la diffusion spatiale des ateliers de céramique gallo-belge, les lieux de production de la sigillée connaissent une expansion vers le nord et vers l'ouest. Dans cette dernière direction, c'est essentiellement la vallée de la Biesme qui profite de cette dynamique d'implantation. À ce propos, il faut souligner que les ateliers de céramique se limitaient dans un premier temps au territoire de la cité de Verdun (si l'on suit les limites des diocèses de l'Ancien Régime) (fig. 25). L'expansion de la phase II déborde très marginalement sur le territoire de Reims, avec quelques ateliers connus dans la vallée de la Biesme, formant une séparation entre les deux évêchés. Durant l'Antiquité tardive (phase III), l'extension vers le nord de l'aire de production voit apparaître des ateliers plus nombreux à l'intérieur du diocèse de Reims.

Excepté quelques grands centres de production dont le fonctionnement s'inscrit dans la très longue durée, les ateliers sont éphémères. Cela indique qu'en dehors des grandes officines qui fixcnt la production pcndant dc longues périodes, il existe une kyrielle de petits ateliers " itinérants " que l'on déplace " rapidement ".

La continuité entre les différentes productions apparaît, hormis l'unité de lieu, dans une utilisation constante des mêmes argiles et des mêmes dégraissants, au moins au sein des mêmes ateliers: des analyses par fluorescence-X montrent que les productions de la sigillée, de la céramique gallo-belge et de la céramique commune sur le sitc du Prixdes-Blanches à Avocourt ne diffèrent pas dans leur composition chimique (Deru, Feller, 1992, p. 92).

Le nombre insuffisant de fouilles correctement documentées sur les ateliers fait que la datation de la poterie de l'Argonne continue à poser un certain nombre de problèmes, la recherche n'ayant pas connu d'avancée significative sur le sujet depuis la publication des céramiques tardives par Chenet en 1941. Pour l'heure, les céramiques de la région, et notamment les sigillées et les gobelets des $\mathrm{II}^{\mathrm{e}}$ et $\mathrm{III}^{\mathrm{e}}$ s., voire du IV ${ }^{\mathrm{e}}$ s., gagnent à être comparées avec les typo-chronologies des productions de Lezoux, Puy-de-Dôme (Bet et al., 1989 ; Bet, Delor, 2000) et de Jaulges - VilliersVineux, Yonne (Séguier, Morize, 1996), qui offrent un spectre proche de celui de l'Argonne.

L'exception importante par rapport aux autres ateliers reste la production des bols Chenet 320 décorés à la molette, qui n'est attestée que dans l'Argonne durant l'Antiquité tardive, même si l'on soupçonne la présence d'ateliers secondaires dans la vallée mosane (Dijkman, 1992b) et en Île-de-France (Van Ossel, 1995, p. 227). La valeur de ce très fort marqueur chronologique est basée sur l'évolution supposée du décor (chronoclassification de Hübener, 1968), une approche qui s'est avérée peu probante. Une remise à plat de ce dossier complexe est actuellement en cours (Bakker et al., 1996).

Le succès des céramiques de l'Argonne a souvent été expliqué par la position privilégiée de cette région par rapport au réseau de voies de communication suprarégional. Ce réseau mettait la vallée de l'Aire, tout en étant située en marge des différentes cités de cette partie de la Gaule, à peu de distance des grands centres urbains de la région, qui forment autant de marchés pour la production argonnaise, mais aussi autant de centres de redistribution. En comptabilisant les indications de distance notées dans l'Itinéraire d'Antonin concernant la voie directe ReimsMetz, on constate que la traversée de l'Aire par cette route se situait à mi-chemin entre ces deux grandes villes (respectivement 30 et 31 miles). Les stations routières intermédiaires (Axvenna et Basilia vers Reims ; Verdun, Fines et Ibliodurum vers Metz) forment probablement autant de points de distribution locale sur cet axe commercial. Malheureusement, nos connaissances sur ces sites routiers nc permettent pas d'approfondir la question. Pour la céramique argonnaise, la position privilégiée de Verdun sur la Meuse a été relevée par plusieurs auteurs en tant que point de transbordement potentiel de la marchandise. Mais d'autres points sur le fleuve, comme le gué de Cumières au nord, ont pu remplir le même rôle.

Ce qui est certain, c'est que l'importance du marché régional a été longtemps sous-estimée dans l'explication du dynamisme de la production céramique argonnaise. Le fait que les sigillées, largement exportées, ont été les plus étudiées, a eu comme conséquence de masquer le marché régional et les produits autres que les sigillées, qui lui sont sans doute associés : les céramiques gallo-belges et les différentes poteries communes, ainsi que les tuiles qui ont été produites pendant toute la durée d'activité des ateliers.

Les synthèses régionales concernant la distribution des productions argonnaises dans l'Empire romain ont, en effet, essentiellement trait aux sigillées. Peu d'études ont été consacrées aux gobelets et aucune ne concerne la production de céramique gallo-belge.

La diffusion de la sigillée du Haut-Empire produite dans l'Argonne a été établie en premier lieu par le recensement des estampilles attribuées à la région (Chenet, Gaudron, 1955, p. 206-211), ce qui donnait une aire de consommation englobant tout le territoire situé entre la Seine et le Rhin, et 
quelques points isolés en Angleterre. Cette carte de diffusion a été considérablement améliorée par Hofmann en 1979. Mais en dehors des incertitudes liées aux estampilles, cette répartition n'apporte guère de renseignements sur l'importance commerciale (dans le temps et dans le volume) des exportations argonnaises, même si cette méthode a montré que les importations en Angleterre depuis l'Est de la Gaule sont très peu importantes par rapport à celles de Lezoux au II ${ }^{\mathrm{e}} \mathrm{s}$. (Marsh, 1981). Les estampilles ont également été utilisées en Normandie pour évaluer l'importance des différentes régions de production sur le marché normand. Les sigillées estampillées de l'Est, provenant majoritairement de l'Argonne, arrivent dès la première moitié du $\mathrm{II}^{e} \mathrm{~s}$. sur les sites de la Seine-Maritime, où elles représentent jusqu'à $1 / 5$ de ce type de céramique. La diffusion en Normandie occidentale a été beaucoup moins importante (Blaszkiewicz, Jigan, 1989). Il semble que la sigillée argonnaise du Haut-Empire n'ait été prépondérante au II ${ }^{e}$ s. que sur les marchés du bassin supérieur et moyen de la Meuse et à Reims (Raepsaet, 1985).

Deux études récentes, respectivement pour la Picardie (Bayard, 2001) et le territoire sénon au sud-est de Paris (Delor, 2001), montrent une approche plus exhaustive, avec des quantifications de l'ensemble de la céramique fine. En pays sénon, le $\mathrm{II}^{e} \mathrm{~s}$. voit un quasi-monopole des sigillées $\mathrm{du}$ Centre de la Gaule, alors que l'Est ne représente que $2 \%$. Même si, au cours du premier quart du III $^{c}$ s., l'Argonne augmente sensiblement ce pourcentage (jusqu'à environ $17 \%$ ), la consommation totale de sigillée chute de façon importante et le volume commercialisé par l'Argonne également. Les mêmes rapports entre les ateliers du Centre de la Gaule et ceux de l'Argonne et le même phénomène de chute de consommation se constatent en Picardie. En Picardie, une partie au moins du recul de la sigillée est compensée par une présence accrue de gobelets et notamment de gobelets à projection argileuse provenant en grande partie de l'Argonne (Bayard, 2001). Les gobelets argonnais sont également bien attestés en Normandie durant tout le $\mathrm{II}^{\mathrm{e}}$ s., comme l'ont montré des caractërisations physico-chimiques (Blaszkiewicz, Dufournier, 1989). Des analyses identiques ont mis en avant la présence d'autres types de gobelets, notamment des Niederbieber 33, produits à partir de la fin du $\mathrm{II}^{\mathrm{e}} \mathrm{s}$. environ à Amiens, à Arras et surtout sur le vicus de Braives en Wallonie (Bocquet et al., 1995). Pour l'Angleterre, l'hypothèse selon laquelle le stock important de gobelets à projection argileuse proviendrait de la Gaule, dont l'Argonne, a été proposée (Anderson, 1981), mais aussi sévèrement critiquée (Symonds, 1987).

Les premiers recensements de la distribution des sigillées tardives de l'Argonne, et notamment des céramiques décorées à la molette, remontent au début du $\mathrm{XX}^{\mathrm{e}} \mathrm{s}$.
(Unverzagt, 1919), et ont ensuite été complétés par G. Chenet en 1941 et W. Hübener en 1968. Depuis, des mises au point régionales ont été publiées pour les îles britanniques (Fulford, 1977), le Nord-Ouest de la France (Piton, Bayard, 1977), la Bretagne (Galliou, 1977), la Normandie (Jigan, Halbout, 1987) et pour la vallée mosane (Dijkman, 1992a et b). Une synthèse qui contient également de nombreuses données inédites a été publiée par P. Van Ossel (1995). Les quelques études quantitatives montrent que durant le Bas-Empire, les ateliers de l'Argonne avaient conquis la quasi-totalité du marché des sigillées en Gaule du Nord, concurrencées faiblement au niveau régional par des centres de production comme Jaulges - Villiers-Vineux (Séguier, Morize, 1996, en particulier fig. 18) ou des imitations locales. Des découvertes en Picardie indiquent que ce monopole de fait s'est peut-être installé dans certaines régions dès le milieu du

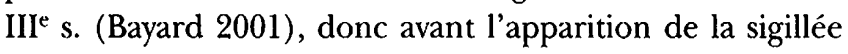
décorée à la molette. Ce sont alors des mortiers Drag. 45 et des gobelets qui dominent. La diffusion des mortiers Drag. 45 de l'Argonne semble avoir été très large, couvrant une bonne partie du Nord de la Gaule (Mitard, 1979) et descendant jusqu'en Bourgogne vers le sud (Mitard, 1996).

Cette activité artisanale florissante contraste avec un déclin constant du nombre de sites d'habitat à partir du III ${ }^{e} \mathrm{~s}$. Ce phénomène est général pour le Nord de la Gaule (Van Ossel, 1992, p. 177) et s'accompagne, en dehors de changements dans les modes de construction, d'une réorganisation spatiale des activités économiques. La plus évidente est l'installation de fours de potiers sur le plateau du site de hauteur de Châtel-Chéhéry : l'activité artisanale y côtoie donc au plus près les fonctions d'habitat et, peut-être, de défense. Cette réorganisation ne s'est pas faite au détriment de la production. Comme l'a souligné K. RothRubi : « une industrie très performante a pu se maintenir sur le long terme en Argonne, où les forces de production étaient donc entièrement conservées [durant l'Antiquité tardive] » (Roth-Rubi, 1990, p. 947), ceci en synergie avec: " une distribution généralisée dans les territoires des cités du Nord de la Gaule [...], impliquant nécessairement des centres de redistribution, un réseau de communication en bon état et un minimum d'échanges commerciaux " (Van Ossel, 1995, p. 223).

La question de la continuité de la production des sigillées de l'Argonne entre les phases II et III reste une difficulté majeure. Faut-il croire qu'il y a eu un arrêt de la production des bols moulés Drag. 37 dans le courant du III' $s$. et qu'il n'y a plus que des formes lisses et des mortiers Drag. 45 avant l'apparition des bols Drag. 37 décorés à la molette (dans le courant de la première moitié $d u \mathrm{IV}^{\mathrm{c}} \mathrm{s}$.) ? 
Ce n'est pas du tout certain. Des bols moulés sont attestés dans des contextes très tardifs comme à Lezoux. Mais il semble que ce ne soit pas la question essentielle. Le hiatus entre les deux productions de sigillée du Haut- et du BasEmpire paraît plus lié à une marginalisation temporaire de ce type de production par d'autres produits, en particulier les gobelets.

Quand on intègre dans cette hypothèse les autres artisanats du feu attestés à une échelle importante en Argonne (fer, verre), cette impression d'économie florissante durant la majeure partie de l'Antiquité se renforce. Notons à ce propos l'importance des $\mathrm{III}^{\mathrm{e}}$ et $\mathrm{IV}^{\mathrm{e}} \mathrm{s}$. pour les ateliers de verrerie de la région.

Il apparaît alors que la production de la céramique n'avait pas le monopole de l'activité artisanale à grande échelle dans la région. Même si aucune étude n'a été réalisée sur la diffusion des verres produits en Argonne, l'importance des vestiges des ateliers et l'organisation des supposés puits d'extraction de gaize permettent d'affirmer qu'il s'agissait d'une activité qui n'était pas limitée au seul marché régional. Cette impression est renforcée par la nature même d'une partie de la production. En effet, jusqu'à maintenant, les tesselles en pâte de verre n'ont pas été trouvées sur les sites d'habitat de la région, suggérant par là même un produit d'exportation.

On comprend alors tout le poids des conditions naturelles de l'Argonne : la région fournit à la fois les matières premières pour différents artisanats et le bois nécessaire pour leur transformation en matériaux bruts ou en produits finis ; l'étendue des formations géologiques a garanti la rentabilité de l'artisanat du feu sur plusieurs siècles à une échelle « semi-industrielle ». Le réseau des voies de communication qui traversait la région, permettant l'accès aux marchés, avec ou sans transbordement fluvial, apparaît alors comme un facteur qui a facilité mais qui n'a pas commandé le développement économique particulier de la région. 


\section{BIBLIOGRAPHIE}

\section{ANDERSON A. C.}

1981 : Some continental beakers of the first and second centuries A.D. Oxford, BAR International Series, 123 (2), p. 321-347.

Bakker L., Dijkman W., Van Ossel P.

1996 : "Corpus de la céramique sigillée d'Argonne de l'Antiquité tardive ", in Rivet L. (dir.), SFECAG, Actes du congrès de Dijon, 16-19 mai 1996, p. 423-426.

BARTHÉLEMY E.

1865: Notice historique et archéologique sur les communes $d u$ canlon de Ville sur Tourbe (Marne), suivie du cartulaire de l'abbaye de Moiremont. Paris, Auguste Aubry, 128 p.

BAXARD D.

1990 : « L'ensemble du grand amphithéâtre de Metz et la sigillée d'Argonne au V' siècle ". Gallia, 47, p. 271-319.

2001 : « La céramique dans le bassin de la Somme du milieu du II $^{\mathrm{e}}$ siècle au milieu du III" siècle apr. J.-C. Bilan de 20 ans d'études ", in Rnver L. (dir.), SFECAG, Actes du congrès de Lille-Bavay, 24-27 mai 2001, p. 159-181.

\section{Beaulieu Y.-L. Ducas de}

1843: "Antiquités d'Autrécourt et Lavoye ". Archéologie de la Lorraine, II, p. 5461.

\section{BEN REDJEB T.}

1987 : « La commercialisation de la céramique gallo-belge à Amiens ». Revue archéologique BET P. de l'Est, XXXVIII, p. 93-100.

1988 : "Groupes d'ateliers et potiers de Lezoux (Puy-de-Dôme) durant la période gallo-romaine ", in Rivet L. (dir.), SFECAG, Actes $d u$ congrès d'Orange, 12-15 mai 1988, p. 221-240.

\section{Bet P., Delor A.}

2000 : « La typologie de la sigillée lisse de Lezoux et de la Gaule centrale du HautEmpire. Révision décennale ", in RuvET L. (dir), SFECAG, Actes du congrès de Libourne, 1-4 juin 2000, p. 461-484.

Bet P., Fenet A., Montineri D.

1989 : " La typologie de la sigillée lisse de Lezoux, $\mathrm{I}^{\mathrm{er}}$-III $\mathrm{s}$., considérations génćrales et formes inédites ", in RIvET L. (dir.), SFECAG, Actes du congrès de Lezoux, 4.7 mai 1989, p. 37-54.

BlaszKIEWICZ P., DUfouRNIER D.

1989 : "Diffusion des gohelets bruns d'Argonne entre la fin du I $^{\text {er }}$ siècle et la fin du II" siècle en Normandie ". Gallia, 46, p. 253-259.

BlasZKIEWICZ P., JigAN C.

1989 : "Les importations de céramiques sigillées estampillées en Normandie ( $\mathrm{I}^{\mathrm{er}}$ III' $\mathbf{s}$.). Étude quantitative et historique ", in RNET L. (dir.), SFECAG, Actes du congrès de Lezoux, 4-7 mai 1989, p. 209-221.

Boceuet A., Vilvorder F., Laduron D., BRULET R.

1995 : «Production of Roman fine dark colour-coated wares in north Gaul : pluridisciplinary approach ", in Vinc..N7INI P. (dir.), The Ceramics Cullural Heritage, Proceedings of the international Symposium The Ceramics Heritage of the $8^{\text {th }}$ CIMTECWorld Ceramics Congress and Forum on New Materials, Florence, Italy, 28 june-2 july 1994. Techna, Faenza, p. 449-455.

\section{BROUILLON L.}

1909 : Histoire de la ville de Sainte-Menehould. Sainte-Menehould, Martinet-Heuillard, $270 \mathrm{p}$.

BRULET R.

1994 : " Les agglomérations secondaires de Wallonic et du Grand-Duché de Luxembourg ", in PETTT J.P., MANGIN M. (dir.), Les agglomérations secondaires. La Gaule Belgique, les Germanies et l'Occident romain, Actes du colloquc de BliesbruckReinheim/Bitche, 21-24 oct. 1992. Paris, éd. Errance, p. 122-135.

Brun N., Pernot M., Velde B.

1991 : "Ateliers de verriers ct tesselles de mosaique ", in FoY D., SFNnequier G. (dir.), Ateliers de verriers de l'Antiquité à la période pré-industrielle, Actes des $4^{\text {es }}$ rencontres de l'Association française pour l'archéologie du verre, 24-25 nov. 1989. Rouen.

BÜCHER S.

1988 : « Gesatus, potier à Avocourt au II ${ }^{e}$ siècle après J.C. ". Horizons d'Argonne, 56, p. 3-11.

\section{BUVIGNIER A.}

1852: Statistique géologique, minéralogique, et paléontologique du département de la Meuse. Paris et Verdun, Ballière et Buvignier, 694 p., cartes.

CHAW H.

1989 : "Sainte-Menehould ", in FoY D., SenNEQuiER G. (dir.), À travers le verre $d u$ Moyen Âge à la Renaissance. Rouen, éd.
Musées et monuments départementaux de la Seine-Maritime, p. 57.

Chenet G.

1913 : « L'atelier céramique gallo-romain du Pont-des-Rèmes, Florent (Marne) ". Bulletin de la Sociélé archéologique champenoise, 3, p. 47-98.

1917 : «Les potiers gallo-romains d'Avocourten-Hesse ». Revue archéologique, p. 152-157.

1919 : " Rouelles de plomb et persistance d'emploi des rouelles gauloises ". Bulletin archéologique, p. 243-251.

1920a : "Anciennes verreries d'Argonne". Bulletin archéologique, p. 253-286.

1920b: "Gobelets ovoides moulés d'AutryLavoye ". Pro Alesia, p. 129-142, pl. XII-XX.

1922a: "L'établissement gallo-romain et le "Bourge" de Senon (Meuse). Les fouilles allemandes de 1917 à Senon ". Bulletin archéologique, p. 127-144.

1922b : «Buste balsamaire du Princier (Pont-Verdunois) et bassin de bronze d'Avocourt ". Pro Alesia, ns, t. 7, p. 146-160.

1927a : " Céramique gallo-romaine d'Argonne, les ateliers de la valléc de la Biesme ". Bulletin de la Sociélé archéologique champenoise, 2, p. 76-96.

1927b : «L'atelier céramique gallo-romain et le "Puisard" du Pont-des-Quatre-Enfants au Bois de Cheppy, Avocourt (Meuse) ". Bulletin de la Société archéologique champenoise, 2, p. 47-64.

$1928 \mathrm{a}$ : «Fours de potiers gallo-belges et leurs réutilisations funéraires ". Bulletin de la Société archéologique champenoise, 3, p. 11-26.

$1928 \mathrm{~b}$ : «Verdunaise et Pont-Verdunois". Almanach Matot-Braine, p. 305-316.

1929 : «Vestiges d'une villa gallo-romaine d'Argonne à Auzéville (Mcusc) ", Revue des Musées, p. 105-110.

1934 : « Poteries d'Argonne à glaçurc plombifère et décorées à la pipette ». L'art populaire en France, p. 61-68.

1935 : « La tombe 319 et la buire chrétienne du cimetière mérovingien de Lavoye (Meuse) ». Préhistoire, p. 34-118.

1936 : « Sépultures gallo-romaines de Dieue et de Varennes-en-Argonne ". Bulletin de la Société des naturalistes et archéologues du nord de la Meuse, p. 8-13.

1941 : La céramique gallo-romaine d'Argonne du $I V^{*}$ siècle et la terre sigillée décorée à la molette. Mâcon, Protat Frères, 194 p., XXXVIII pl. 
1946 : «Le Claon (Meuse) ». Gallia, IV, p. 363-364.

Chenet G., Gaudron G.

1955 : La céramique sigillée d'Argonne des IF et III siècles. Paris, éd. du CNRS (coll. Suppl. à Gallia, VI), $249 \mathrm{p}$.

Chossenot M., Chossenot D.

1987 : «Introduction à l'ćtude de la céramique gallo-belge dans la vallée de la Vesle (Marne) ". Revue archéologique de l'Est, XXXVIII, p. 113-123.

CotTineau Dom L.-H.

1939-1970: Répertoire topo-bibliographique des abbayes et prieurés. Mâcon, Protat Frères, $3 \mathrm{vol}$

Dauzat A., Rostaing C.

1983 : Dictionnaire étymologique des noms de lieux en France. Paris, Librairic Gućnćgaud.

\section{DELMATRE R.}

1995 : " L.cs enfouissements monétaires, témoignages d'insécuritć? ". Revue du Nord-Archéologie, LXXVII, p. 21-26.

DELOR A.

2001 : " Diffusion et commercialisation de la céramique sigillée: le territoire sénon durant le Haut-Empire ", in RIvET L. (dir.), SHECAG, Actes du congrès de LilleBavay, 24-27 mai 2001, p. 265-282.

DERU X.

1996: La céramique belge dans le Nord de la Gaule. Louvain-la-Neuve, Publications d'histoirc de l'art et d'archéologie de l'université catholique de Louvain, I.XXXIX, $463 \mathrm{p}$.

Deru X., Feller M.

1992 : " La céramique gallo-belge d'Argonne ", in RIVFT L. (dir.), SFECAG, Actes du congrès de Tournai, $28-31$ mai 1992, p. 91-99.

Dijkman W.

1992a : "La terre sigillée décorée à la molette à motifs chrétiens dans la stratigraphie maastrichtoise (Pays-Bas) et dans le nordouest de l'Europe ". Gallia, 49, p. 129-172.

1992b: " La diffusion de la terre sigillée décoréc à la molette dans la vallée mosane (IVe-V siècles) ", in RIVFr L. (dir.), SFECAG, Actes du congrès de Tournai, 2831 mai 1992, p. 291-296.

Estior S.

1998 : « Le trésor de Troussey (Meuse) : 5864 antoniniens et nummi, $303 \mathrm{AD}$. Annexe I. Trésors de monnaies romaines trouvés dans la Meuse ". Trésors monétaires, XVII, p. 218-223.

FELLER M.

1989 : "Céramique gallo-romaine d'Argonne, les méthodes de prospection terrestre appliquées à la reconnaissance des ateliers du groupe du massif de Hesse et de la vallée de la Buante ", in Rrvet 1 . (dir.), SFECAG, Actes du congrès de Lezoux, 4-7 mai 1989, p. 223-230.

\section{Feller M., BRULet R.}

1995 : « Nouvelles recherches sur la terre sigillée argonnaise du Bas-Empire dans les sites de production ". Rei Cretariae Romanae Fautorum, Acla, XXXIV, p. $69-87$.

1998 : " Recherches sur les ateliers de céramique gallo-romains en Argonne -1Prospection-inventaire dans le massif de Hesse et le site de production des Allieux 1 ". Archaeologia Mosellana, 3, p. 229-368.

FöLZER E.

1913 : Die Bilderschüsseln der ostgallischen Sigillata-Manufakturen. Bonn, A. Marcus und E. Webers Verlag (coll. Römische Keramik in Trier), herausgegeben von der Direktion des Trierer ProvinzialMuseums, 87 p., XXXIII pl.

\section{Fulford M.}

1977 : " Pottery and Britain's Foreign Trade in the Later Roman Period ", in PeAcock D. P. S. (dir.), Poltery and Early Commerce. Characterization and Trade in Roman and Later Ceramics. London, Academic Press, p. 35-84.

Galliou P.

1977 : « Les importations de céramiques du IV siècle en Armorique ». Figlina, 2, p. 83-95.

\section{GAMA F.}

1997 : Verdun. Paris, AFAN, 160 p., 14 plans (coll. Documents d'évaluation du patrimoine archéologique des villes de France, $15)$.

\section{GIANORDOLI M.}

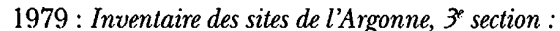
Botanique. Services régionaux du ministère de l'Agriculture ChampagneArdenne, atclier régional d'études économiques et d'aménagement rural. P.A.R. de l'Argonne.

\section{GILLANT J.-B.}

1886-1887: Fouilles d'Auzéville, lien-dit: Sur le Moulin. Découvertes archéologiques $I$. Bibliothèque de Verdun, cahier manuscrit, $42 \mathrm{f}$.

\section{GILLES K.J.}

1985 : Spätrömische Höhensiedlungen in Eiffel und Hunsrück. Trierer Zeitschrift für Geschichte und Kunst des Trierer Landes und seine Nachbargebiete, Beiheft 7 , 246 p., $48 \mathrm{pl}$.

Guelliot $\mathrm{O}$.

1920-1929 : Dictionnaire historique de l'arrondissement de Vouziers, ms.

\section{HASELGROVE C.}

1996 : « La romanisation de l'habitat rural dans la vallée de l'Aisne d'après les prospections de surface et les fouilles récentes ". Revue archéologique de Picardie, $\mathrm{n}^{\circ}$ spécial 11 , p. 109-120.

HaWkes C. F. C., HuLL M. R.

1947 : Camulodunum, first Report on the Excavations at Colchester 1930-1939. Oxford, University Press (coll. Reports of the Research Committee of the Society of Antiquaries of London, XIV).

HoFmann B.

1968 : "Catalogue des poinçons pour moules à vases sigillés des décorateurs argonnais ». Ogam, XX, 3-6, p. 273-307, pl. 94-128.

1972 : Calalogue des estampilles sur vaisselle sigillée, 2 partie. Groupe d'archéologie antique du Touring Club de France, notice technique $\mathrm{n}^{\circ} 22$.

1979 : « L'Argonne témoin de l'évolution des techniques céramiques au cours du III $^{\mathrm{c}}$ siècle ". Rei Cretariae Romanae Fautorum, Acta, XIX-XX, p. 214235.

HÜBENER W. $\quad-110$

1968 : " Eine Studie zur spätrömischen Rädchensigillata (Argonnen sigillata) ». Bonner Jahrbücher, 168, p. 241-298.

HUSSENET J.

1982 : Argonne 1630-1980. Reims, Cendrée, $443 \mathrm{p}$

1990 : "Préhistoire en forêt de SainteMenehould". Mémoires de la Sociélé d'agriculture, commerce, sciences et arts de la Mame, CV, p. 7-21.

JANNIN $\mathbf{F}$.

1980 : "L'industrie du verre en Argonne", Patrimoine et Culture en Lorraine. Metz, éd. Serpenoisc, p. 83-103.

1989 : " Verreries d'Argonne du XIII au XVIc siècle ", in FOY D., SENNEQUiER G. (dir.), À travers le verre du Moyen Âge à la Renaissance. Rouen, éd. Musées et monuments départementaux de la SeineMaritime, p. 67-69.

1990 : " Pairu-Les Bercettes, verrières forestières des XIII ${ }^{e}$-XIVe siècles ", in Verrerie de l'Fst de la France, XIII-XVIIT siècles, fabrication-consommation (coll. Suppl. à la Revue archéologique de l'Est, 9), p. 247-274.

2001 : «La ligne des puits ». Horizons d'Argonne, 78, p. 5-10.

Jigan C., Halbout P.

1987 : « La céramique d'Argonne décorée à la molette des IVe-Ve siècles en Normandie ", in RIVET L. (dir.), SFECAG, Actes du congrès de Caen, 28-31 mai 1987, p. 45-50.

JOFFROY R.

1974 : Le cimetière de Lavoye (Meuse). Nécropole mérovingienne. Paris, Picard, $178 \mathrm{p}$.

LÉMANT J.P.

1992 : "Les Ardennes des origines au Moyen Âge ", in Lusse J., Patrol.in A. (dir.), 
L'archéologie en Champagne-Ardenne 1960 1990, Actes des assises des $1^{\text {er }}$ et 2 déc. 1990. Société archéologique champenoise (coll. Bulletin de la Société archéologique champenoise, 85, 4), p. 121-140.

\section{LENOBLE M.}

1986 : «Céramique sigillée provenant d'un entrepôt rue Saint-Dominique à Châlonssur-Marne ". Bulletin de la Société archéo logique champenoise, 79, 2, p. 73-83.

LIÉNARD F.

1853: "Notice sur un camp romain et quelques antiquités gallo-romaines de l'Argonne ». Mémoire de la Société philomathique de Verdun, V, p. 157-180.

1881-1885: Archéologie de la Meuse, description des voies anciennes et des monuments aux époques celtique et gallo-romaine. Verdun, Ch. Laurent, 3 vol.

1891: "Compte rendu des travaux de la Société philomathique de Verdun ". Mémoire de la Société philomathique de Verdun XII, p. XI-XII.

LuTz M.

1991 : “Les estampilles sur vases unis de l'atelier de la forêt de Hesse (Argonne) au II ${ }^{e}$ siècle apr. J.-C. ". Les Cahiers lorrains, 2, p. 93-109.

Mangin M., Fluzin P., Courtadon J.-L., FonTAINE M.-J.

2000 : Forgerons et paysans des campagnes d'Alésia (Haut-Auxois, Côte-d'Or) : la terre, le fer, la route en pays mandubien, Ir siècle avant J.-C.VIIT siècle après J.-C. CRA Monographies, 22, CNRS Éditions, 508 p.

MARSH G.

1981 : London's Samian Supply and its Relationship to the Development of the Gallic Samian Industry. Oxford, BAR International Series, 123 (1), p. 173-238.

Massy J.-L.

1994 : "Les agglomérations secondaires de Lorraine ", in PETrT J.-P., MANGIN M. (dir.), Les agglomérations secondaires. La Gaule Belgique, les Germanies et l'Occident romain, Actes du colloque de BliesbruckReinheim/Bitche, 21-24 oct. 1992. Paris, éd. Errance, p. 103-106.

MAUGET L.

1906-1907 : « Découverte d'une verrerie d'art gallo-romain aux Houis, écart de SainteMenehould (Marne) ". Mémoires de la Société d'agriculture, commerce, sciences et arts de la Marne, X, p. 363-386.

MEUNIER J.

1905 : « L'établissement céramique de Lavoye (Meuse) ». Bulletin archéologique, p. $137-148$.

1908 : «Second rapport sur l'établissement céramique de Lavoye (Meuse) ". Bulletin archéologique, p. 185-198.

\section{MITARD P.-H.}

1979 : «Mortiers Drag. 45 de la Gaule de l'Est: l'atelier argonnais du Champ-desBierres à Avocourt (Meuse) ». Rei Cretariae Romanae Fautorum, Acta, XIX-XX, p. 85-95.

1986 : « Les ateliers de l'Est de la France, groupe d'Argonne ", in BÉMONT C., JACOB J.-P. (dir.), La terre sigillée galloromaine. Lieux de production du HautEmpire: implantations, produits, relations. Paris, Maison des sciences de l'homme (coll. Document d'archéologie française, 6), p. 195-207.

1996 : "Les mortiers Drag. 45 en Bourgogne ", in RiveT L. (dir.), SFECAG,

133 Actes du congrès de Dijon, 16-19 mai 1996, p. 181-188.

Ouzoulias P., Peluecuer C., Raynaud C., VaN OsSel P., GARMY P. (DIR.)

2001 : Les campagnes de la Gaule à la fin de l'Antiquité, Actes du colloque de Montpellier, 11-14 mars 1998. Antibes, APDCA, 640 p.

PETTT J.-P.

1987 : «La céramique gallo-belge du vicus de Bliesbruck (Moselle) ". Revue archéologique de l'Est, XXXVIII, p. 211-218.

PITON D., BAYARD D.

1977 : «La sigillée d'Argonne décorée à la molette dans le Nord-Ouest de la France ". Cahiers archéologiques de Picardie, 4, p. 221-275.

RAEPSAET G.

1985 : «L'organisation du commerce de la céramique sigillée dans le Nord de la Gaule au II" siècle ", in BuRNAND Y., Vertet H. (dir.), Céramique antique en Gaule, Actes du colloque de Metz, 1982. Nancy, Presses universitaires de Nancy (coll. Studia Gallica, II), p. 71-77.

RIGBY V.

1981 : The potter Julios. A suitable case for study? Oxford, BAR International Series, 123 (1), p. 39-50.

ROGERS G.-B.

1999 : Poteries sigillées de la Gaule centrale-II- Les potiers. SITES, hors série $n^{\circ} 40,2$ vol.

\section{Roth-Rubi K.}

1990 : "Spätantike Glanztonkeramik im Westen des römischen Imperiums. Ein Beitrag zur Leistungsfähigkeit der Wirtschaft in der Spätantike ». 71. Bericht der Römisch-Germanischen Kommission, 2, p. $905-971$.

SAVY A.

1855 : "Notice sur les chemins, camps et tumulus romains du département de la Marne ". Congrès archéologique de France, p. 203-223.

SCHEERS S.

1977 : Traité de numismatique celtique -II- La
Gaule belgique. Paris, Les Belles Lettres, Annales littéraires de l'université de Besançon, 195, Centre de recherches d'histoire ancienne, vol. 24, 986 p., 28 pl.

\section{Schmrт E.}

1926-1928 : "Répertoire abrégé de l'archéologie du département de la Marne des temps préhistoriques à l'an mil ». Mémoires de la Société d'agricullure, commerce, sciences et arts de la Marne, XXII, p. 99-303.

Séguiter J.-M., Morize D.

1996 : «Les céramiques à revêtement argileux de Jaulges - Villiers-Vineux (Yonne) : éléments de typo-chronologie et approche de la diffusion d'après les données de l'île-de-France ", in RIVET L. (dir.), SFECAG, Actes du congrès de Dijon, 16-19 mai 1996, p. 155-178.

\section{SYMONDS R. P.}

1987 : « Le problème des gobelets ovoïdes sablés ", in RIVET L. (dir.), SFECAG, Acles du congrès de Caen, 28-31 mai 1987, p. 69-74.

Tilloy R.

1979 : « Deux voies romaines en Argonne. Les photographies aériennes et les voies romaines ". Horizons d'Argonne, 39, p. $35-41$.

Toussaint M.

1946 : "Répertoire archéologique du département de la Meuse (période galloromaine) ". Mémoires de la Société des lettres, sciences et arts de Bar-le-Duc, L.

UNVERZAGT W.

1916 : Die Keramik des Kastells Alzei (Rheinhessen). Frankfurt a. M. (Materialien zur römisch-germanischen Keramik, Heft 2, herausgegeben von der RömischGermanische Kommission), 36 p.

1919 : Terra sigillata mit Rädchenverzierung. Frankfurt a. M. (Materialien zur römischgermanischen Keramik, Heft 3, herausgegeben von der Römisch-Germanische Kommission), 50 p., VII pl.

\section{Van Ossex P.}

1986 : "Céramiques de la fin du IV siècle et $\mathrm{du} \mathrm{V}^{\mathrm{e}}$ siècle en Gaule Belgique ". Bulletin de la Société archéologique champenoise, 79, 2, p. 63-71.

1992 : Établissements ruraux de l'Antiquité lardive dans le nord de la Gaule. Paris, éd. du CNRS (coll. Suppl. à Gallia, 51), 470 p.

1995 : « La sigillée d'Argonne du Bas-Empire dans le nord de la Gaule: distribution, imitations et concurrences (IVe-Ves.) ". Rei Cretariae Romanae Fautorum, Acta, XXXIV, p. 221-230.

VERNHET A.

1976 : «Création flavienne de six services de 
vaisselle à La Graufesenque ». Figlina, 1, p. 13-37.

WHITTAKER D.

1995 : "L'importance des invasions du BasEmpire: peut-on faire confiance aux historiens? ", in ThOIIARD P. (dir.), Insécurité et militarisation en Gaule du Nord au Bas-Empire, Actes de la 17" journée d'étude du centre de recherches archéologiques de l'université Charles-de-
Gaulle - Lille III, 3 déc. 1994 (coll. Revue du Nord-Archéologie, LXXVII), p. 11-20.

\section{WidRANGES H. DE}

1862: " Notes archéologiques sur l'ancienne localité gallo-romaine, qui existait sur les territoires des villages d'Autrécourt, Berthaucourt et Lavoye, département de la Meuse ". Mémoires de la Société d'archéologie lorraine, IV, p. 37-58.

1871 : « Découverte d'objets antiques faite à
Nubécourt au mois de septembre 1867 ". Mémoires de la Société des lettres, sciences et arts de Bar-le-Duc, I, p. 143-148.

YounG B. $\mathrm{K}$.

1984 : Quatre cimetières mérovingiens de l'Est de la France. Lavoye, Dieue-sur-Meuse, Mézières-Manchester et Mazerny. Étude quantitative et qualitative des pratiques funéraires. Oxford, BAR International Series, 208,239 p. 